QL 641 W47 turmiffenichaftlicbe 1909

$\mathrm{V} .2$ REPT (ब) abegweifer एक

g gemeinberfä̈slicber Sarffollungen

\title{
8.2Serner
}

Qlmuhibien uni 9 Reptilien II

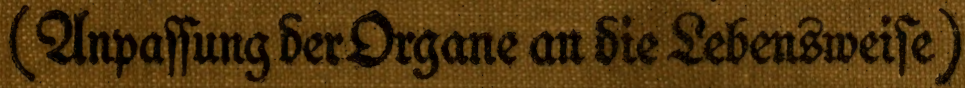

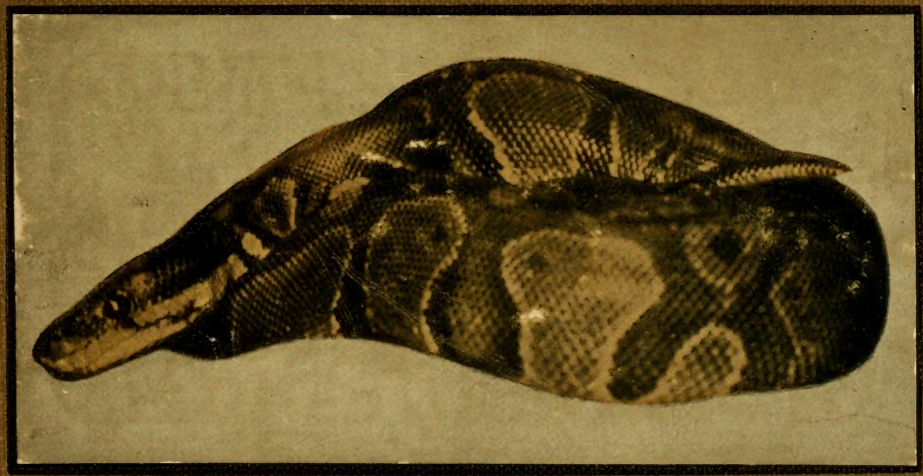

Serie A

Serausgegeben oon Prof. Dr. Rurt Sampert Derlegt bei Strecker \& $G_{\text {cbrober in }}$ Stuttgart 


\section{Naturwiffenichaftliche Wegrweijer}

Gammlung gemeinverftändlicher Tarfitellungen Seraugigegeben von Profefior Dr. Rurt Lampert Zoritand Der R. Naturalienjammlung in Stuttgart

Die Bämbe Der Gerie A umfaffen biz zu 150 Geiten Tert in RleinOftay ( (a) Sert in Mittel-Oftav. Seder Band ift reich) mit Safeln und $2 \mathfrak{b}$. biloungen gef(h)müct't, für fich abgejd)lofien uno einzeln fäuflich). Die Preife find folgende:

Serie A: gebeftet $\mathfrak{N} 1,-$, đhön gebunden $\mathfrak{N} 1.40$

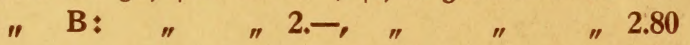

Mehr Denn je fteht heute bie Menfhheit im 3auberbanne ber Natur. Millionen von Nenichen find Naturfreunde geworden; fie benugen jebe freie Stunde zu 2 andertngen in $2 B$ ald und Flur und fuchen Dort Erbolung und 3eritreuung von Des Sagez Lait und Nühe. 2lber erit

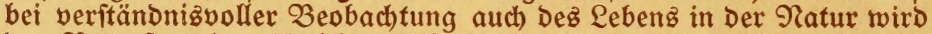
Der Naturfreund zablreiche glüctliche Etunden erleben; feine Gorgen

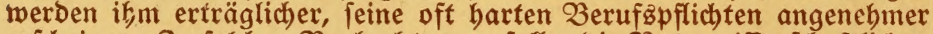

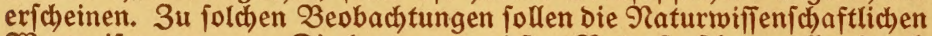
Wegweifer anregen. Die herborragenditen शaturforidher wollen Durch

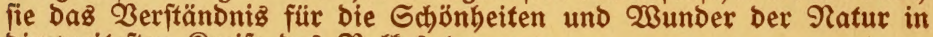
Die weitejten Rreife Dez 2 Blfez tragen.

\section{Wie urteilt die Prefle iuber Die Naturwiffenjchaftlichen $\mathfrak{B}$ egweijer?}

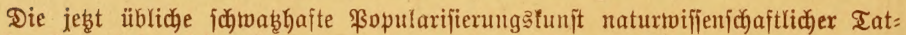

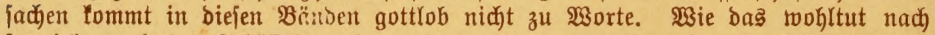
fo biel garmierten Sajüffel । und berzierten Torten, wieder einmal ehrliche natur=

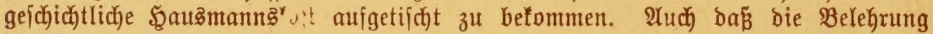

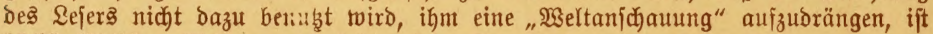
hödift löblich. Wir empfeblen bie Sammlung a

(\$ropyläen, Mündyen.)

Die beliebte Sammlung bient reolid. ber 2Yufgabe, bie ofreube an ber Ratur

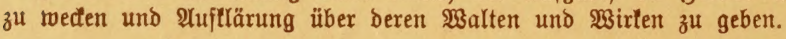

(ভtaaţ̊anzeiger in $\mathfrak{B u ̈ r t t e m b e r g . ) ~}$ 


\section{Berlag von Gtrecter \& Gahröber in Gtuttgart}

\section{WBie urteilt Der Lejertreiz $\mathfrak{i b e r}$ Die Naturwifienichaftlichen $\mathfrak{B}$ egweijer?}

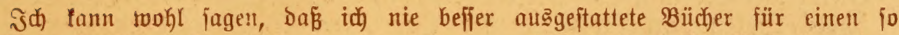
billigen ßreis erbalten habe.

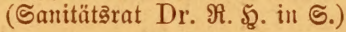

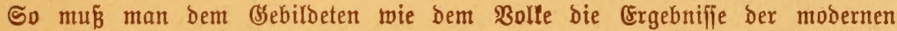
Raturwiffenichaft barbieten, wie Sie es tun.

(\$ajtor $\mathfrak{M}$. i. \$.)

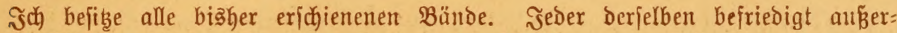

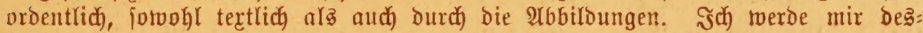

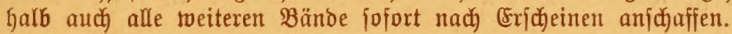

(Bürgeridyullebrex ₹. in $\mathfrak{B}$.)

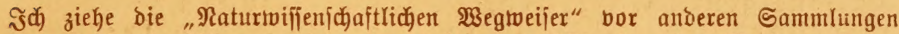
vor, tweil bie Darftellung mehr ausెgearbeitet und lichtooller ift. (B. \$. in $\mathfrak{B}$.)

Die Sammlung berbient bas ßräbilat "a us gezei d) net".

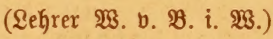

3 ir empfehlen bieje Bücher, ba fie zur Borbereitung für ben biologijdyen unterridjt jệr geeignet fino.

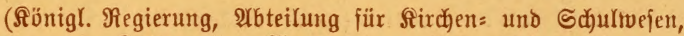

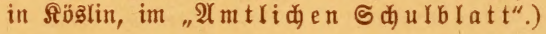

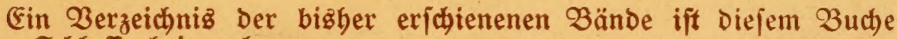
am Sֲluाfe beigegeben.

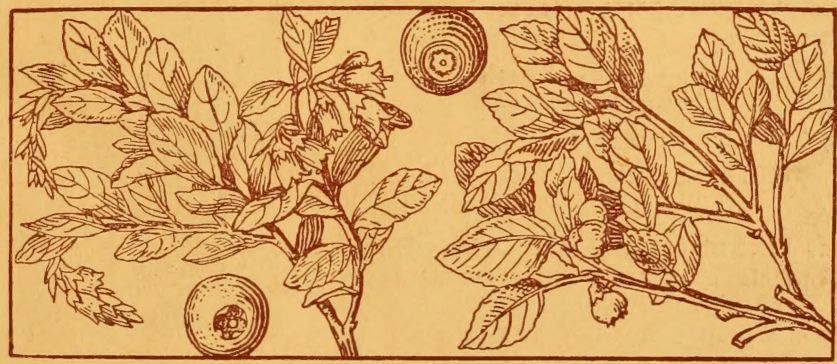

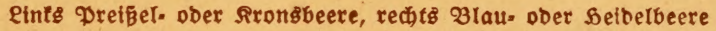
abbilbung aus: "Braebner, Seibe uno शroor" 


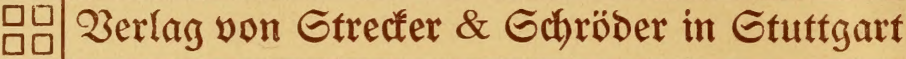

\section{Illuitrierte Bölferfunde}

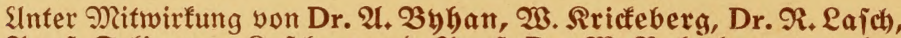

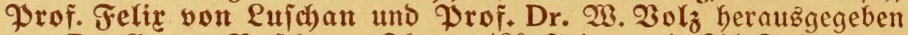
von Dr. Beorg $\mathfrak{B u j c h a n . ~ O f t a v . ~} 480$ Geiten mit 211 Safeln uno abbiloungen.

(3eb. $\mathfrak{M} 2.60$, geb. M 3.50

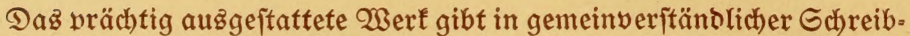
tveije cine überfichtliche (Daritellung Der Taturvölfer und Der noch

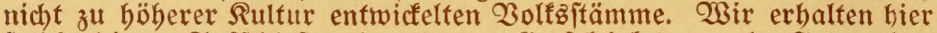

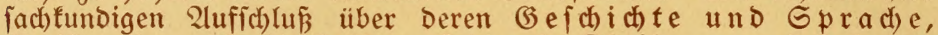
Raffeneigentümlidfeiten, SbDad), unterbalt, Ébe, Gllaverei, foziale Derbältniffe und

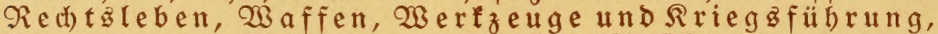
fiander unb verfebr, religiöfe anfdiaungen uno

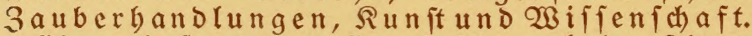

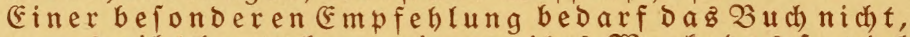
bennes gibtheute faum ein zweites $\mathfrak{B}_{\text {er }}$, Das foviel

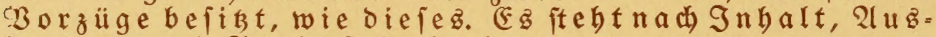
it attung uno Preis fait einzig $D$ a.

In 3ettalter Der Entichleierung unje= res Eีroballes gehört bie Renntnis frem= ber 2 ölferichaften $z$ ur allgemeinen $3 i l=$ bung. Das 3 uch gehört beßhalb in jebes Saus. alt und jung werben ibre Freube baran baben.

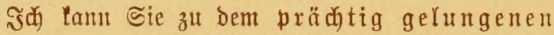

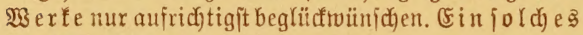
Bud hat un

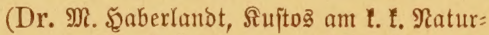
Gijt. Şofmujeum in $\mathfrak{\text { Wien.) }}$

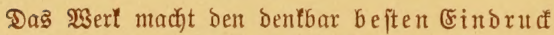

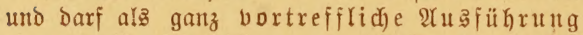

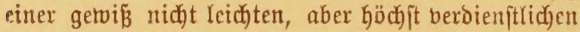

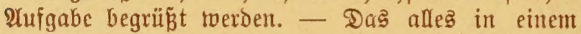
einzigen ftarfen Bande zu einem gerabezu mini= malen, für iebermann leidterfdringliden

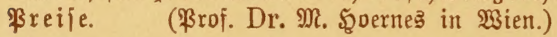

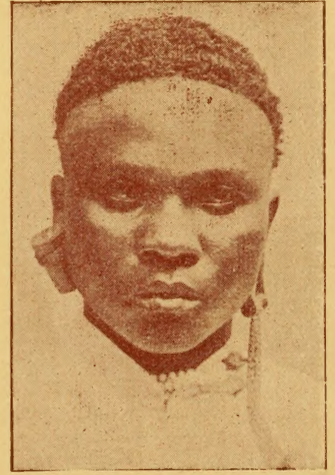

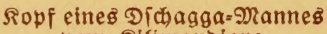
vom Rifimandiaro 
Amplibien und Reptilien II (2lmpañung Der Organe an die Lebenzmeije) 


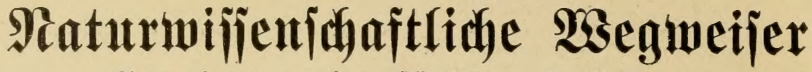

\section{Sammlumg gemeinveritändidider Darjtelfungen \\ Şerausgegeben von Prof. Dr. $\Re$ urt $\&$ a mpert}

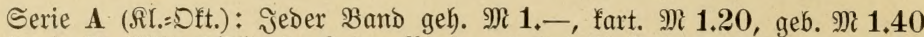

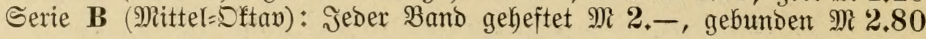

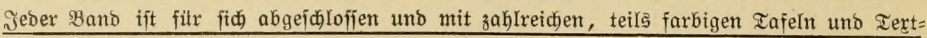
abbilsungen verieben.

\section{Anthropologie}

Mienidjenfunbe von Dr. G5. Buj(dan. 273 Seiten. B 2.

\section{Ajtronomie}

Die Crrbe $\mathfrak{a l} \mathfrak{S}$ Simmetaförper von ßrof. Dr. Э. B. Mefierjomitt. 232 Seiten. B 1.

Die $\mathfrak{B}$ elt ber Sterne won \$rof.

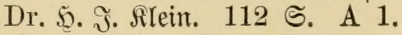

\section{Botanit}

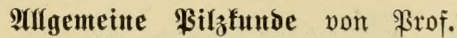
Dr. Migula. 104 Seiten. A 8. Deutide Mioje uts Farte von \$rof. Dr. Migula. 149 Seiten. A 5. Die Bäume แกญ Sträudjer unjerer Wä̈loer von Forftaffeffor Jeucht. 128 Seiten. A 4.

Die $\mathfrak{B f l a n z e n w e l t ~ b e r ~}$ Arlpen von 5. Marzell. 102 Seiten. A 7. Sceibe unt Moor von \$rof. Dr. \$. Graebner. 102 Seiten. A 9. ßarfbäunte แแ⿰ Bieriträud̆er von Foritafiefijor Feudyt. 108 ऽ. A 14. Fraftijde $\mathfrak{B}$ \$rof. Dr. Migula. 144 S. A 20/21 (Dopperband).

\section{(E)emie}

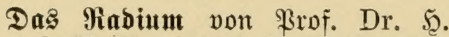
Rauffmant. 101 Seiten. A 12.

\section{Erofunde}

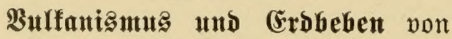

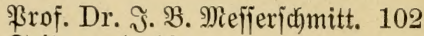
Seiten. A 13.

\section{शaturict)uk}

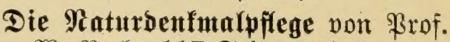
3. Bocf́. 117 Seiten. A 10.

\section{Gammel= und $\mathfrak{A n l e i t u n g e s : ~}$ biicther}

Der $\mathfrak{B f l a n z e n j a m m t e r ~ v o n ~} \Re$. Mi badf. 95 Seiter. A 18.

Die Minturphotographie von $\Re$. Zim= mermann. 98 Seiten. A 17.

\section{3oologie}

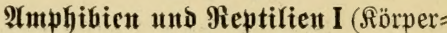
bau und Rebensweife) von Prof. Dr. F. Merner. 112 S. A 15.

$\mathfrak{A m p h i b i e n t}$ und $\Re$ ieptilien II (2̂T= paffung Der Drgane an bie Rebens: meije) von \$rof. Dr. F. 23 erner. 84 Seiten. A 16.

Bilber aus bem Räferleben von

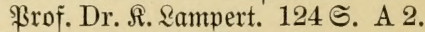
Die Sanßtiere it 9fbitammung uto Entwifflutg von Dr. M. 5̧ilz= heimer. 134 Seiten. A 11.

Die 2 seidtiere Dentidylands von D. Gener. 116 Seiten. A 6.

Maturgeidjidfte ber fleinjten Tiere v. Dr. 23 . Effenberger. 120 S. A 22. Tierleben bes beutidyen $\mathfrak{B a l d e}$ von ßrof. Dr. R. Erfftein. 136 S. A 3.

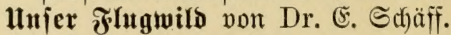
105 Seiten. A 19.

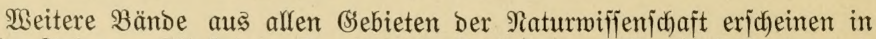

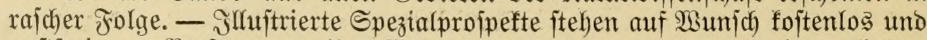

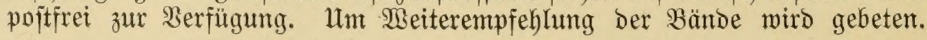
Antidjtafarten

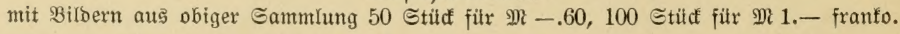

3erlag von Strecter \& Schröber in Stuttgart 



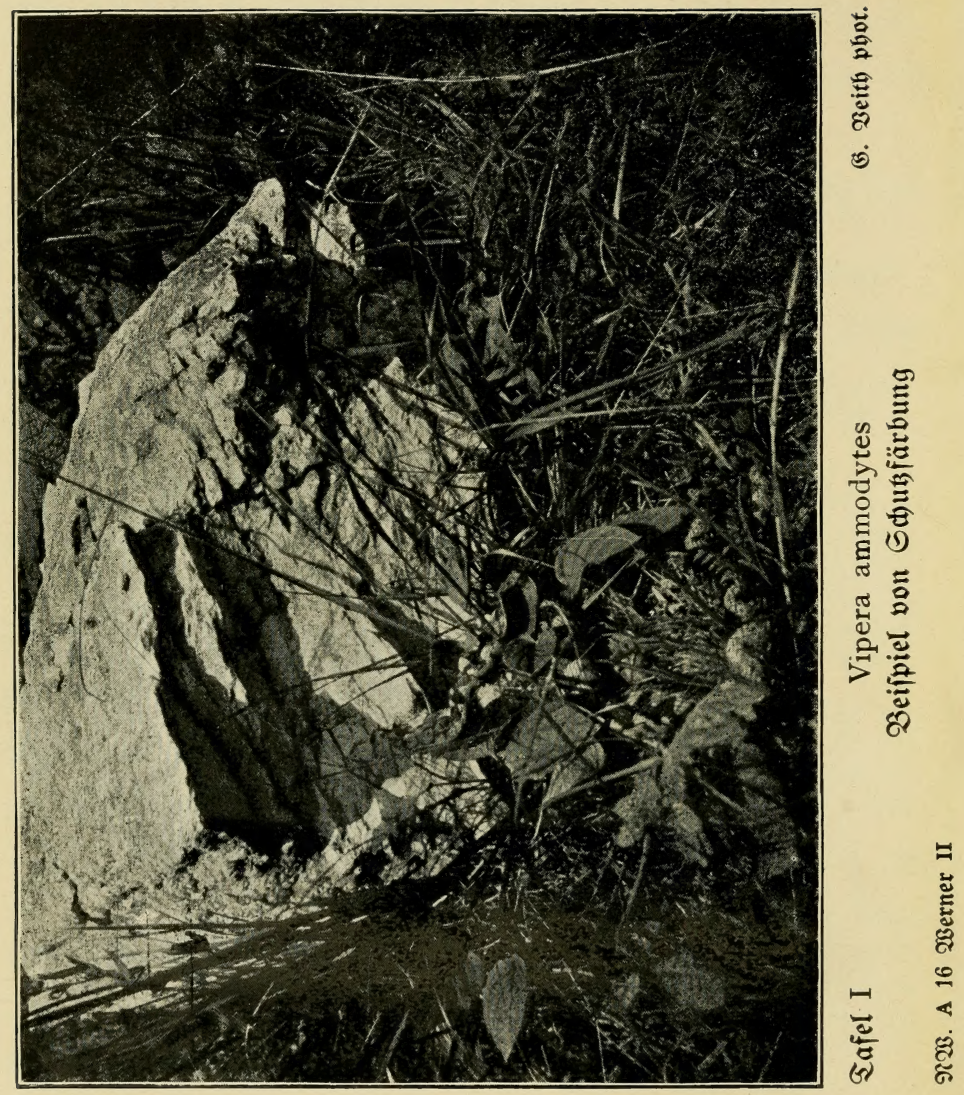




\section{Paturwifjenj(haftliche $\mathfrak{B}$ egweijer}

Gammlung gemeinverfiänd licher (Darfitelfungen

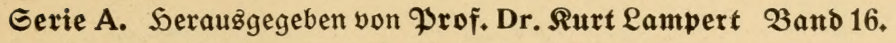

\section{Almphibien und Reptilien II (21npaffung Der Organe an bie Lebenzweije)}

$\mathfrak{o n}$

Profeffor Dr. $\mathfrak{F}$. $\mathfrak{H e n n e r}$

(2Bien)

Mit 1 Tafel und 40 2lbbilbungen im Tert

1,-5. Taujend

Gtuttgart

Zerlag von Etrecter \& Echröber 
Alle Red)te von Der Berlagsbuch)handhung vorbebalten

\section{8}

Druct voit Gtrecter \& Sdröber in Gtuttgart

bolgfret 2utotypie-Druatpapier von 3obnenberger \& Ete., Papierfabrif, Niefern in Baben 


\section{Inlyaltånerzeidunis.}

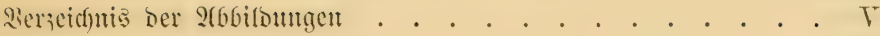

S3ormort . . . . . . . . . . . . . . . . . VII

Einteitutg . . . . . . . . . . . . . . . . . 1

Iie 5ant ber 2(mplibien uto Reptilien . . . . . . . . . 11

Eintges von Den Sintesorgaten unjerer Tiere . . . . . . . 21

இout Darn und vou Der Mafrutg . . . . . . . . . . . 37

Iie Suftröfre un bie Sungen Der Meptilien: 2(tmung, Sonmter=

und Binterj)laf . . . . . . . . . . . . . 48

3on Der Bernefrumg mo Regenteration . . . . . . . 58

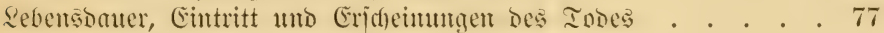

๔đ)luñwort . . . . . . . . . . . . . . . . . . . 79

Siteraturmadyets . . . . . . . . . . . . 80

Megifter . . . . . . . . . . . . . . 84

\section{Berzeiduniż ber âbbildumgen.}

a) Itmiaflagbils.

งutıe Röniggid)lange (Python regius).

b) Tafer.

Vipera ammodytes (Beijpiel von Sdunfärbung), Iitelbilo.

266.

c) $\mathfrak{A b b i l b u n g e n ~ i m ~}$ Text.

1 Ropf Der Bieritreifentatter (junges und erwadjenes Tier) . . 7

2 Entitelung bes bunten Farbleidmuters der Rorallententen . 8

3 Entitefung Des bunten Farbleiomuiters bei einer giftlojen Rattem= gattung . . . . . . . . . . . . . . . 9

4 Trichobatrachus robustus . . . . . . . . . 11

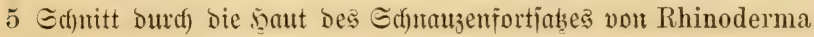
darwini . . . . . . . . . . . . . . . . 12

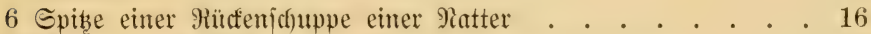

7 Sduppe des Rütfents von Coluber quatuorlineatus . . . . 17

8 Rürfenpanzer von Hydromedusa tectifera . . . . . . . 19

9 Ropf uno \$orberförper Der Ringernatter in Б口äutung begriffen, bie alte 5̧aut umgefd)lagen . . . . . . . . . . . 20

10 Gehirn eines Rarpfens, eines Jrojdes und eines Sutgenfifdes 22 
9t6b.

11 Ropf von Dryophis fasciolatus (Baumid)lange von Sumatra) 23

12 Ropf eitter fübamerifmija)en Dänmterungsbammid)lange . . . 24

13 2uge von verjuiedenen Racertiden . . . . . . . . 25

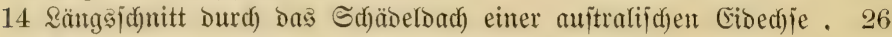

15 Ropf a) von Lacerta, b) von Varanus nuchalis . . . . . 27

16 Ropf einer amerifanijchen Waffernatter . . . . . . . . 28

17 Ropf von Rana esculenta (Mäntuchent) . . . . . . . . 30

18 Ropf und Brujt von Rana temporaria von unten . . . . 31

19 Iarve von Salamandra maculosa . . . . . . . . 33

20 Ropf von Herpeton tentaculatum . . . . . . . . 35

21 Vipera ammodytes (Sanootter) . . . . . . . . 36

22 3unge a) pon Lacerta, b) von Calotes . . . . . . . . 40

23 Ropf und ફ̧alङ einer Rrötentotter . . . . . . . . . . 41

24 Heloderma suspectum (2lrizona) . . . . . . . . . . 42

25 (Fierjchlange (Dasypeltis scabra), Borberförper, von unten geöffnet 43

26 \&utröhre und Brondfien von Testudo pardalis . . . . . 49

27 Sambotter, Vipera ammodytes, Borberförper, von ber Unter= feite geöffnet . . . . . . . . . . . . 51

28 Rloafengegend der Sumpfijhilofröte (Emys orbicularis) . . . 53

29 \&ängäfdritt burd) ben Ropf eines jungen Rilfrofobiles . . . 54

30 Männţen (a) uno MBeibchen (b) von Ceratophora stoddarti, einer Baumagame aus Eeylon . . . . . . . . . . .

31 Männḑen (a) uno Weibchen (b) von Chamaeleon gallus von Mabagasfar . . . . . . . . . . . . . . 60

32 Ropf Des grünen Reguans (Iguana tuberculata), a) Mämnd)en, b) Weibdjen . . . . . . . . . . . . . . . .

33 Centropyx pelviceps, Männdben, Scinterbeine uno Sd)wanzmurzel von unten

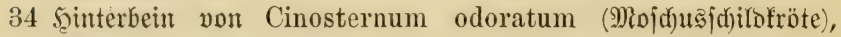
Männdjen, von unten , . . . . . . . . . . 63

35 Borberbein Des Mämnđens von Leptodactylus ocellatus . . 64

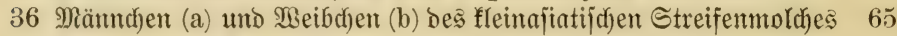

37 Raffel einér Rlapperjalange . . . . . . . . . . . 66

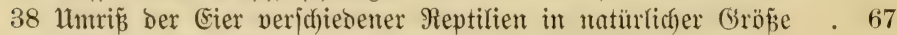

39 Eijdniele von Crocodilus niloticus (a) unb porosus (b) . . 69

40 Eizahn pon Gecko verticillatus . . . . . . . . 70 


\section{Borwort.}

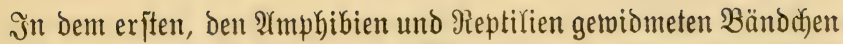
wurbe zu zeigen berjudt, wie ber Rörperbaut im allgemeinen burdit) die 2lupaijung an verjhiedenartige Rebenabebingungen beeinflup̄t wird und weldye $\mathfrak{B}$ eränderungen namentlid) die erjtgentannten fotwohl im

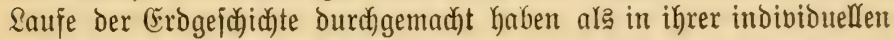
Entwictlung immer nod) burdamadjen.

Nachjtehend jollen num, abgejeken von der Rörperbedectung, die inneren Drgane unjerer beiden $\mathfrak{B i r b e l t i e r f l a j j e n ~ j o m e i t ~ b e h a n d e l t ~}$ twerden, als fie burdy die 2lupentwelt merflid) beeinflupt werden; anfangameife wurben auch ben mit ber Fortpflanzung jomie mit Dem Beginne, der Dauer und dem Bnde des individuellen Sebens

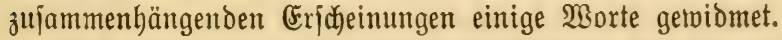

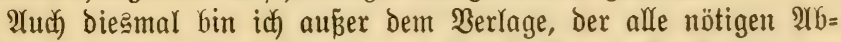
billoungen bereitmilligit betwilligte, Şerrn $\Re$. u. \&. Şauptmann (53. Beith für einige gelungene Raturaumahmen, Dem Berlag

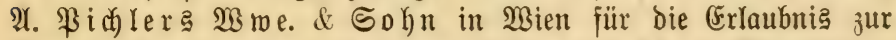

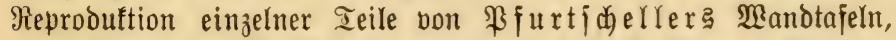
jomie Şerrn Dr. R. Mieftinger und Frl. A. Mayer für ber= jujiedene 2tufnahmen zoologifajer Dbjefte ju aufridtigem Danfe verpfilictet.

Bien, 17. April 1910.

Brofejior Dr. $\mathfrak{~ W e r m e r . ~}$ 



\section{Cinteitumtr.}

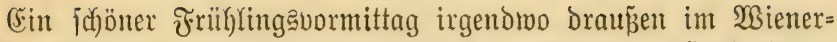

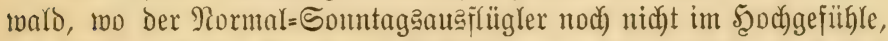

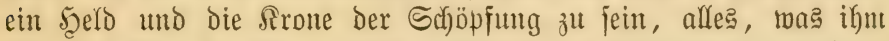
iiber Den Weg freuditht, zu Iode gepriigelt und gefteinigt hat, fondern

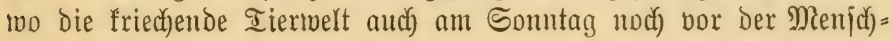
heit Ruhe hat ...

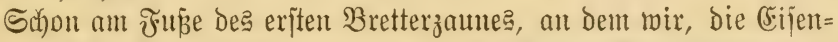

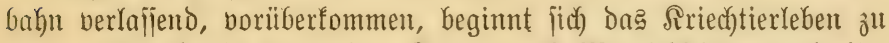
regen. Im (Braje liegt, Den Sïrner nad) Më̈glichfeit ausgebreitet uno gegen bie einfallenden Sonnenjtrahlen jenfrecht gejtellt, ein

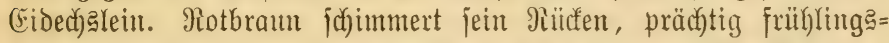
grün, "laete viridis", frendiggrün, find bie Seiten. Man jieht, Der fleine 尺rieger - Denn Rrieger find alfe ihres Stammes, ob Männ= lein oder $\mathfrak{B} e i b l e i n$, und von einer Furd)tlojigfeit, bie, wenu ber

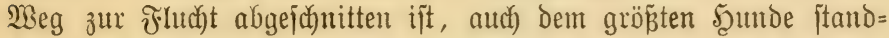

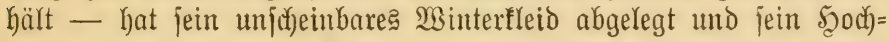
zeitsgemand angetan. 2(ber aud feine Fran (Semahlin, obrwohl

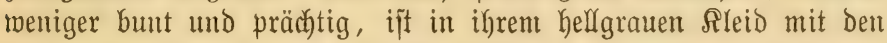

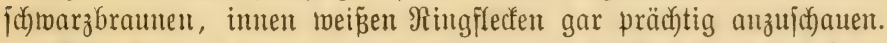

Aber feiner, der an ihnen vorbeigeht, Denft Dabei, daß̄ bieje Sinder ber Sonne, bieje fleinen Raubritter im Schuppenpanzer in

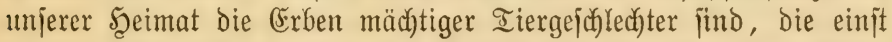

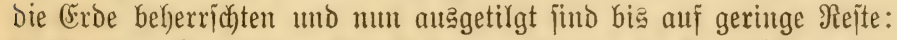
Die heutigen Rrotodile. Sie jund zmar 3werge im ßergleidhe zu Den Dinojauriern der Jurazeit, ebenjo wie bie zierlichen, farbenprächtigen

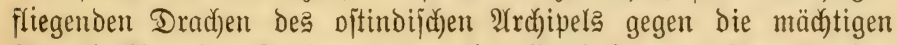
Flugeidedjjen ber Sreideperiode; aber fie haben mit dem Sunda=

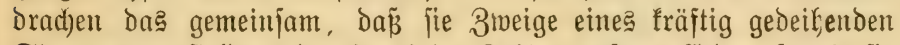
Stamme voritellen, ber in vielen Ieilen unjerer Eroe, foweit fie

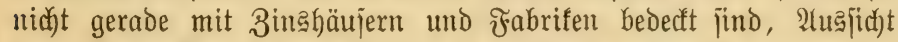
hat, fich im Sampf ums Dajein zu erfalten und zu befaupten.

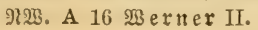


Die 3eiten der Riejentiere unter den Reptilien find vorbei;

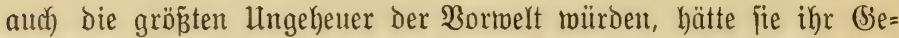

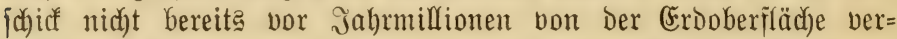
ja)twinden Yafjen, im Beitalter der modernen Sprenggejajojie ihr Seben lajien müljen. Aber ihre fleinen, ichlanfen, flinfen Epigonen werben fich erbalten fönnen, jolange noch dem Menjachen jelbjt bie freie Natur uno grïnende Befitlde ein Bedürfnie find. Wie jehr fich bie Sleinreptilien uno =amphibien audich der modernen Sul= tur anzupajjen wijien, betweijt bie Borliebe von (Eidect)jen (3aum= und Manereidechjen) für (sijenbahndämme, two jie namentlid) an benjenigen Stellen, Deren Betreten berboten ift, in ziemlicher Menge borfommen fönuen, dic Anpafjung von ?mphibienlarben an verunreinigtes $\mathfrak{B a f j e r}$ (namentlich) Der Saulquappen unjerer beiden Unfentarten, von denen Bombinator pachypus iiberfaupt nicht emp= findlid) ift, dagegen B. igneus anjoniten zwar flares Wafjer liebt, fid) aber in ber Umgebung von MBien bercite an Die ärgiten S(t)muts=

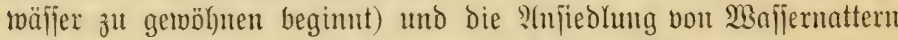

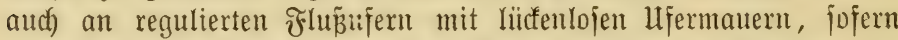

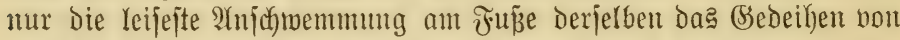

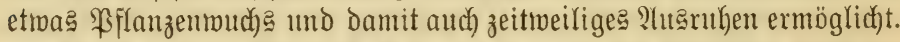

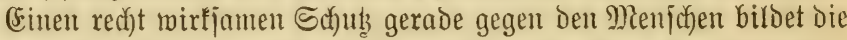

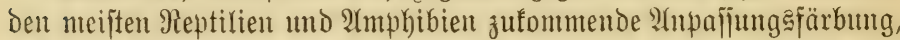
D. h. Dia ütbereinftimmung Der Färbung Der Dberjeite mit Der Umgebung. Dieje übereinjtimmende Färbung wirb baber autu Sd)udärbung genamnt, und es unterliegt feinem 3meifel, baj jie unjere İiere bis zu einem gewiffen (Srabe nidyt nur gegen ifre Berfolger, aljo joldse

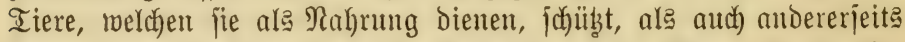
Denjenigen Raubtieren, welche Schutzfärbung bejiz̧en, Dus unbe=

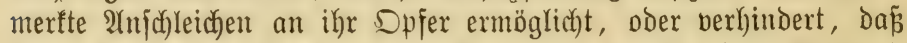

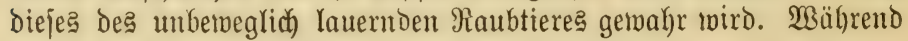
Der Sdutus, Den bie Tiere Durdih ihre Färbung gegen ihre Feinde geniēen, mur ein bedingter ijt, da er von mancherlei Umitänden

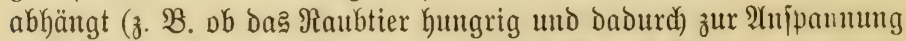
alfer Sinne genötigt ober idjon gejättigt ijt, ob Beute oder Freino ein junges, unerfahrenes oder ein erwadjenes Tier ift $\mathfrak{u}$. a.), fann

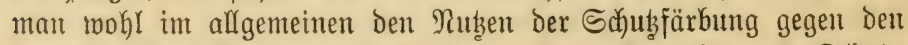

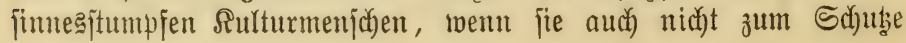


gegen ifn entîtanden ift, ziemlid hod) veranja)lagen. Daher fommt

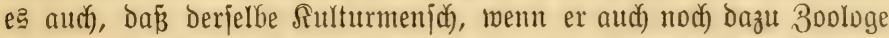
iit, überall Sdhuzfärbung wittert, weil or bas lebende Iier fo leich)t

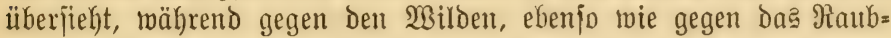
tier, Dem ber fnurrende Magen bie Sinne jäärft, eben mur unter

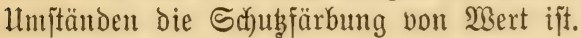

Itm auffallenditen, meil der Bejuaffenheit des Bodengrumbes am genaueften entiprechend und auperdem weil bei einer iiberaus

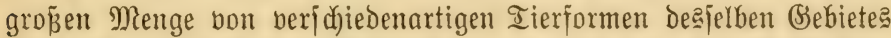

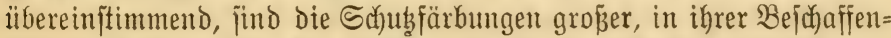
heit gleid)artiger Strecten (WBiiften, grope Sumpfgebiete, bie Meerea =

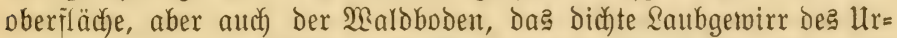
waldes, das Steingeflüft des farftes u. Dgl.). Sandjarbig find zabl= reiche Peptilien ber afrifanijachen, wejt=, mittelajiatijchen und vorber= indijd)en Wüjten; aber wie verijhiedenartig ift bie Bodenfärbung aller

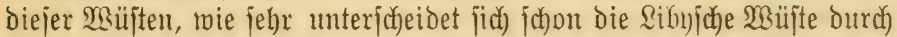
ihre lebbaft hellgelbe F̈̈rbung von ber mehr graugelben $2(r a b i j d) e n$

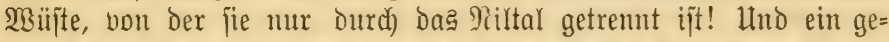

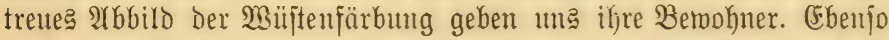
ift bie Sd)Yanmfarbe der Sumpfbemohner, dą Blaugrün Der See=

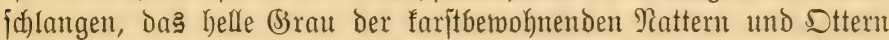
(bei allen mur bie Sherjeite mit Schuzfärbung!) veridoieden nad) Dem bejonderen ?(ufentfyaltsort. - Cine Farbenaupajung an eine ganj bejtimmte Unterlage, wie jie $\mathfrak{z}$. $\mathfrak{B}$. Die übereinjtimmung von Jn= jeften ober Injeftenlarben mit ifrer Futterpiflanze borjtellt, ijt bei

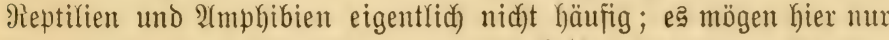
bie rindenfarbigen (Eidectjjen, namentlick) Befofos (Uroplatus, Ptycho-

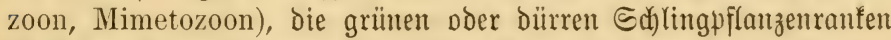
ähnlidyen Baumid)langen (Oxybelis, Dryophis) erıähnt werben.

Man hat jich lange 3eit Damit begnïgt, bieje S(j)uzanpajiung einfad) auf die Wirfung Der Seleftion, der natïrliden AHzleje,

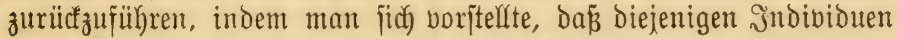

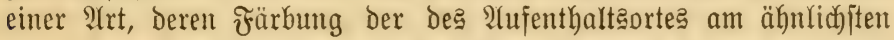
war, bon ihren Feinden am Yeictejten überiehen wurben und jich Daher am eheften erhalten und fortpffanzen fonnten; da junter ihren ఇachfommen, da ja hödjit wahridjeinlid) mehrere Jndividuen beiderlei

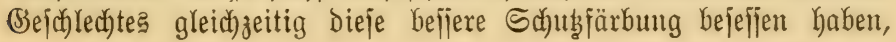


bieję Merfmal ni.jht nur erhalten, jondern in einzelnen Individuen jogar nod) gejteigert wurbe, fo baß̄ im Saufe viełer aufeinander.

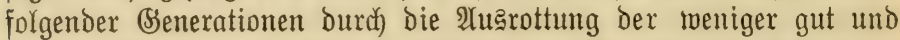
die Fortpflanzung der befjer gejchübten im Rampfe umb Dajein die 2̂npafjung eine immer volffommenere wurbe.

Şeute ift man auf experintentellem Bege zu Der begründeten

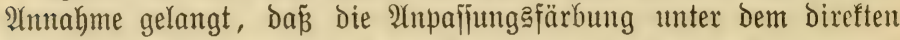

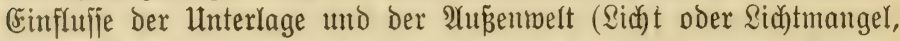
Wärme oder Rälte, Iroçenbeit oder Freudutigfeit) zuftande fommt,

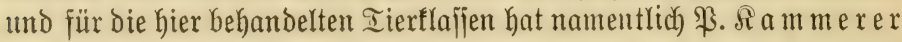

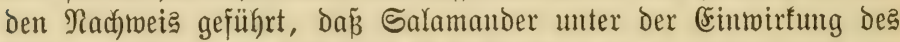
Bodengrundę ganz auffalfend ihre F̈ärbung zu verändern imjtande

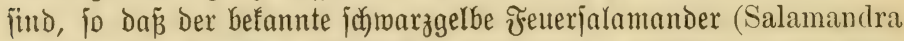
maculosa) auf gelbem Rehmboden eine nahezu einförmig gelbe ₹är= bung annimmt. Ebenjo fonnte er bie Wirfung von Sidat, Wärme

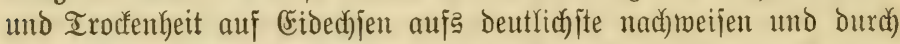
(sintwirfung Koher Iemperatur bei trocfener \&uft jütwarze Formen (Nigrinos) aud bei jolden (sidedjenarten erperimentell hervormfen, won benen foldhe im Freileben nidgt befannt jind. Freilid) Darf nid)t

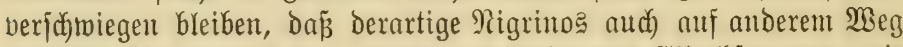

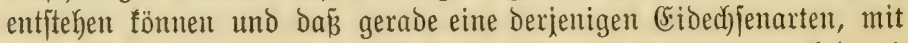
benen $\mathcal{A}$ a m me e e r experimentierte (Lacerta oxyc ephala), aud burd)

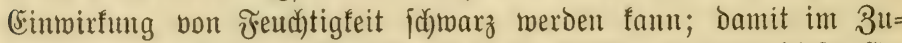

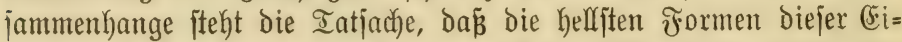
Dechje auf den heiß̄en, wafjerarmen Injełn Mitteldalmatients, die jobwarzen im ziemlid) falten, relativ regenteid)en herzegominij(d)en Bebirgaslande leben.

Dieje Beränderungen gehen aber immerhin ziemlich langiam

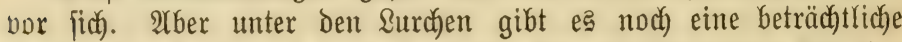

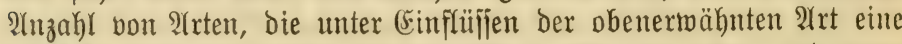
oft fehr rajaj eintretende farbenreaftion erfennen lajien, und jtwar fönnen wir bei Sonnenjobein, Wärme und Iroctenbeit in Der

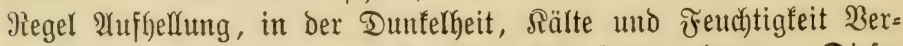
Dunflung Der Färbung, menigitens Der Dberjeite, erfennen. Diejer Farbentwechjel ift bei manchen Frojd)lurden ein jefr rajdjer, leb= hafter und mannigfaltiger, und unjer Raubfrojact ift jołljagen bas (Shamäleon unter unjeren Keimiją̧en Surd)en; Die Färbung feiner 
Sberjeite fann vom Gellften Brrün in Dunfelgrïn, Błaugrün, Blau= grau, Brraugrün, Dlivengrün, Braubraun übergehen, jogar in Bselb

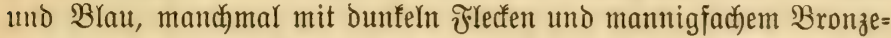
joimmer. Ifber aud unjer (Brasfrofd) (Rana temporaria) fam eine nette Sfala von Berniteingelb zu Sd)ofoladebraun, Der Spring=

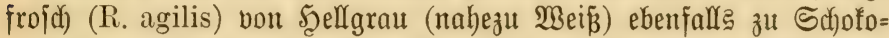
ladebraum durdiblaufen. IIm geringiten ift der Farbentwedjel bei

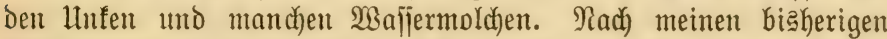
(Erfahrungen ijt er bei ben tropifaten Surdjen im allgemeinen weniger auffällig ale bei den umjerigen.

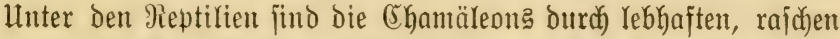
uno mannigfachen Farbenmedfiel feit langer 3eit befannt, uno fie gelten in ber Siteratur als Simnbiloer charafterlofer, ihr Mänteldyen

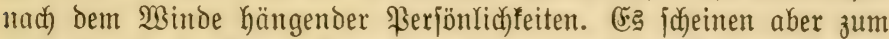
mindejten einige fleine Irten, bie Der afrifantid)en Battung Rhampholeon und ber madagafifict)en Battung Brookesia angehören, nur

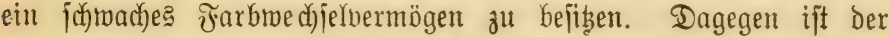
Farbentwedjel nod) jehr lebhaft bei vielen (Sectonen, bei Dem mada= gajititifen Rindengeffo Uroplatus fimbriatus, Den indifichen Baum= und (Sebüjcheidechjen der Itgamidengattung Calotes, bei Den bereits mehrfach) ermähnten, eine ähnliche Rebenameije führenden tropijach= amerifanifiden Anolis, bei ben in Sand = und Felamuijten, aber auth) wie die Siebleragame, Agama colonorum, auf Bäumen Yebenden Igamen, bei den Dornjabünzen (Uromastix) und vielen anderen Bertretern ber IIgamiden= und Jguanidenfamilie. Saum nod merf= bar ift der Farbentwedjel bei mandyen nüftenbetwohnenden Waranen, bei einigen (blattedjjen (Eumeces), dagegen fehlt dieje Fähigleit völig ben meiftent anderen (Eidechjen, Den Schlangen und allen ïbrigen Reptilien.

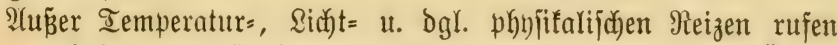

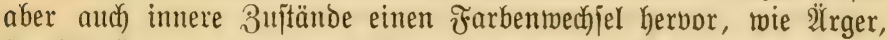

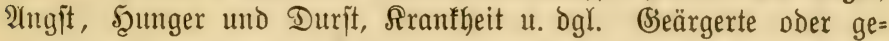
ängitigte (Shamäleone (Ch. vulgaris) werden häufig nahez̧ı jớtwarz mit gelben oder hellgrünen Flecten; franfe fehr hell, gelblide und

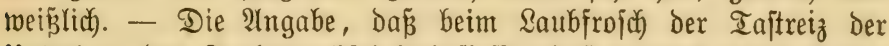

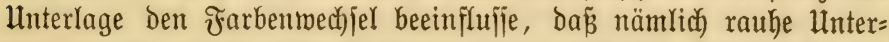
lage bunfle, glatte helle Färbung herworrufen foll, bedarf jehr ber 
Rad)prüfung, da meine Erfahrungen an freilebenden Exemplaren feinerlei Bejtätigung ergeben haben.

Wägrent bei bem Farbentwedhjel bie Färbung von einem matten Gelbbraun zum brennenditen Rot, zum jattejten Blau, zum inten=

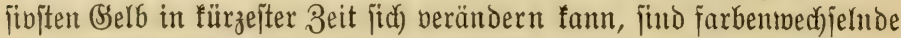
Tiere nidjt imitande, mit igrer Beidynung oder dem "Farbfleid= mujter", ๖. h. Der Âtrt und Meije Der Ânoromung ber Flecten uno Streifen der 5ृaut, dasjetbe zu tun. Die bunfeln Duerbänder

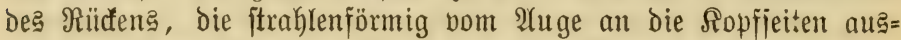
gehenden Sinien, bie Kellen Sängäbinden ber Rörperjeiten, Die runden, hell geränderten Fłlecfen auf Schnauze und Scinterfopf des (Shamäleon? fönnen bie verjhiedenartigiten 2tbjtufungen von Brün, Braun nder BSelb aufweijen, die Frlecten, Bänder und Sinien jelbjt befjalten itets

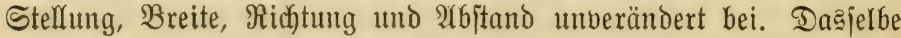
gilt auch) für andere farbentwedjelnde Reptilien; ebenjo jind bie bei

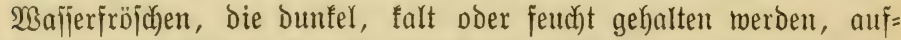
tretenden Dunfeln frlecfen Der Bauddjeite beptändig in ihrer Eage zu=

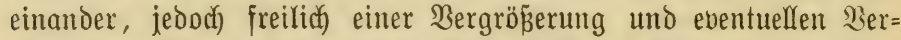

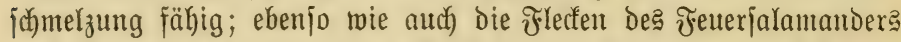
nach Sammerer unter dem (Finflufie des Bodengrundes fich ver= gröpern und miteinander berichmelzen oder aber andererjeite fleiner werben uno jidf) in einzelne Stï̛fe auflöjen fömten.

Mitunter wiro auth von S(h)langen ein Farbentwed)felvermögen angegeben. Dieje irrige 2 (ngabe beruht einfact) Darauf, daß̧ bei

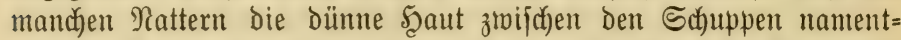
(id) am Scalje eine andere Färbung bejiz̧t als bie Schuppen jelbjt,

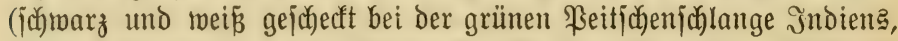
Dryophis mycterizans, rot bei mandiden Balfernattern ujw.). Bährend

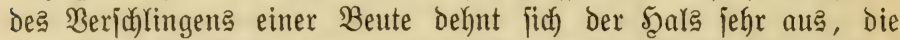

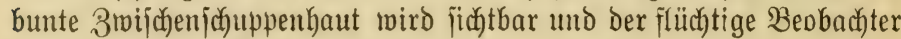
fomitatiert einen Farbenwechjel.

Ein ganz langjamer Farbentmedjel wirb oft im Berlaufe ber Entwicflung beobachtet, jo bas junge Tiere bann volläändig ben alten unähnliç find unt früher lange 3eit für verjodiedene 2Yrten gebalten wurben. F(m häufigiten find die Fälle, too bie jungen Tiere aller

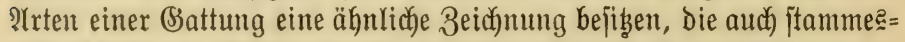

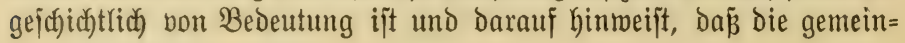


fame Stammiform diejer 21rten eine Derartige 3eid)mm getragen hat, Dieje 3eichum! aber mit zunehmendem ?Iter mehr poer weniger voll=

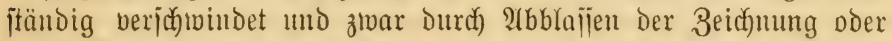
burd) Berbunflung der helferen Grumbfärbung, erjterę 子. B. bei Der 2̈afulapnatter (Coluber longissimus), Yetzteres bei dem nord= amerifaniijon Coluber obsoletus. In anderen Frällen ift bie Jugeno= jeid)mung eine andere als bie ber ermadj) fenen Tiere; bei ber filid= oiteuropäiijd)en $\mathfrak{B i e r i f t r e i f e m u a t t e r ~ ( C o l u b e r ~ q u a t u o r l i n e a t u s ~ [ : ( 6 6 . ~ 1 ] ) ~}$ uno bei ber jübrejteuropäija)en Ireppennatter (Coluber scalaris) find bie Jungen Dunfel geîlecưt (Flecten ber Dberjeite in 5-6 Sängğ= reihen, bie Deb Rüufens am größ̄en, meift verjumolzen, aljo nur in einer ?eilhe; Baudr) bicht dunfel gerlectit; Ropf mit inmmetrijicher Dimfler 3eidfnumg); Die er= madjienen Iiere laben fait feine Ropfreichnung (nur ein Dunfles Band vom 2̂tuge zum Mundwinfel), einen un= geflectten, hellen Banta) umb vier bzrw. zmei bunfle Säng乌=

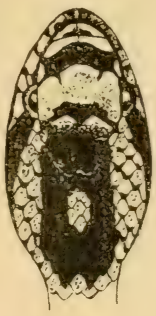

a

Ytob. 1. hopf ber Biutreifematter (Coluber quatuorlineatus). a b jutges, c ermadbienes Tier.

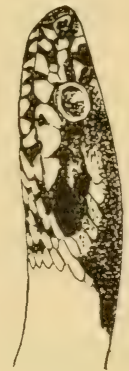

)

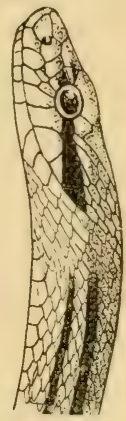

C

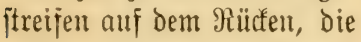

mit zunefymendem 2flter in Dempelfen Brabe hervortreten, ale

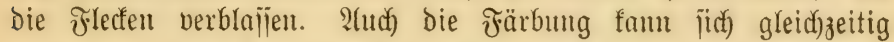
berändern, wie bei der Bierjtreifennatter, die in Der Jugeno hellgrau, im 2llter gelb=, rot= oder graubraun ijt. Serjuchedene (Fibed)jen aus der Familie der Scinciben haben jafmarze Junge mit

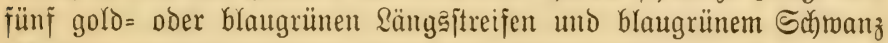
(Mabuia quinquetaeniata, Eumeces quinquelineatus, Lygosoma cyanurum) und werden in âtter gallz einfarbig braun ober

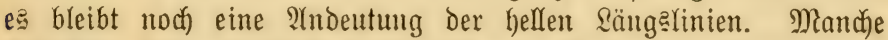
(5idechjen find oberieits in ber Jugend breit quergebändert, im

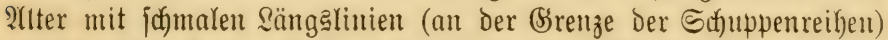
geziert, wie bas auf Den Sundainjeln nidyt jeltene Lrgosoma 
olivaceum. Die Jumgen dę im Arter bunfeł quergebänderten Scincus officinalis find oberjeits einförmig jandfarbig. - Reptilien, die im

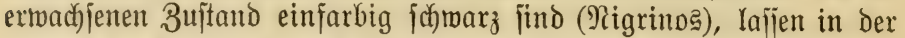

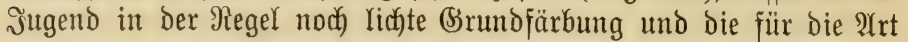
Doer (Sattung darafteriftifoche Beichnung erfennen; jo jund bie Sungen
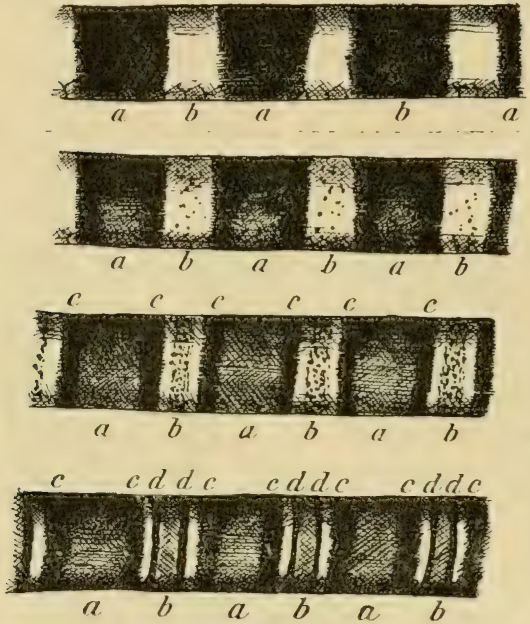

Stb6. 2. Entitefumin bes bunten Tarbfeismufters ser Sorallemattern (Elaps). Iie greithen vind)= ftaben zeigen bie হage ber gleidnertigen :Hingel an. a ift bei ber urjpringlidiften form (oben) jdywarz, baum rot, fadwarz gefüunt; b gelb, bam

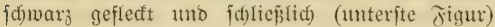
f(d)warz geringelt (d).

Der jogenannten Şöllenotter, Der jđjwarzen Barietät Der Sreuzotter, bon normalen Sreuzottern nicht z̆u unter= jueiden, und basjelbe gilt für bie jaymarze Barietät Der Pfeilnatter (Zamenis gemonensis var. carbonarius).

In den Bereid) Der S(futs= färbung fällt nun aud die Mimifrn, bas ift bie auf= fallende übereinftimmung einer mehrlojen Iierart in Färbung, 3eid)nung, Rör= perbaltung, Rebenameije uno 2tufentbaltanort mit einer anderen Tierart, meldye burd) irgentmelche Wafien vor ifren Feinden gejuitht ijt und mit eriterer zujammen vorfommt. Da: $\mathfrak{B}$ orfommen won Mimifril murbe und wird noch immer für ver= idjiedene Sidlangen behaup. tet, und nody in neuejter Beit werden Mimifryfälle von Stern=

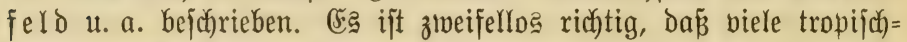

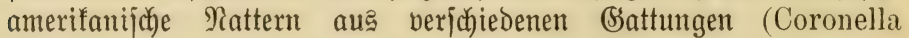
[2Gb6. 3], Atractus, Lystrophis, Simophis, Urotheca, Homalocranium, Erythrolamprus) den meift Dreifarbig (job)warz, gelb und rot) geringelten (Siftnattern der Battung Elaps Desjelben Bebiete马

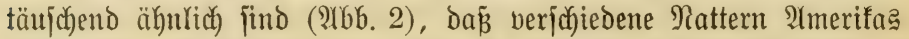
(Heterodon, Xenodon) vou gewiflen bortlebenden Dttern der (5iattung 


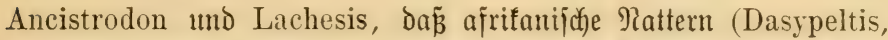
Rhamphiophis multimaculatus) bon dortigen Dttern als den (5at= tungen Echis und Bitis bei flürftiger Betrachtung faum gu unterjociden jind, und man fönnte die Reike diejer ঐ̈lnnlichfeiten um eine jiem= licke $\mathfrak{A n z a b l}$ weiterer ver $=$ mefren.

Yrber alle dieje jochein= baren Mimifrufällle fallen in

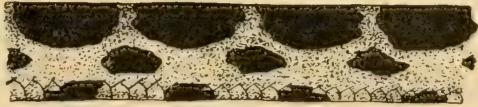
nichts jujammen, wenn man

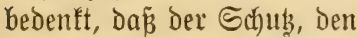
die ertwähnten "giftlojen" Schlangen burdy ibre Ülyn= Yidffeit mit (Siftnattern und Dttern genieß̄en, ein nur jucinbarer ijt, besmegen, meil bieje lebsteren jelbjt burd) ihre Waffen, die in erjter Sinie Dem Rabrungserwerbe bienen, feinerlei Sdubs vor ihren regelmäß̄igen テeinden haben. Rein ich)langenfrei= jenbes Sier veridont (Sift= joblangen, fick auf giftloje bejaränfend, und twenn $e$ द audi) flinfen, bifigen und fräftigen Schlangen gegen= lïber vorjiatiger vorgeht als gegen wehrloje, jo ift das Ende des fumpfes doct) nakezu immer die Nieder= lage ber Siflange, gleich= gültig, ob ein Jgel, eine

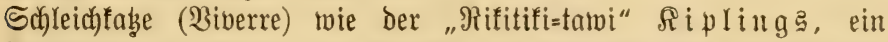
Rauboogel, ein Heiher, eine (sibed)je, ein frotodil ober eine Schlange
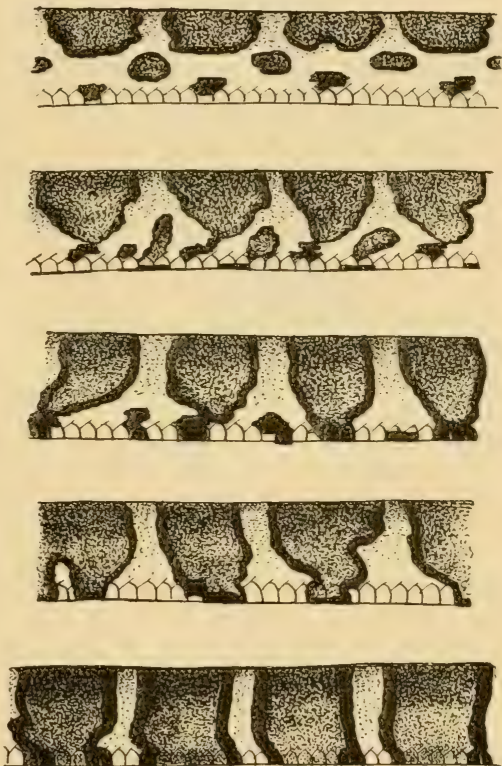

966. 3. Entitehung ๖еต bunten Farbfleiomuiters bei einer giftlofen Patterngattung (Coronella, Untergattung Ophibolus). Die jumarzen Flefen Der primitiviten Form fino bei ben übrigen rot= braun bis rot, jumwar geründert, bie fellen 3wiid)enräume hellgraubraun bis gelb. 


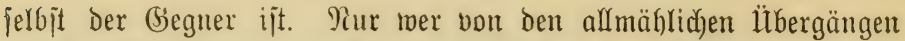
z'wijd)en dem nakezu wirfungalojen Sefret der (Siftorüje mandjer

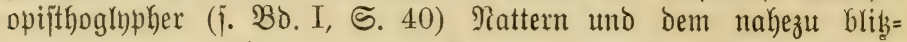
artig tötenden Bift anderer Nattern berjelben Bruppe feine

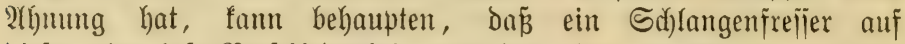
dieje minuziöje Berjojiedenteit eingehen doer die Brenze zmijaten (Biftichlange und harmlojer Ratter fejtiftellen fömue. Um ein Der= artigę Beippiel anzujühren, ift $z$. $\mathfrak{B}$. Die jübamerifanijaje opiftgo= glnphe, aljo anjd)eineno harmloje Ratter Erythrolamprus aesculapii eine entidjieden gefäbrlichere (siftjolange als bie meiften ber

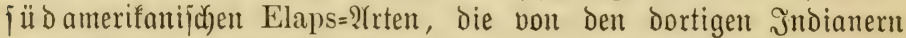
gar ni(f)t einmal als (Siftificlangen betrad)tet merden, da jie gar nidat bifijig ïno. R(tre in der Siteratur angeführten Beijpiełe von Mimifrn) bei Sthlangen falfen bemuad) einfad) in das (biebiet ber fonvergenten

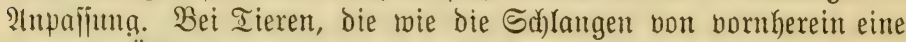

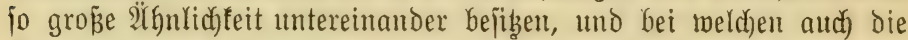
\{uesbildung des Farbfleidmuiters von Denjelben Birumoformen aus=

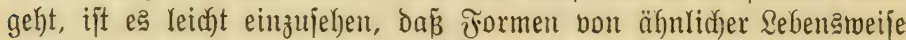
Gäufig in Färbung und Beichnung miteinander ïbereinjtimmen; ıno da äfuliche Sebenzineije aud) auf die Sörperverbältniffe bejtimmeno

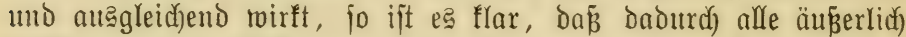
jidftbaren uno auffalfenderen Unterid)eidungamerfmale jid) bermijden

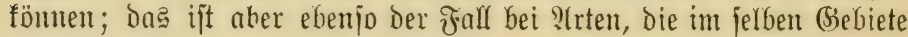
wie in meit getremnten Sebieten leben, mie aus der verblifffenden श̈̈fulidfeit bes indifden Pryophis prasinus mit bem amerifanij(f)ent Oxybelis fulgidus (beides Baumidylangen) bervorgeht. T(ud) gibt e马 etliche Beifpiele von Sdy)langenmimifrn), bei benen das "nad)=

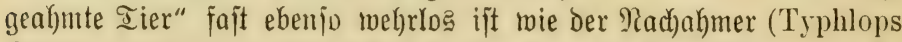
Howeri und Cylindrophis rufus) DDer bei Denen Der Scauptfeind Der nad)= abmenden IIrten (Calamaria) bie nact)geafme (Callophis) ijt. AYber audf) Dann, menn ein Iier aus einer ganz anderen flajje einer (siftidylange ähnlid) fieht, ift nod) immer fein (Srund vorhanden, an Mimifry zu

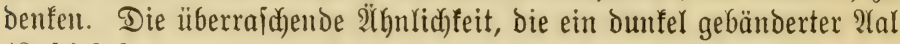
(Ophichthys colubrinus) der Suldjee mit einer bort lebenden See= id)Iange (Platurus) aujmeift, ift meder ein Schut gegen bie gemeinjamen Feinde beider (5̧aie) noch aud bor ber Schlange jelbit, bie mit $\mathfrak{B o r}=$ liebe ihre Beute eben aus aalartigen Fijachen (Muränen) auzmählt. 


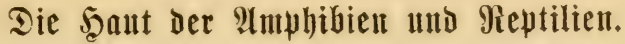

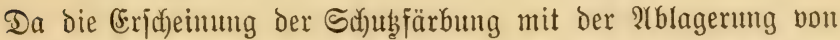
Farbjtoffen (Pigmenten) in ber Şaut zujammentängt, fo wirb e? (iid) als nüblich) ermeifen, bie 3ujammenjekzung ber leb̧teren und ihre Bejdaffenheit etwas näher fennen zu Yermen, nad)dem wir jajon bei friiheren Belegenbeiten bie eine oder bie andere (5igentümlichfeit ber Şaut bet den Gier zu be= ipred)enden Iieren flü(b)tig gejtreift Gaben. Da aber Surche und Rriech)= tiere gerade in biejer Beziełung (iid) jehr beträ(f)tlid) unterj(çeiden, jo wollen wir beide gejondert bes handeln.

Die $2(m p h i b i e n h a u t$ zeid)net jid Durd) einen groß̈en Reidxtum an Driijen aus, bie, über die ganze Dberfläche des Sörpers verteilt, bei vielen (Gattungen aujerdem nod) in grö̈̄eren (Sruppen, wie bie Dhr= bruijen (\$arotoiden) Der fröten und Salamander, angebäuft erjadeinen. Die Scaut füfilt fich Daber meiftens feudft, oft jod)leimig ant. (5马 wäre aber irrig, wenn wir bies fïr eine burchgehendes den 2Ymphibien zu=

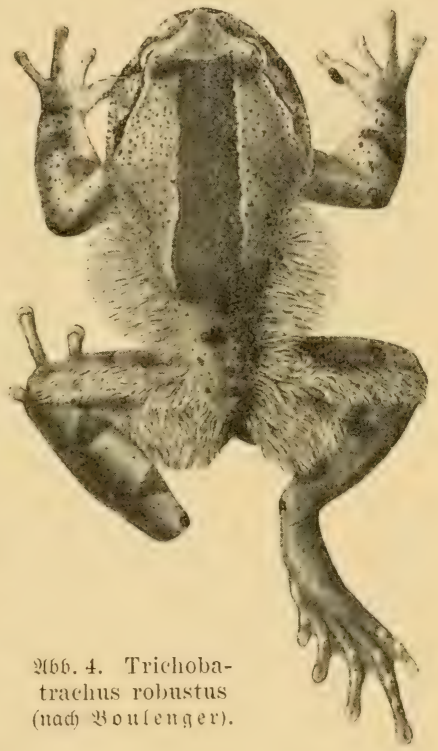
fommende Eigenjuaft halten wür=

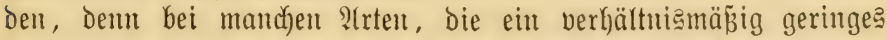
Fend)tigfeitabedürfnis haben und imitande find, ihr Seben lüngere 3eit ohne Mafjer zu friften, ift bie Scaut in biejem fralle voll=

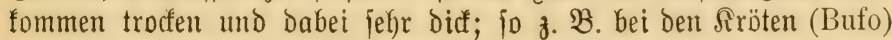
Der Mittełmeerländer, von Denen Bufo regularis audich bei twarmem Metter wodhenlang ohne 2 ajijer aughalten faum.

Da bie $2(m p h i b i e n$ im allgemeinen als nactthäutige Tiere be= faunt find, jo ermectte vor etlichen Jahren die Entbecfung eines Frojdes in Mejtafrifa (Giabun), Dejien Mäund)en jich burch bidjte 
Behaarung an den Sörperjeiten und am Sher. und Şinterrande Der Dberidyenfel auszeid)nete und der deshalb von Boulenger ale Trichobatrachus robustus bejurieben wurbe (2lb6.4), groß̈ę Interefie. Dieje bei $100 \mathrm{~mm}$ Rörperlänge $12-15 \mathrm{~mm}$ Yangen Şaut= ankänge haben aber freilich) mit mirflichen Scaaren nidfte zu tun, find aber audh, ba ifnen Pierven fehlen, nicht als Sinnesorgane zu Deuten.

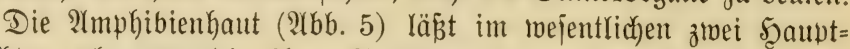
fichichten erfennen, bie ifrer Entiftehung uno ifrer Funftion nach

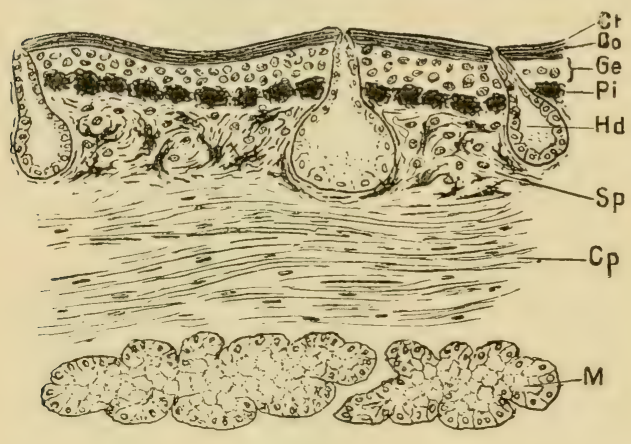

9(66. 5. Ed)nitt durd) bie Saut bes Ed)nausenfortjabes von Phinoderma darwini. Ct Eberbüutden (Cuticula), Co Stratum corneum, fie stratum germinativum oer eppi= bermis, Pi \$igment, Hd 5autoritien, Sp Stratum spongiosum, Cp Stratum compactum ber Eutis. mejentrich verichie= Den ind. Die obere Schidfte ift Die Dberbaut oder Epidermis; ;ie bes fteft bei bell Rar= ven aus einer ein= zigen Rage von an Der Dberfläche bid)t mitærlimmer= Gärchen, die in frühefter Jugend allein bie Bewe= gung ermöglicyen, bejebsten 3ellen. Mit junehmendem Arter vermefren

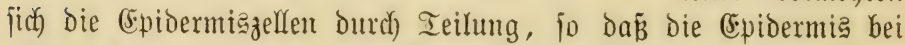
älteren Sarven (reich) an einzelligen Drüjen) bereits aus zmei, bei Den verwandelten Iieren aus mefreren Bellagen bejteht. Die unterften

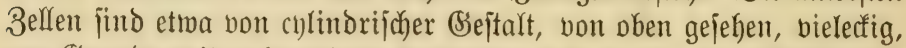
am Bsrumbe mit zafnartigen Fortjäz̧en, die in bie barunterliegende Sederbaut eingreifen, nach oben werben fie allmählich platter, und bie oberften fund mehr oder wentger ftarf verhornt. Bei Der Şäutung mird dieje oberite Schidhte, bie Scomichid)te (Stratum corneum),

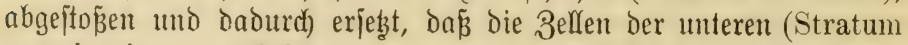
germinativum, auch Stratum mucosum oder Malpighii) ourdy leb= hafte Ieilung netre Bellididyten bilden.

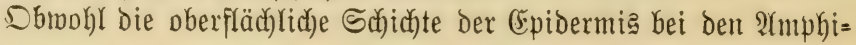


bien im alfgemeinen von jehr geringer Diffe ijt (jie befteht mur aus eincr einzigen 3ellage) uno ganz gla verhornte Stellen von beträarthicher Stärfe burd)aus feine Seltenheit bei ihnen. So futl bie Marzen, auf Denen die Şautorïjen bei Siöten uno Unfen ausmünoen, bei grojen Exemplaren fajt regel=

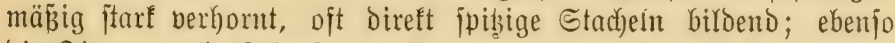
bie Finger $=$ und Behenjpizen, Die jogenannten Ferjenthöffer (immerer

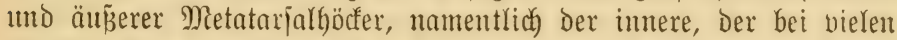

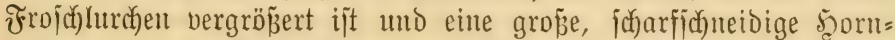
fappe trägt, die beint singraben in ben (5roboden als Sanaufel Dient - wie bei Der ภnoblaudffröte, Pelobates fuscus [1. 3D. I, S. 84], Dem afrifanijd)en (3rabjrojoje Pyxicephalus adspersus mo den Bier=

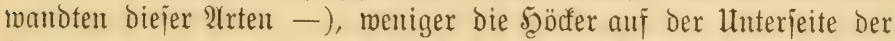

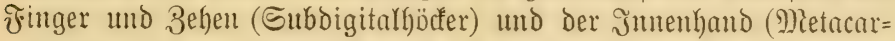

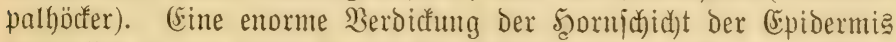

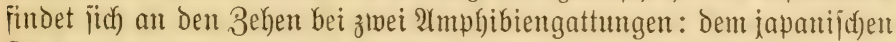
Sraflenialamander, Onychodactylus japonicus, der alle Finger umo

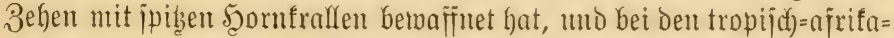
nijachen Spornfröfden (Xenopus uno Hymenochirus), bei benen die

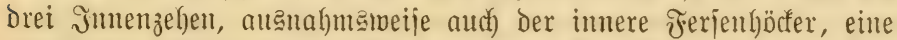
jefarfipitzige Sralle tragen. Dieje modernen 2 (mphibientrallen bejtehen

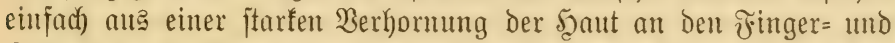
3ehenipiben, twährend mand)e der auagejtorbenten Stegocephalen aus Der (Siruppe der Microjantier mirflid)e firallen getragen Kaben bürften.

Die Unterfaut, Rederhaut (Eutis, (5orium), ift Derjenige Ieir Der Şaut, meld)er die Farbzellen, die Blutgefäß̈e, গerven, Driijen, Die etroaigen Snocheneinlagerungen entfält; jie ift von weit bedent=

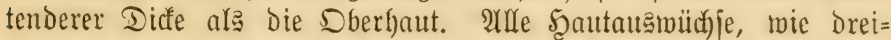
ecfige Sappen auf Der Schnauzenjpitze, Den 2tugenbrauen, Der Ferje

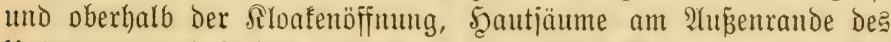

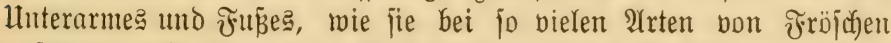
auftreten uno ifnen ein oft jo abjonderfidyes Afujeken verleiben find non der Sederfyaut gebildet und werden mur von Der Dberhaut ïherzogen; ebenjo entittehen die ßanzerbildungen des Sääbels uno

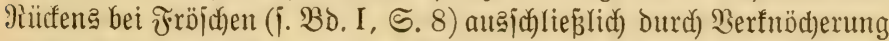
in ber Sederhaut. Die gropent, flajujenförmigen Szautoriijen (fleinere S(f)leim= und größ̄ere (siftorüjen) liegen ebenfalls in bie Sederhaut 
eingejentt, und nur ihr feiner 2(ueführungagang burdforingt bie

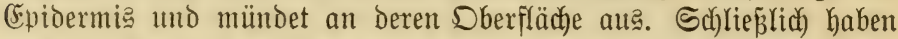
auch bie Farbzellen (5hromatophoren) ihren hauptjäblichen Sib in Der (Sutis, obwogl fie auth) in ber (Epidermis, und zrwar vorwiegend in iffrer unteren Sidjicht, gefunden werden. Die 3ellen enthalten Farbitoffe (Pigmente) in Form bon Rïmern oder Iropfen. Mir unteridgeiben nad) Rrufenberg idfwargbraume Pigmente (Mela= nome) bie in entiprechender Serbümung braum erjedeinen, gelbe oder rote Fettfarbjtofife (Sipod)rome); auperdem ein meí̄ę ober meišrgratte ment ((Suanin) und demnad) bie Bigmentzellen als Meland=, t.tantho= und Seucophoren. Die rutoricken oder vielectigen țanthophoren enthalten in der giegel aud) (Suanin und merden baher ale tantho= Yeucophoren bezeichnet; fie Yiegen in einer zufammentängenden Lage

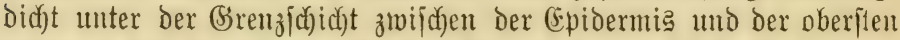
fajerigen Rederhautichid)t. In den Melanophoren, weld)e fternförmig veräjtelt find, ijt dą braume ßigment beneglid) und faun fich bald in Der Mitte Der 3elle zujammenballen, balo mehr oder weniger weit in bie Atuäuruer mandern. Die (Ghromatophoren ftehen unter Demt

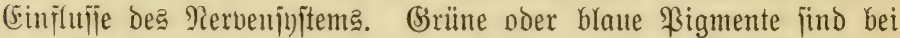
Den 2Amphibien tookl ebenjo jelten wie bei den Pieptilien; die blaue Färbung entjteft burch bie litberlagerung einter j(c)rärzlichen

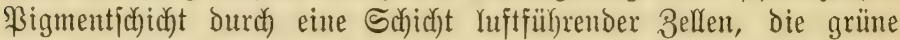
Durch) gelbliche Färbung Der ïber bieje nod) Darïbergelagerten Epidermis. Daker merben Spritpräparate grïner (Eided)jen, Sdylangen, Fröiche häufig blau, da bie horngelbe (Epidermis durch den ?llfohol

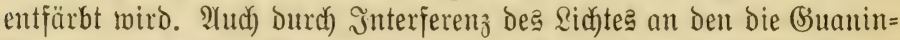
förner unigebenden Melanophoren, bie burch eine gelbe Ripod)rom=

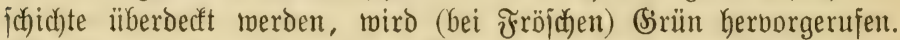

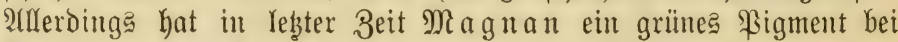
S(mphibien entbectt, aber nicht etwa bei grïnen Fröjd)en, fondern ge=

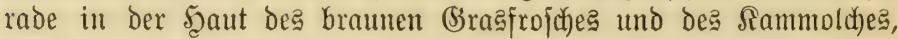
und zwar neben einem gleid)falle noch unbefannt gemejenen gelbbraunen Bigment. Farbenmed)jel (j. 5. 4) entiteft im einfad)jten Falle burd) bie 3ujammenziełung oder 21usdehnung Des Pigmente in Melano= whoren (Aufhellung und Berdunflung Der Färbung) Dber aber Durch) entiprect)end abrwechielnde Iätigfeit von Farbjelfen mit verjojieden ge= 
färbtem Jnghalt, bie in mefreren Schichten ïbereinanderliegen twie

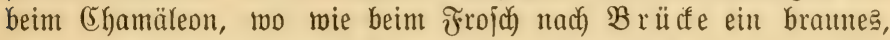

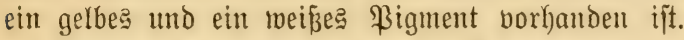

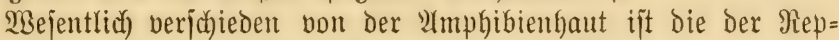
tilien, und zwar nidft nur Dadur(d), Dá̃ fie bejchuppt oder ge= panzert ijt - biejes Merfmal trifft zudem mahricheinlich für manthe ber ausgejtorbenen Reptilien nicht einmal zu -, fondern meil jie Der Drüjen jogut wie bolftändig entbehrt und weil ihre Sberhaut

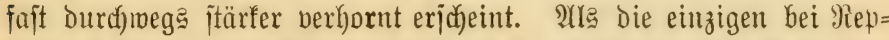

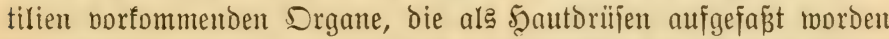

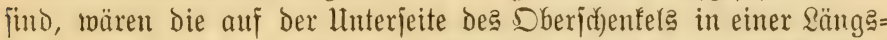
reibe oder mehreren (Sruppen altamündenden Femoral= (Schenfel:) Driijen (A66. 33), Die vor der Rloafenjpalte in eimer Duerreihe oder zmei (5ruppen angeoroneten, mitunter mit den Femoralorüjen eine zu=

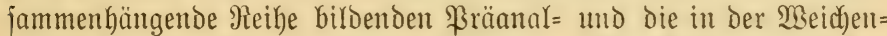
gegend riegenden Inguinalorüjen zut nemen. WBie I D̈lg gezeigt hat, handelt es fid) bei biejen Drganen, bie burch eine runde Difinung auf

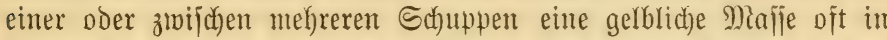
langen 3apfen entleeren uno beim Miännd)en entweder ftärfer als beim Beibchen oder ï̈berbaupt nur bei eriferen entricfelt find, um feine Drüjen, fondern um hühneraugenartige (Bebilde, ähnlid) Dem ßaa=

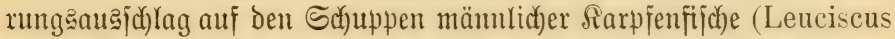
virgo), bie abgej(chiedene Majije bejtegt im twejentlichen aus berhornten (Epidermizzellen. Itber aud bie biejen Drganen vielfach) zugejurtiebente

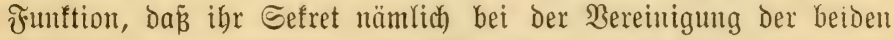

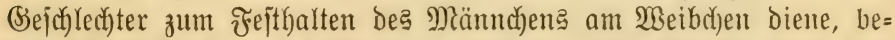

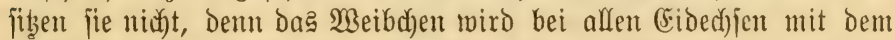
Siebiß̄ am Ropf oder bor Den Şinterbeinen feitgehalten und bie angeblichen "Scaftoriijen" berühren niemale den förper Dę Weibchene.

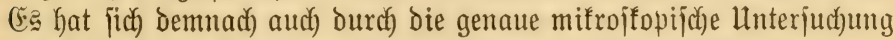
nichte über bie Bebeutung biejer Drgane feitiftellen lafjen.

Die Şaut Der Meptilien bildet befanntlich in Der Jiegel S(f)uppen,

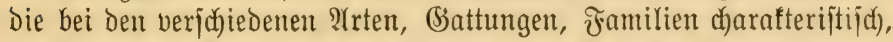

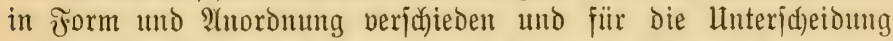
Der Pieptilien, namentlich) ifrer niederen Rategorien (2Irten, Battungent)

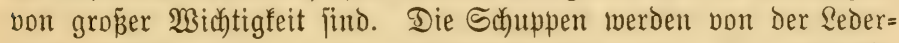
haut gebildet und bon ber Epidermis ïberzogen. Die einfad)fte 
Form ftellen bie jog. Sïmerichuppen vor, bie flein, gleid)artig, etwa? gemölbt, jelten mehr flach) und glatt find; jie finden jid namentfich

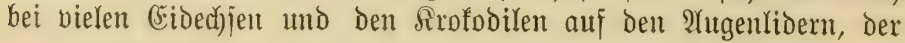
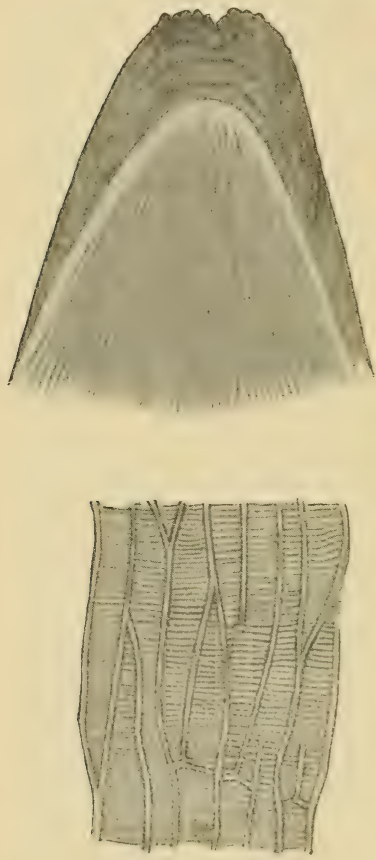

:(66. 6. Enize einer Mildenjof)upe einer Matter (Zamenis dahlii), Sarminter ein Etitif aus ber Mitte ber Echuppe, ftärfer vergröpert.

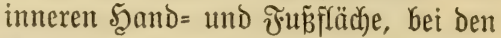
Scaftzehern Doer Bsectoniden vielfach auf Der ganzen Dberjeite. 2Yu foldyen Schuppen gehen bie anderen Formen hervor, deren mejentlichjte auf ver=

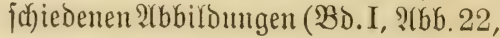
$24,29,31,32,35,38$, Bd. II, 2(bb. 1 , $11,12,15,20,32,33,34)$ erjid triticf find. Ralfeinlagenungen in Der Seder= haut in Frorm einzelner $S_{d y}$ uppen oder eines zujammenkängenden ßanzers (i. BD. I, S. 55) find bei den Reptilien jehr häufig. (Eine Bermadjiung ber Sopflyaut mit bem Schäbel wie bei gemififen Fröjchen tritt ebenjo bei Den Irofodilen wie bei berjobiedenen (sidect)= jen, wie ż. B. manchen Bsectos, auj. Die Bejduppung Der Reptilien hat aber nicht mur Bedeutung als Sörperbedectung uno bamit Sörper= ichus, jondern fie fpielt eine Rolfe im Sapitel "Beidyledotsdimorphismus",

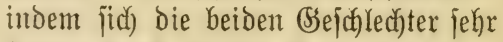
bäufitg burd̆ ftärfere (Entriçf́nng ge= mifjer S(f)uppen im männlidyen (Sese=

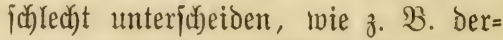
jentgen, melch)e den Rürfenfamm Der

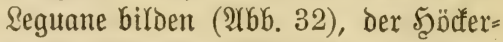

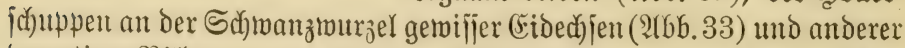
berartiger Bildoungen, bie jpäter nod) bejprod)en werden jollen. - Alber

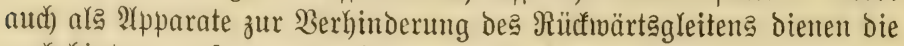
nad) hinten zugeipiżten, gefielten und jtarf bergrößerten S(buppen an Der Unterjeite ber Śdymanzmurzel gemifjer Baumeidedjen, wie z. B. Gei

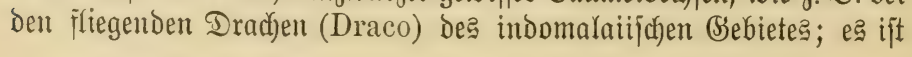




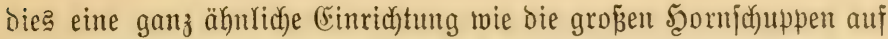

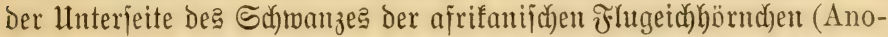

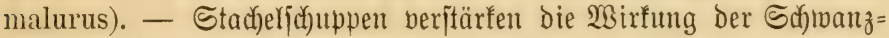

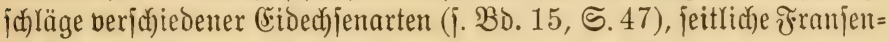
juchpen ber finger und Beben verhindern bei twüjtenberwoh= nenden (5idect)jen das (5injinfen in Den Sand (ㄹ․ I, S. 82), Sdfuppen mit gejägten Rielen all den Rörperjeiten mandjer

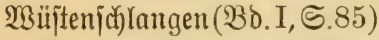
wirfen beim Eingraben in ben ๔and als Sandpfrïge; platte, quererweiterte, auffellbare Sctuppen (Ramellen) ant der Unterjeite Der Finger und Behen der Şaftzeher (Secto= niben) un $\mathfrak{A}$ noligeided)jen fungieren als \$ૃaftapparate an glatten oder überbängenden

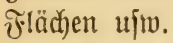

Shlieplidy find bie Sayu= pen uno zroar die groṕen, querberbreiterten, in einer Sängareibe den Baud be = dedfenden Baudjictilder oder Bauchfichuppen auch bei der ge= wöbulictyen saufbetwegung ber Sd)langen bou grofier Bedeu= tung. Reh hat auf die in
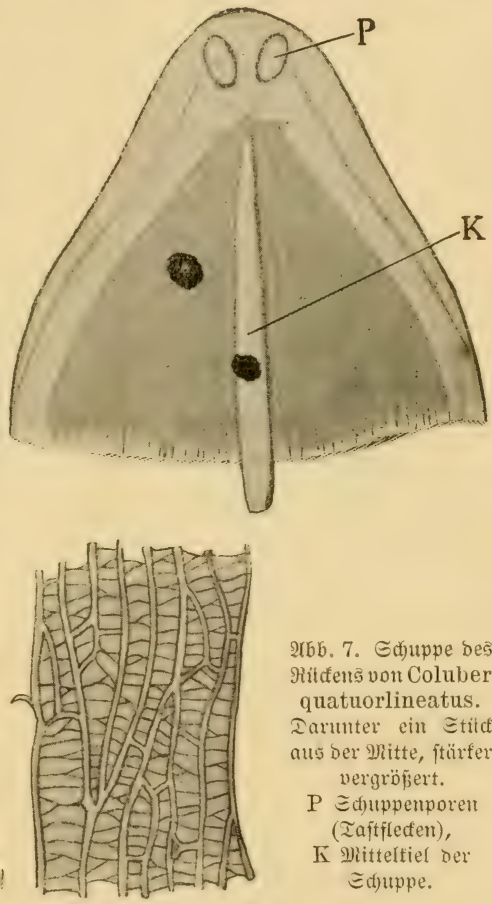

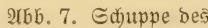

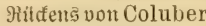
quatuorlineatus.

Iarunter ein Etitct aus ber $M$ itte, ftürfer vergröpert.

$\mathrm{P} \Xi$ こ) upenporen (Taftflecten),

K Mittelfiel Der Ed)uppe. Sebrbü̈fern allgemein verbreitete, aber gänzlich irrige Darjtellung hin= gemiejen, daj̃ bie Schlangen "auf Den Spizen ber unter der Scaut verborgenen Piippen" laufen jollten, twas praftijich ganz unmöglich ift, und er hat eine Errflärıng gegeben, weldłe für die getwöhnlicke Form des \&aufens ber S(t)langen zweifellos ridytig und ausreichend ift, für

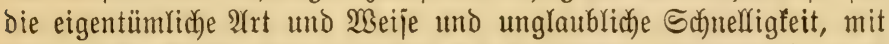
Dor gemilje Müjtenjd)langen, wie die Sूornvipern (Cerastes), audf)

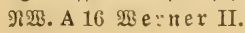


auf glattem Boden umo anjajeineno mit unveränderter Beibefaltung ciner beftimmten Rörperbaltung in fohiefer Ridutung babineilen, allerbings nidet genügt. Die langjame Betwegung auf bem (unebenen)

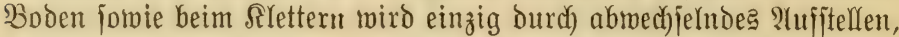
2Hitemmen und Utmlegen Der freien Şinterränder ber Baudfojdjildoer

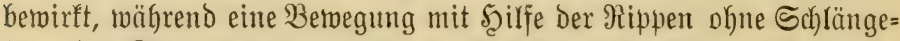

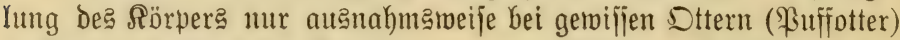
vorfommt, jowie beim Sriect)en in engen Söbern unb wäbrend Der Şäutung (bie ja audr) ein Şerausfried)en aus eintem engen sod), nämlich aus ber alten Şaut, vorftellt). Bei biejen (Selegentheiten

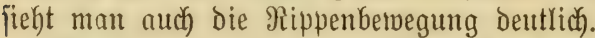

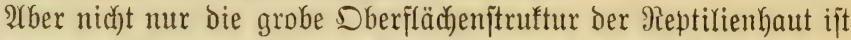
eine mannigfaltigere ala bei den 2 mtphibien, aud bie Schuppen jelbit bieten in ifgrent feineren Bau vieles Jnterefiante. So ift bei vielen Sd)langen und (Fidedjjen dą jogenannte Sberhäutchen (Cuticula, (Epitrid)ium) butch ein Syjtem zahlreid)er ïberaus feiner, mandfomal verzıneigter Sängłleiftct)en, bie burd) viele parallele Suerbälfdyen ver=

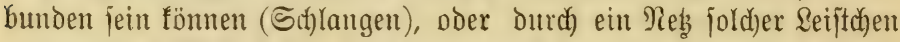

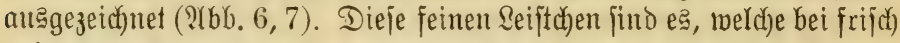
gehäuteten (Exemplaren im Sonnenjachein den mundervollen Mietall=

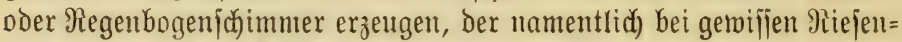

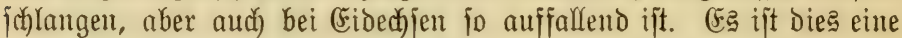

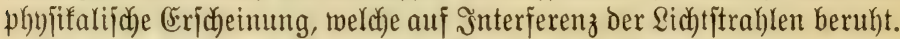

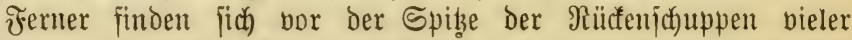
Sablangenarten und auth anderer Reptilien einfad)e ober paarige helle Flecten, jog. Iajtfflecten, bie ał马 Şautjinnesorgane gedeutet werben.

Die Scäutung Der Reptilien geht rie bei ben 21mphibien burd)

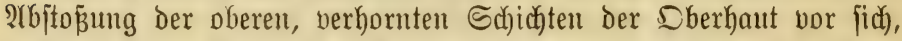
wobet an den 3ellen der Irennungazone eigentïmlidue fehr feine

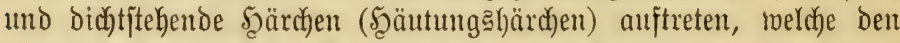
abzujtónenden Ieil Der Dherbaut von Der Unterlage abjeben und Daburd) bie 2(blöjung vorbereiten. Bei mand)en Siblangen (Miejen= ¡d)langen) und einigen (Eidechjen unteritübt ein flebriges, übel=

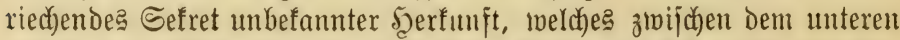

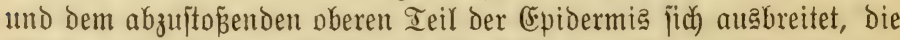
Wirfung der Scäutungąhärd)en; joldhe S(t)langen fönnen fich aud ohne

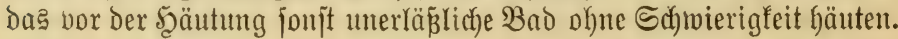


Bei den Srofobilen ifft eine Scäutung nidyt zu beobad)ten; bei S(f)ildfröten fommt fie mur außnahmandije vor. Eine Scäutung dę ganzen Şornpanzers, wobei bie jefr rauken, ftrahlig gefurchten, ein=

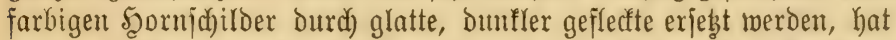

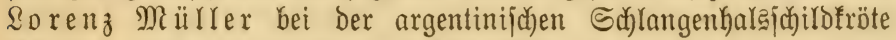
(Hỳdromedusa tectifera) beobuchtet (26b6.8).

Bei (Fibechjen geht bie şaut in ber Fegel in fleineren und

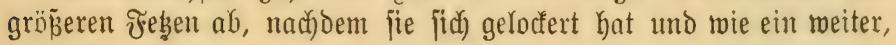

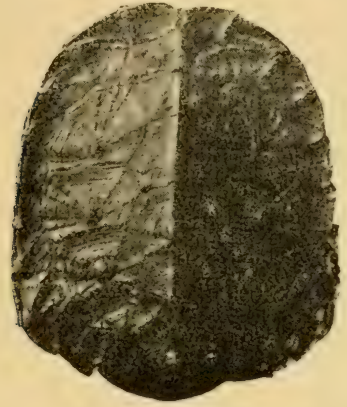

a

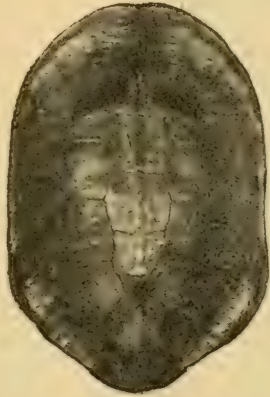

b

2(66. 8. Mitdenpanjer von Hydromedusa tectifera, jung (a) uno alt (b).

locferer Sact ben Sörper umgift. Mitunter gelingt e⿱

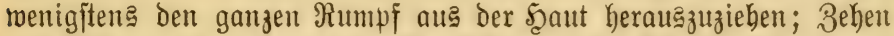

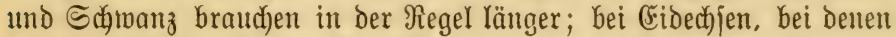

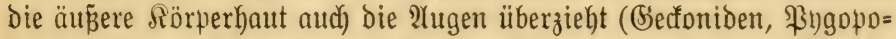

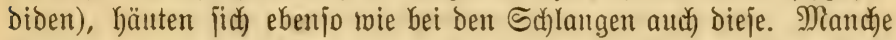

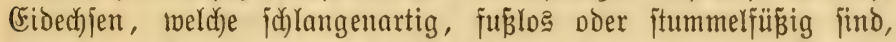

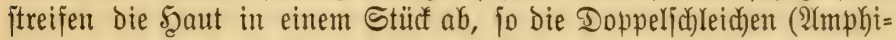
jbänen), ferner bie Birteljobleidyen (Inguiden), zu benen unjere Błlinoj(d) Yeid)e gehört; hier wird bie ganje abgejtreifte Scaut zut einem furjen Ring zujammengejđobben. Die Flofijenfilïe, twenigitena Pygopus, häuten fich wie bie Saflangen, indem fid) bie Scaut umfehrt,

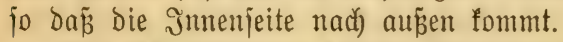

Bie jiut) Sd)langen bäuten, ift allgemein befaunt, joll baber nur furł mit Şervorhebung einiger wejentlicher (Figentümlidjteiten hier 


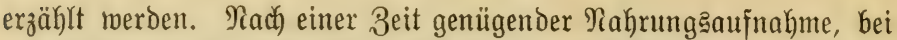

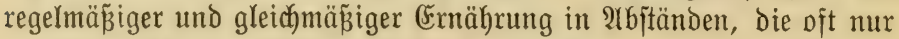
um einen Iag berichieden find (bei mand)en Der großken Priejen=

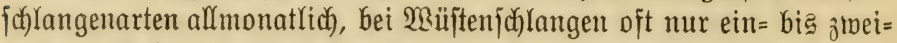
mal im Jahre), beginnt bie Scaut unfahembar, büjter, glanjloe ju

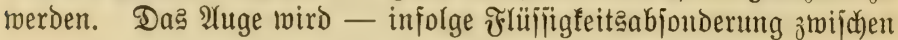

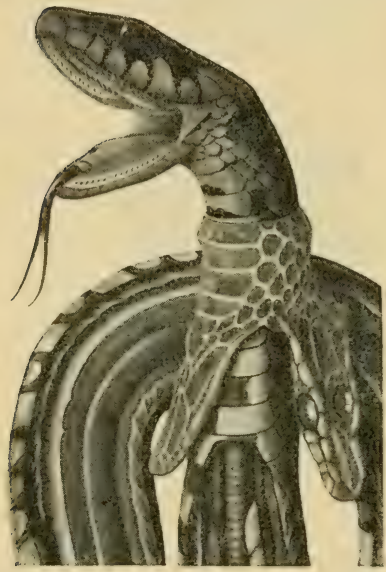

গ๖b. 9. Siopf und Borberförper ber Ringelnatter, in 5eäutung begrifien, bie alte 5ुaut umgeid)lagen. Man fieht,

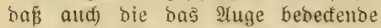

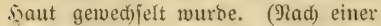
Banotafel von \&furtidelfer.) Der alten und neugebildoten Şorn=

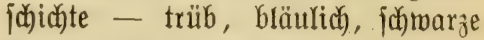
Stellen der Şaut merden ebenfalle

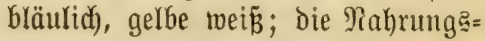
aufnakme meift geringer. Diejes ijt ber erfte 2(bjochnitt. Dann beginnt bas 2luge allmählich mieder flar zu merden, Die Rörperfarben werden wieder reiner, jo dá man mitunter im 3roeifel jein fann, ob bie Şäutung fidon ftatts

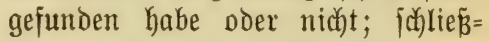
lich wirb bie Sallange unruhig und beginnt herumzumandern, mobei fie ihre Sd)nauze beitändig an barten Begenftänden (Baumrinde, Steine) reibt, bis die Scaut bon ber Dber= und Unterlippe, und zmar an ben an ber Sdynauzen = uno Rimnipibe fich) befindenden Sichildern (Roptrale Doer Stynauzen = und Symphyitale oder Sinnminfeliffild) jidch loctert und

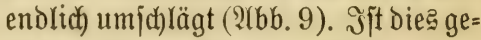
ichehen, jo friecht bie Schlange zmijhen Moos, (Bezmeig, Steinen lin=

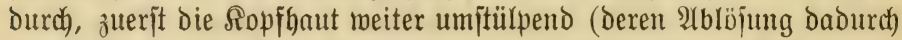

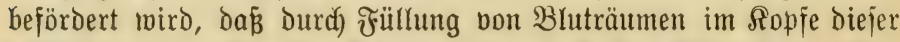
jelbjt etwaß anf(d)ellen fann), bann aud bie Rörperhaut; hier

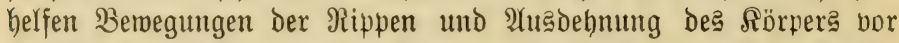

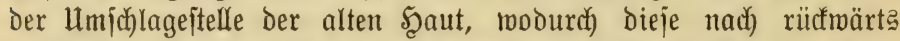

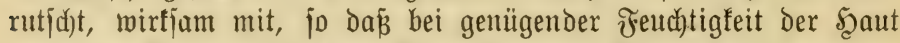
Der ganze Borgang in einer Biertelitunde vollzogen fein faum; im anderen Falle fönnen Mochen vergehen, bis die Scaut ganz abge= 
gangen ift, was freilich im Freien fajt niemala, um jo öfters in (Bie.

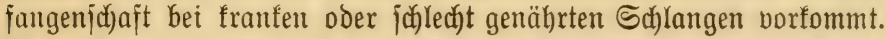

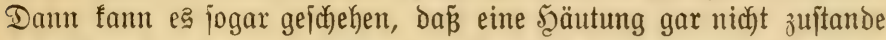
fommt und bei ber näbjiten eine Doppelte Şaut abgeitreift miro.

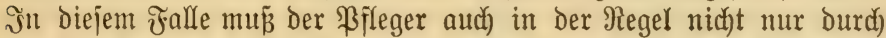
Berabreidung reichlicher warmer Bäber, fondern auch burch bor=

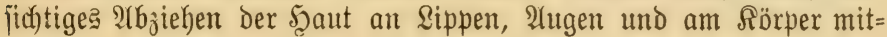
helfen.

Befamutfich hinterlafien die Sdylangen bie abgeitreifte, meift glähelle (bei genauter Betrad)tung aber die Rörperzeichnung in blajfem Braun wiederholende, bei fdymarzen Sdylangen - Nigrinos aber trüb raudbbraune) Scaut auf Biejen und Feldern, im Seeidefraut

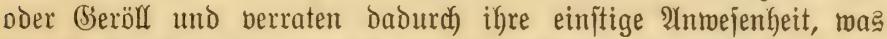
freilid) bei ifrer umiteten Sebensmeife niddst viel jagen will, da jie

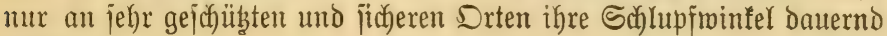
beibehalten.

Wir wiffen aber von anderen Reptilien, nämlidy den fleinen

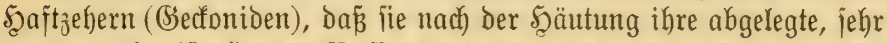

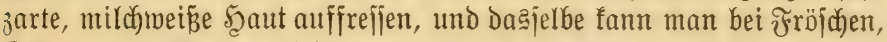
Rröten und Moldhen fajt regelmä̈ig beobarchten, ja bei ben unge=

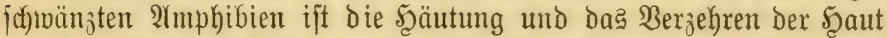
meiłt ein einz̧iger 2lft, indem mit Şilfe Der Şinterbeine, namentlich) Der langen vierten 3ehe, die Şaut unter fortwährendem Maulauf= iperren, 2lugenjuorïfét, Dreben und $\mathfrak{B i n d e n ~ a b g e z o g e n ~ u n d ~ b i r e f t ~}$ volt beiben Seiten aus ins Maul beföroert miro. Möglichermeije

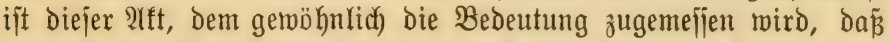
baburd) Die Spur des betreffenden Tieres für jeine Feinde ber=

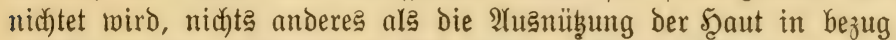

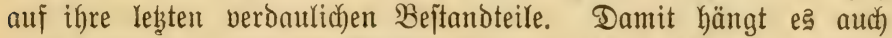
wohl zujammen, daß die Befizer einer itarf berhornten Epi= bermis dieje niemals auffrefien.

\section{Ciniges von Den Simeşorganen แnjerer Tiere.}

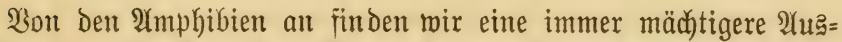
billoung des Behirnes im Bergleid) zum Rücfenmarf und ebenjo

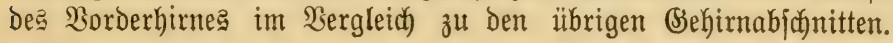


Wenn wir bas Bjehin einer Forelle oder eines Rarpfene mit Dem=

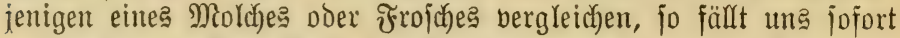

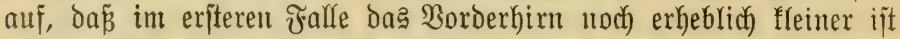

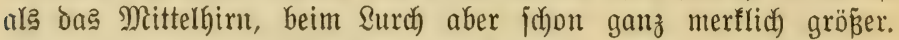
Diejer Unterjachied fällt alleroings Gintweg, wenn mir einen Der

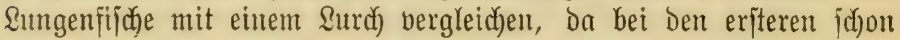
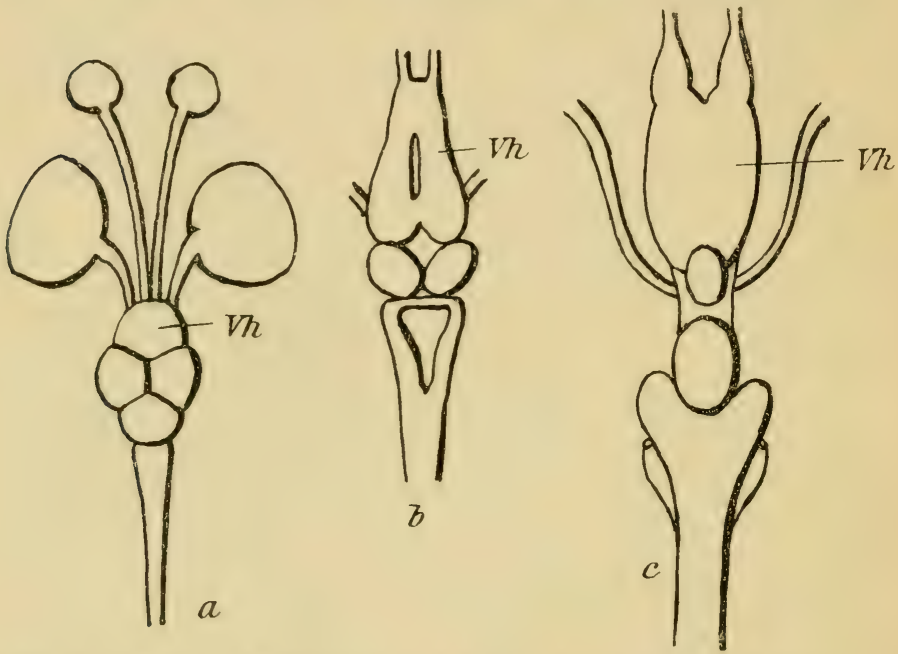

2(b6. 10. Gehim eines Sarpiens (a), eines Frojd)es (b) un eines sungenfifdes (c).

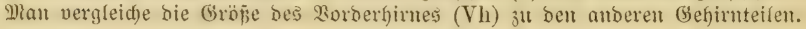

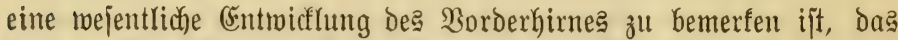

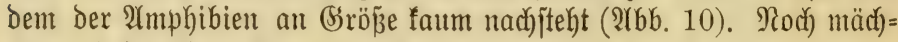

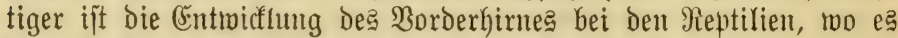

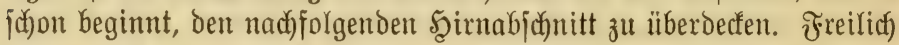
baben nidft nur mand)e von ben ausgeitorbenen Reptilien einen

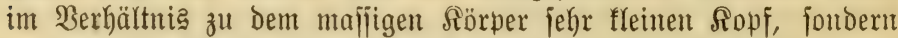

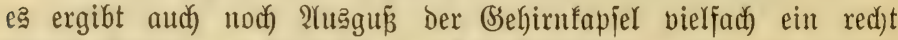
fleines Befirn, zu dem bei mandhen Riejentieren unter ihnen, die ïber einen äuß̌erjt fräftigen uno langen Sdymanz verfügten, wahr = idneinlich ein zweites Nervenzentrum in Form einer ?tnjobellung 


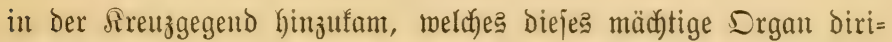
gierte.

Nodf) etwas ift in Der aufitteigenden Reihe Der Mirbeltiere zu bemerfen: $\mathfrak{B}$ on Den in regelmäp̈iger 21toromung an jeder Seite

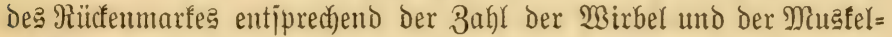

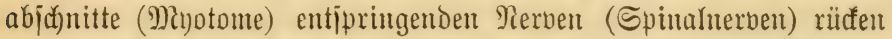

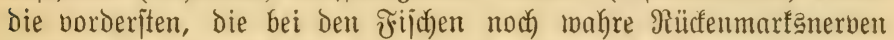

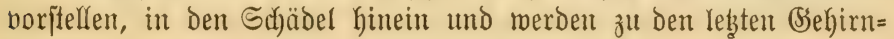
nervert.

Dies mır zur oberflädylichen Drientienung über bie midftigiten

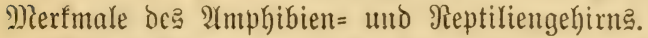

Wir mollen uls mu die Sinneasorgane, und zroar mur jotweit betradten, als jie Durd) Die Cinmirfung ber 2hupenwelt einer ßer= änderung ausgejebt jino, ohne uns in bie Behand= lung bes feineren Baues meiter einzulajien.

Weder $2(m p h i b i e n$ nod) Reptilien fallen burch be= jondere S(f)ärfe irgendeines

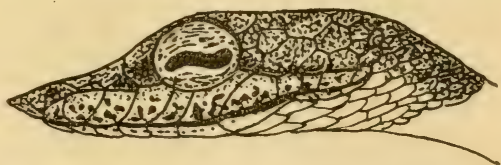

266. 11. Jiopf von Dryophis fasciolatus (Baum= jd)lange von Eumatra) mit horizontaler Fupilfe. Simnes bejonders auf, menn

wir von bem allerding aukerordentlich feinen, an ben Iajtinn ber Blinden erimmernden 3ungenjime ber Sallangen abjehen; auf feinen

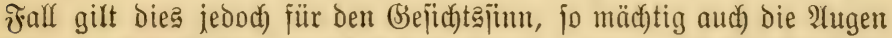

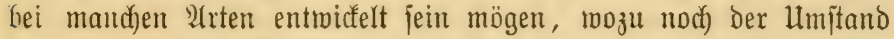
fommt, Dá viełe Âmphibien und Reptilien betwegumgaloje Dbjefte, twenn ę aud) Beutetiere find, mit Şilfe des (Bejichtâjinnes allein nidgt mit Sichergeit zu erfennen imitande find.

Die Bupiffe ift bei Den $2 m p h$ hibien runo, oreiectig oder hori= zontal oder vertifal elliptij(); in leb̧teren beioen Fällfen fann jie bei (sinmirfung namentfid) greffen Ridhtes zu einem haarfeinen Spalt zulammengezogen merden. Währeno eine wagerechte \$upille bie Negel bei joldten Frofid)lurchen ift, welche audf bei Inge ifrem Nahrungaerwerb nad)gehen, ijt bie jenfred)te Stellung Der Pupiffen

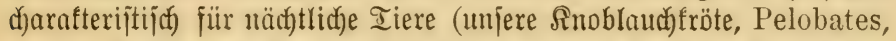
manche $S a u b=$ und Baumfröjche uj̣.). Sanz basjelbe fönnen wir auch) für bie gieptilien amehmen, obrobl hier bie horizontal ellip= 
tijoche Bupilfenform ïberants jelten und eigentlida auf die Baum= fd)langen ber Bsattung Dryophis bejad)ränft ift (melcher der befannte

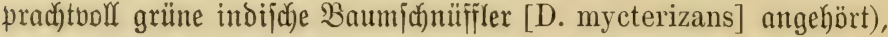

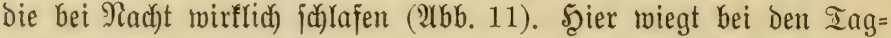

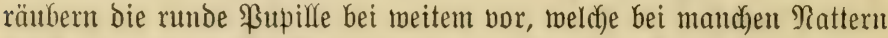
bei Iag zu einem Putnft zufammengezogent werden faum. Boriviegend närbttiche Iiere unter den Reptilien, wie die Rrofobile, bie Riejen= id) langen, Bipern, viele アattern, die meiften

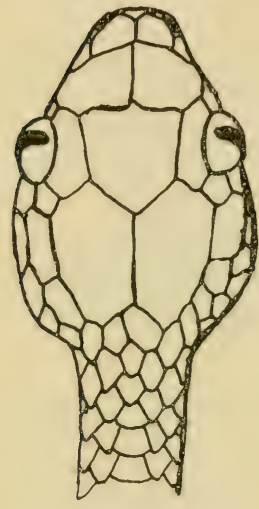

9(65. 12. Siopf cinter jith $=$ amerifanific)en Iämme= runģ̄baumidjlange (Leptognathus)mit weit voripringenden stugen. (Sectoniden oder Szaftzeher, find burch fenfrechte Pupille ausgezeidfnet; bei grelfent Iagealidft ifit jie bei biejen lebgtgenanuten (sibechjen viel= fach) nicht wie jonjt bei den Madytreptilien auf einen einfachen Spalt reouziert, fondern billot eine Reibe bon mit den Spizen anf einanderftehenden fleinen Rauten.

Die J̛rį ift bei den 2 mmphibien häuritg rot $=$ oder grüngoldig, mefïinggelb oder jitber= farbig, feltener jow warz, bei den Reptifien feltener mit Metallglanz, Gäufig gelbfić), gelb oder braun doer jogar rot, in dent verjefiedenften 2(bjtufungen, zlweifarbig bei mantifen Riejen= fdulangen, indem bie untere Şälfte Dunfel, die obere helf gefärbt ijt (Boa). Bei den meijten Srofobilen ift fie olivengrïn, bei bem ineit= afrifanijhen Stumpffrofobil (Osteolaemus) aber dunfelbraun; eine Beriftiedentheit ber Srisfärbututg ift bei Den beiden (Beje)lechtern umperer Sumpfichild fröte (Emys orbicularis) erfennbar. Mädytig entwicfelt find bie 21ugen bei mandjen in Der emigen Dämmerung Dichter Urwälder ber Iropen lebenden Reptilien; jie treten bei ifnen oft halffugelig aus dem Ropf heroor und find auch ber=

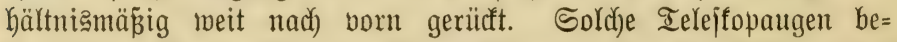
fitzen bor alfem veridjiedene Baumichlangen, wie bie 2 Imblncepha= rioen (ว. B. Amblycephalus in Sübojtajien, Leptognathus im

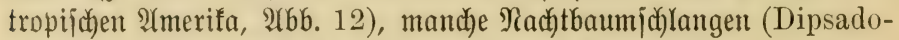
morphus), aber aud) Iagid)langen, wie Dendrophus formosus, grandoculis $\mathfrak{u}$. $\mathfrak{a}$. 


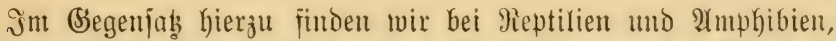
bie unterirbijđ) leben, nicht mur eine Berfümmernug des ?tuges in

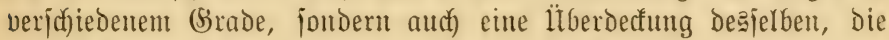

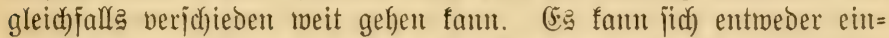
fach) Die äuईere Sïrperhaut über Da马 ?tuge ziehen

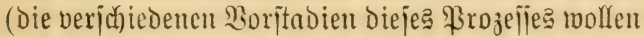
wir etwag fpäter behandeln) uno infolge ifrer Durdjichtigfeit oberbalb Dę Atuges immerbin menigitenes die lntericheidung von helf und duntel ermöglidjen; biez ijt bei den Doppelid)leiden ober

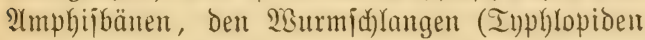
แnd (Slauconitiden), den Blindmilflen und Den (Srottenmold)en (Proteus und Typhlomolge) in verid jedenem (Srade Der Fall, je nach Der Diffe

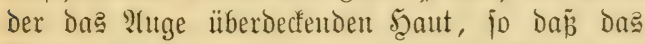

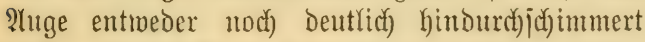
Doer aber nidft mehr wahrgentomment werdent fann; ober aber ez ijt jogar von den Schädel= fnochen überdectt, wie bei mand)en Blindrouiflen, und Dann wohl böllig funftionalog ober im $B c=$ griffe, ę zul werden.

Der litbergang von großen, mit freien Sibem

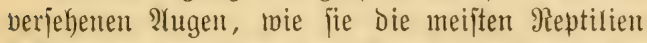
bejitzen, zu verfünmerten ?lugen, die unter der Szaut liegen, ift ein żiemlich allmäglidger, und es find ung gerabe wie für Den llthergang von ci $\mathrm{i}=$ Dechjen mit moblentroidelten fünfzehigen (S)ied=

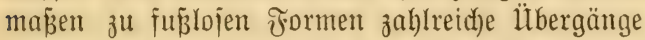
erhalten (26b. 13). Atlfe berartigen Tiere Yeben
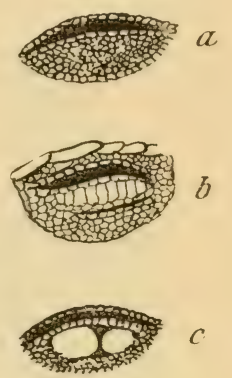
mentigittens zeitweije im Sande oder in Der (5rove

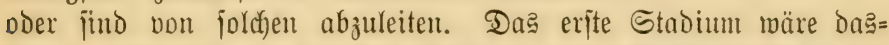
jenige, wie wir e马 bei Den Steppen= und $\mathfrak{B}$ üftentided)ien Der (Battung Eremias finden. Dą untere, normal bejafuppte $\mathfrak{A}$ ugen=

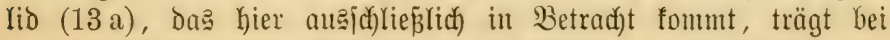
mandyen 2trten biejer Battung in Der Mitte eine Suerreike ver= gröperter, burchfictiger Sthuppen (13b); bei anderen find dieje

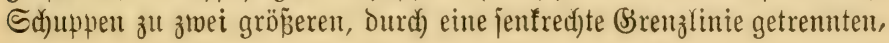




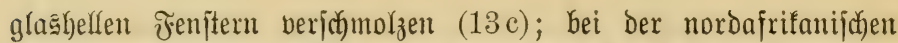
Lacerta perspicillata (13d), bei vielen 2̂rten Der (5̧attung Lygosoma und Mabuia ijt ein einfeitliches, rundes Fenjter im unteren $\mathscr{A}$ ugenlide vorhanden, das bei ben verichiedenten AYrten verjajieden grop fein faun. 2tber nod inmer ift Das untere 2lugenlio frei bemeglidy. Bei vielen

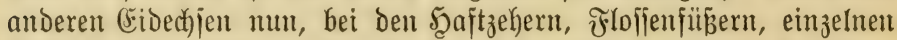
Battungen veridjiedener (Eidechjenfamilien (Ophiops [13 e], Ablepha-

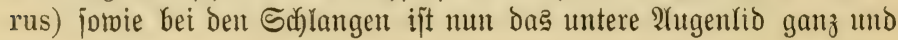

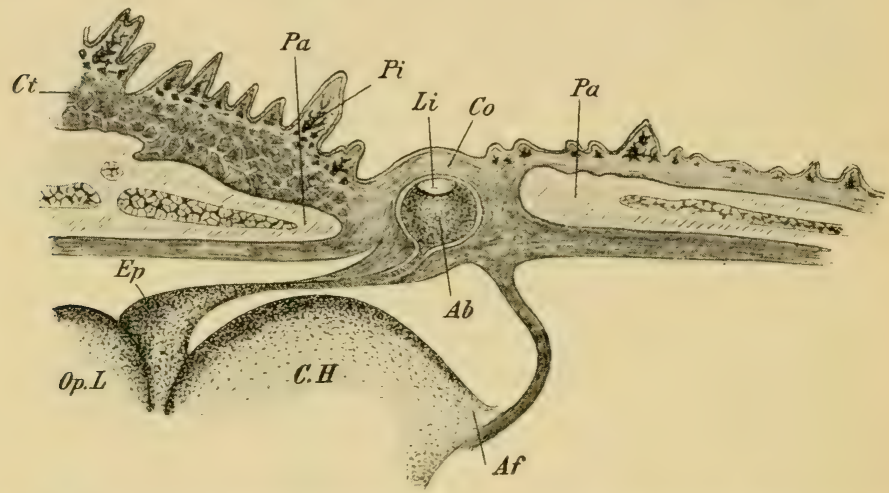

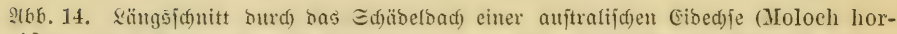
ridus), nad) Epencer. Ab Farietalange, Li \&inje besfelben, Ep Epiphyje (oberer

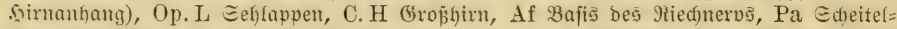
bein (Farietafe), Pi łigntent in ber Unterfaut, Co burdjifdige Saut (Eornea) itber bem Farietalauge, Ct Interfautbindegemebe.

bauerno ïber Dą $\mathfrak{Y}$ uge gezogen uno mit dem rubimentären oberen fejt

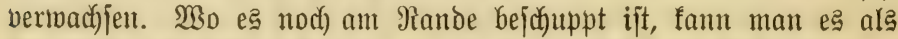
?tugenlio nod) Yeidft erfeunen; wo e马 aber, wie bei ben Sdflangen, in

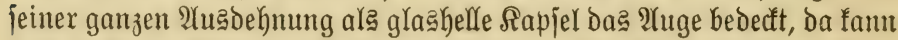
man Yeid)t zur Meinung fommen, als bätten bieje Iiere überGaupt feine

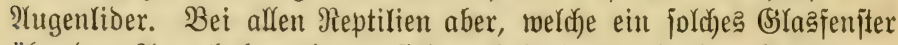
ïber bem 2luge haben, bäutet fid auch Diejes, jo bei Den Bectonioen,

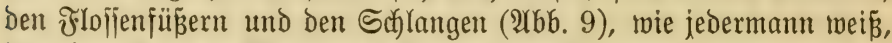
ber einmal ein bollftändiges "Natternhemo" genauer angejehen hat. Nun Grauthen aud) bieje Plugen=lugrgla 


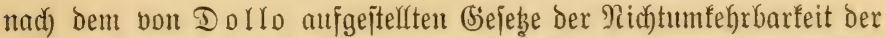

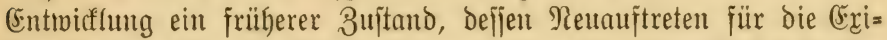
itenz ber betreffenton Iierform notwendig ift, niemale burd) ein=

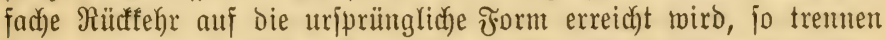

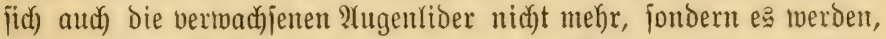
bei mand)en Bsectos (Aelurodactylus in Inoien, Ptenopus in Silomeitafrifa) jomie bei den gectoübnulichen (5ublephariben, neue ?lugenliber gebildet, bie von einer iaton bei ben Bectoniden bor= handenen, ringförmigen, bejachuppten Şaut=

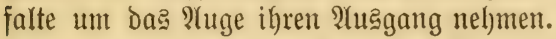
Şinter Dem glaahgellen 2 lugendecfel bepült die majierkelle Iränenfiliffigfeit bą 2luge. Sie reinigt bei ben Reptilien mit freien Sidern bie Scornthaut bon Fremoförpern, welche dae 2Yuge trü= ben. Bei den Biecfoes i fit aber nod) ein (Sla Decfel vor dem $\mathfrak{A}$ uge, welcher burdis bie

Iränenflüffigfeit wobl von innen, nidyt aber won aunen ge= reinigt werden faum.
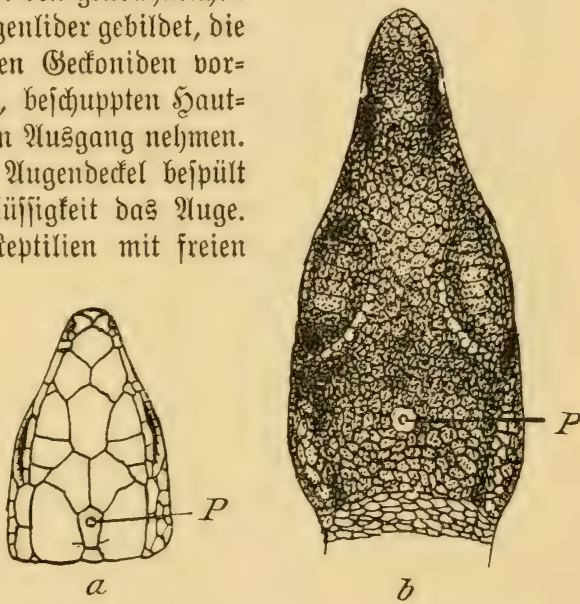

266. 15. Siopf a von Lacerta, b voit Taranus muchalis; von oben. $\mathrm{P}$ Rarietalauge.

Die Reinigung bon

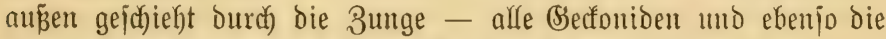
Flolienfüïer fömnen ihre 2lugen jelbjt ablecten!

Jim Schäbeldach) ber ausgejtorbenen ßanzerlurche, ber Stego= cephalen, jomie vieler (5ibechjen, und ziwar in ber Mittellinie, findet

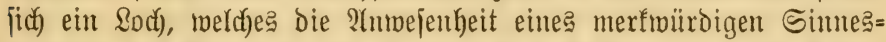
vrganes, des Parietalauges, jo genannt nad) jeiner $2 a g e$ im ßarie= tale (Scheitelbein), anzeigt, ba durd) biejes Soch) Der Nerv findurchtritt, Der bie Epiphyje, Den jogenamten oberen Befirnanhang, mit biejem

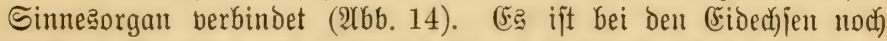

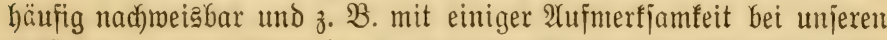

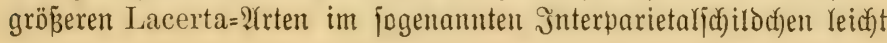


auffindbar. Dą ßarietalorgan ift bei Dem neujeeländijahen Spheno-

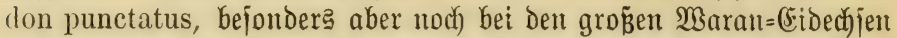
(Varanus) und Reguanen (Iguana und Berwandte), ja auch noch bei

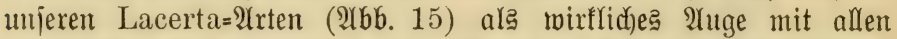
mejentlicken Beftandteilen eines jolchen entwicfelt und bie Dberhaut

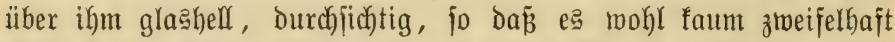
iit, da fann. Jmmerbiu aber j̈no bie paarigen $\mathfrak{A}$ ugen Der $\mathfrak{B}$ irbeltiere ältere Bildoungen als die hier ermähnten Drgane, uno

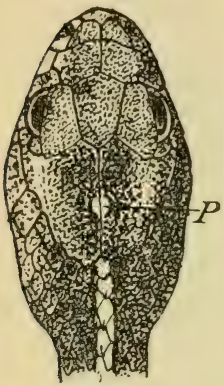

:.6o. 16. Sionf einer amerifan. Wajier= natter (Entaenia saurita). P Qeb̧te Enux bes Rarietal= autges in Form eines forftanten gelben Flectes. bieje leb̧teren treten auch) in Der (Entricflung ipäter auf, erreichen autd) niemale audid mur annäherno Diejelbe crntwicflumg mie die Seitenaugen, Denen fie ïbrigents jomohl ihrem Bau nad) als autd) Durch ifre (Entitebung aus demjelben (Behirn= abjonitt (Mittelhirn) vollfommen entjprecten, jondern bilden fid) aud meift mefre oder meniger vollitändig zurücf. (5in hellgefärbter, meift gelber Frlect zeigt vielfad) auth) bei Denjenigen Reptilien, die feine Spur eine? \$arietalorgan mehr erfennen Iaffen (twie bei vielen Sd)langen, i. $\mathfrak{H} 6$ b. 16), die einitige Stelle deŝjelben an, wie wir überbaupt

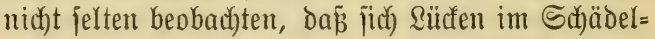

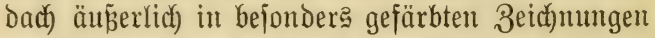
der Darïberliegendent Scaut bemerfbar machen, mie bię namentlich bei den Sd)nauzen= und Şinter= Gauptşgntanellen der çamäleons auffällt.

Die Alccommodation, das ift bie Einjtellung Des 2̂tıge für das möglidjit jacharfe Sehen, wiro auf veridjiedene Weije betwerfitelligt; fie fehlt ben nädthtichen 2 mphibien und Rep=

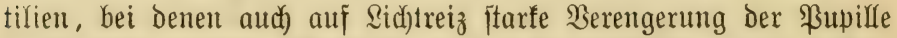

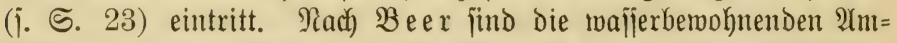
phibien auf Dem Sande ftarf furzilichtig, Dagegen die landlebenden

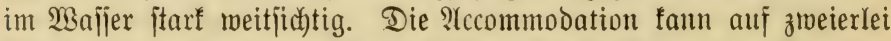

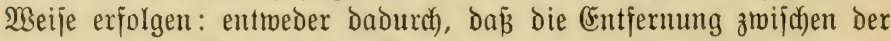

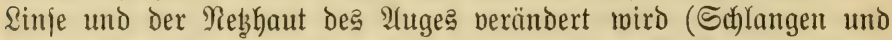

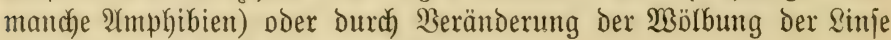
(Schildfröten, Rrofodile und (Eidechjen). 
Dab Behörorgan der Reptilien und 2 mphibien, nad) anken Durcti das Irommelfell abgejd)lofien, entbehrt einer Dhrmujdyel

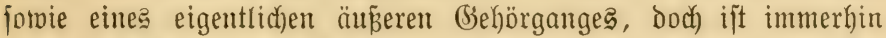
bei viełen (Fibedfjen das Irommelfell jiemlid) tief eingejenft. 2(lz

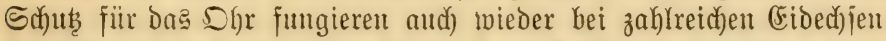
bergröBerte, nom vorberen Shrranto nach hinten ragende, meift breiectige Sduppen, bei Den Rrofobilen aber ein anjehnlidyer auf= flappbarer Shrdecfer. Bei vielen Almphibien ift das (Sehörorgan

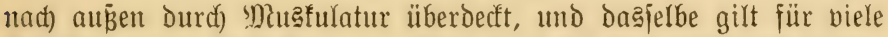

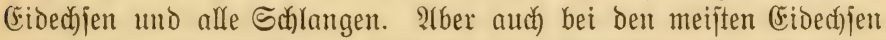
mit freiliegendem Irommelfell ift $e$ s johnierig, eine Reaftion

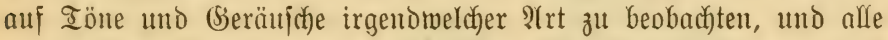
gegenteiligen Ingaben von muiffalipdyen (5ided)jen, Sd)langen und Echildfröten bürften auf Beobac(t)tungäfehler und Selbjttäuj(c)ung

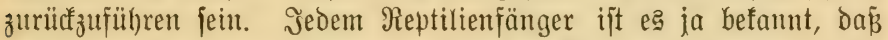
man beim Fang zwar jedmeden Särm volfï̈hren, aber weder fida) jelbït nod) feinen S(j)atten zeigen Darf jolvie aud (ङrichütterungen

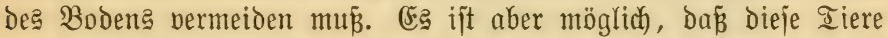
nur auf joldhe (Beräujdhe reagieren, bie ifnen im Freileben normaler= meije vorfommen, bagegen ungetwohnte eben ïberhaupt nicht hören;

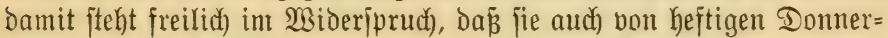

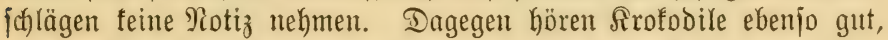
als fie fehen, jie gehören, einmal gemarnt und jahen gemacht, zu

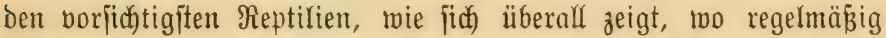
Jago auf fie gemadyt wiro. Daß́ fie eine Stimme bejitzen, weldhe bei Den Jungen quafend, bei ben (5rmad)ienen Dagegen ein mäd)tiges Faudhen oder Brülfen ift, ift befannt. Durch ihr Duafen mad)en auth) bie aut dem (Fi friecten mollenden Rrofodiljungen ihre Mutter Darauf aufmerfjam, Damit bieje jie aus dem Nejt augräbt und befreit (F. BD. I, S. 29). Cine laute Stimme befitzen auch biele ber Scaftzeher Doer Bectoniden, uno der Name "Becfo" ijt ja nid)te

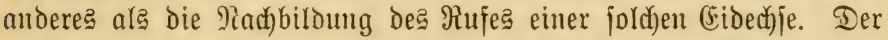
groß̄e jabanij̄je Gecko verticillatus ruft "Iofee". (Einen mäd)= tigen \&ärm foll jogar ber relatio fleine, aber in großęer Menge in Den Wüjten Deutich=Südmejtafrifae lebende Sanogecfo Ptenopus garrulus volfü̈l)ren. Cin Becf́o Bentralajienᄅ, Teratoscincus, vermag dadurch, Daß̄ er bie gropenen, in einer \&ängareike die 
Sd)wanzoberjeite bedecfenden Sajuppen gegeneinander reibt, ein

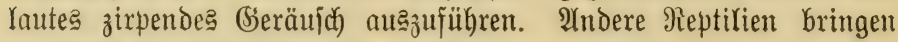

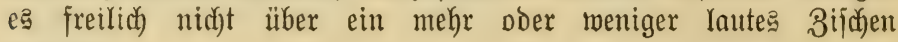
Ginaus. -

Dậ̉ bagegen nidjt mur manche Moldye, menn man fie berührt,

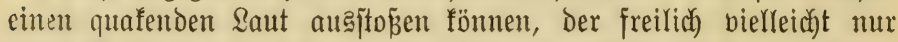
Durd) P(ustritt von Suft aus Den Sungen entifteht, fondern baj bie

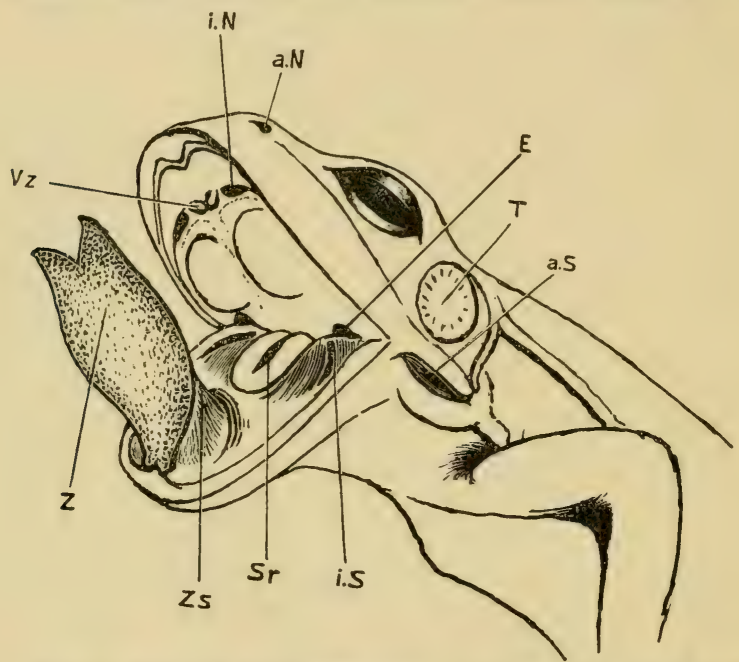

9(66. 17. Siopf von Rana esculenta (Münnd)en), bie inneren (i.S) unઠ äup̃eren (a.S)

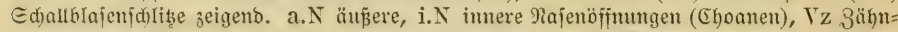

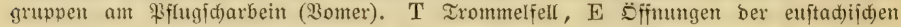

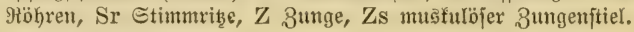

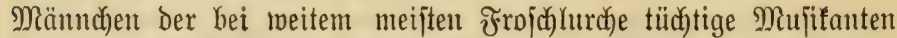
jind, ift mohl befannt. Die Berjtärfung Der Stimnte gejodieht burd)

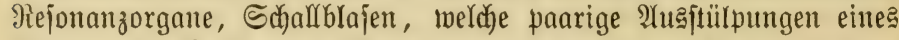
Muatele Der Rehlgegend (Musculus mylohyoideus) (2łb6. 18) find. Benu mir bie Schallblaje eines männlichen Wajferfrojabes betradhten,

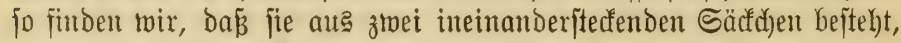
einem Der äuß̌eren Rörperhaut angehörigen, mehr oder weniger ge= fürbten (beim Seefrofich, Rana ridibunda, meift raudograuten) uno einem 
inneren, meījen, weld)es als jeitliche Borjtülpung bes obengenannten

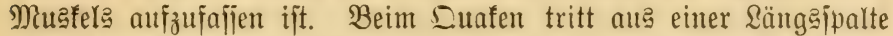

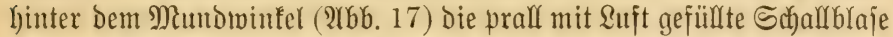

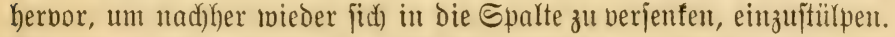

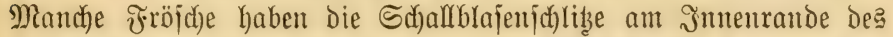
Unterfiefere (wie ber gemeine afrifanij(d) $\mathfrak{B a j j e r f r o j d ) , ~ R a n a ~ m a s c a - ~}$ reniensis); bei unjerem Saubfrojch ftopen beide Sifullblajen in ber

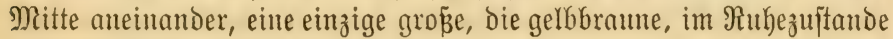
gefaltete Rehlyaut bortrei= bendeß

(b)ilenijacen Rajenfrojd), Rhinoderma darwini, bil= Det Der unter Der Baud haut meit nack Ginten reidjende

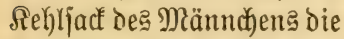
Brutjtätte für die jidc ent= mickelnden Jüungen (iithe

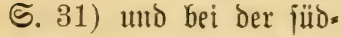
amerifanijochen Paludicola fuscomaculata befteht ber

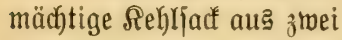
hintereinander liegenden Ilbteilungen, die mit einem Sujtjad unter Derßaud) haut in Berbindung itehen. Ire= ten bie beiden Sd)allblajen Des Männdxens nicht, mie beim Wajjerfrojuc), beim Suafen burch bejondere

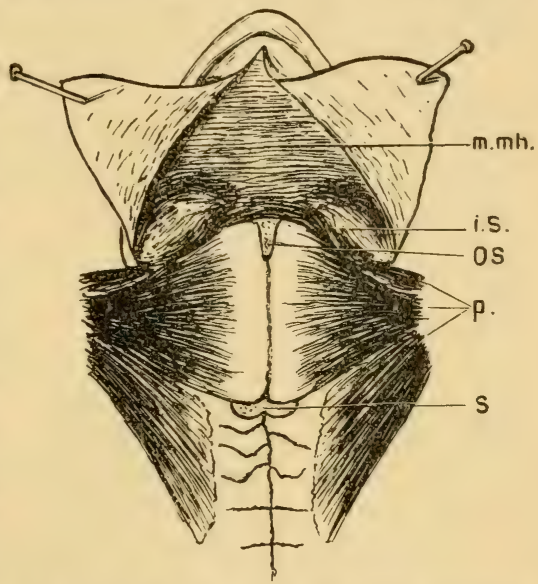

26b. 18. Sopf uno Brujt von Rana temporaria won unten, mit ben imeren ङ Der Phusfel, welder bie immeren こdallblajen (i.s.) bilbet. p. Brujtmuofef. os Dmojtermum. s こter= num (3ruptbein).

Sdhlibe Kerbor, jondern liegen fie unter ber Scaut, dieje beim Suafen vorrölbend, io jprid)t man bon inneren Sd)allblajen (Unfen, Sraes= fröjche [ $\mathfrak{U b G} .18]$ ).

Bähreno wir mut bei ben aud mit freiliegendem Irommelfell

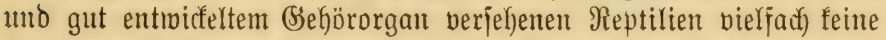

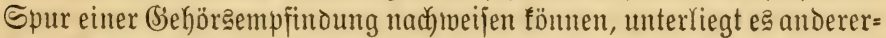

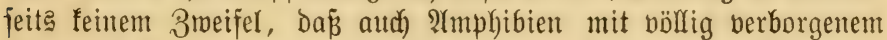
Irommelfell gut Gören, wie bię jadon aus ben Ronjerten Der Unfen und 


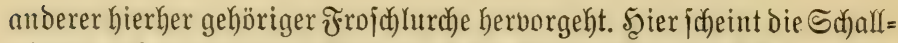
leitung auf molefularem Bege Durd) die Ropffnochen vor jiď zu gehen.

(Fin ähnlicher Fall, ber fich aber auf Reptilien, uno ztwar auf bie ausgeftorbene (Gruppe Der Fijchjaurier (Ichthyosauria) bezieht, ift von Dollo mitgeteilt worden. Bei biejen erfolgt die Sifall= leitung ebenfalls nicht burd das Irommelfell, fondern Durdh dac einzige (Sobörfnöb)eldyen der Reptilien, die Columella, meldye eine bejonders mächtige cantridfung genommen hat, uno ebenjo ijt bei einer anderen meerbewohnenden ausgejtorbenen cibechje, bei Plioplatecarpus aus ber Familie ber गojajaurier, Das Irommelfelf zlwar nicht rücfgebildet, aber infolge Verfalfung als f(c)alleitender

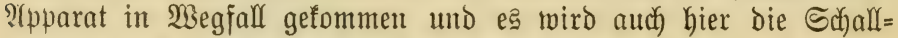
leitung burch die Columella allein vermittelt.

Sehr auffallend jind bei den Bectonen die Sacci endolymphatici, grof̧e, gelblich) gefärbte Wülite, bon denen einer an jeder Seite de?

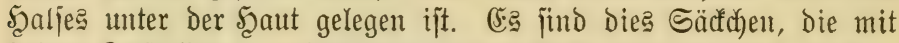
fleinen Rriftallen von phosphorjaurem (?) Ralf erfüllt find und mit Dem (Sebörapparat in Berbindung jtehen. Sie entiprechen bemjenigen Ieil des (Sebörapparates, der ale ftatijđ)es Drgan, aljo als Drgan

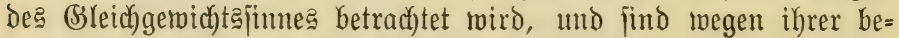
Dentenden (sröß̈e aus bem Sd)äbel herauggerücft und nach binten verlagert. Die in biejen Säcfden abgelagerten friptalle werden

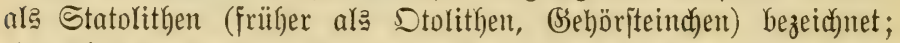
eine ähnlidbe Funftion haben die Ralfjäłdfen zu beiden Seiten der Wirbeliäule ber Fröjue, die ebenfalls in Beziehung zu bem ftatija)en Ieil des Sebörapparates itehen.

Bom (Sieruct) = und (Sejchmadiun unjerer Siere pflegt man im allgemeinen feine hoke Meinung zu haben, immerhin find beide Sinne, wenn aud nidyt Gervorragend entwidfelt. Der (Serudfiun,

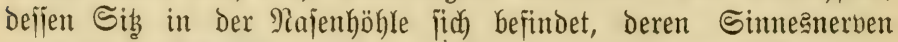
burch) ben erjten (Sehirmerb, Den Drfactorius (der eigentlich wie der Sefnerb einen bejonderen arbichnitt des Vorberhimes jelbjt vorjtellt), mit diejem in ßerbindung jtehen, dürfte bei den wajjerlebenden 2Imphibien und Reptilien faum eine groß̧e Bedeutung haben, wie man

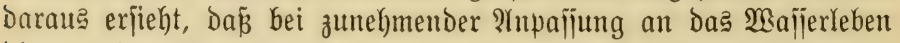
die von den Sinneszellen eingendmmene Dberfläche der Najenhöhle immer fleiner roird. Die bedeutende 2rbnahme dę (Serudjinnes ift 
namentlich bei den wajןerbemohnenden Sdjildofröten im Bergleid) ôu

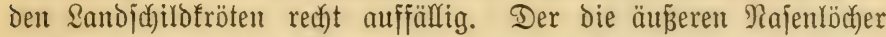
mit ben inneren, Den (5hoanen, verbindende Sang ift in eriter Sinie

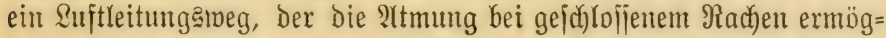

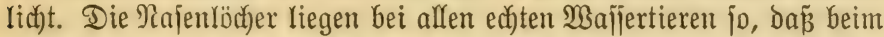

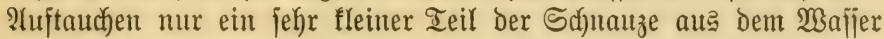
vorgejtrecft zu merben braudat, und jind vielfad) ourch) bäutige Rlappen Doer burth ein jogenanntes Sdyellgemebe, wie bei ben wajierbetwohnenden Schlangen, automatijch verichliep̧bar (Srotodile,

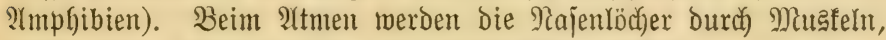
melche dieje Sdymelfgerwebe zujammenorücten, geöfinet.

2(m Deutlidbiten merfbar ijt der (Seruchjün noch bei den

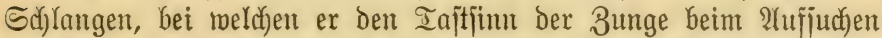
Der Bente nicht untwejentlid) unterjtüht, menn bie Beutetiere einen

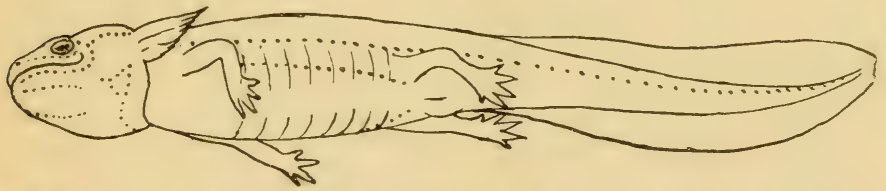

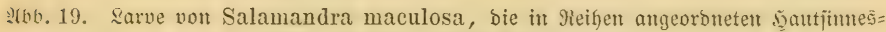

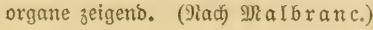

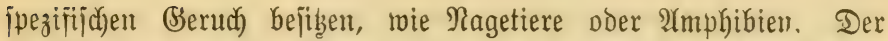
(Bejed)madfium, an bie Mumbhöble und bie 3unge gebunden, joweit

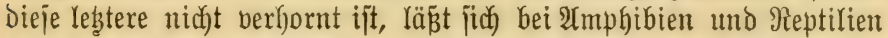
fajt durdinege menigitents in Spuren nadyweijen. Bittere Doer andere, aud) unjerem (Bsej(dmacte miderliche Injeften werden bereits

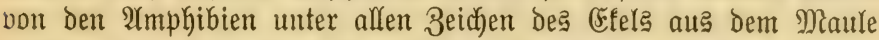
entfernt und diejes durd Reiben der S(f)natze am Boden pder mit

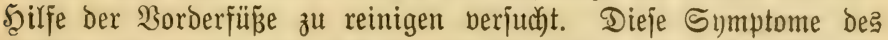

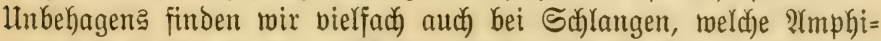
bien mit jtarfer Drüjenaug (d)eidung, bie für fie feine gemöhnlid)e

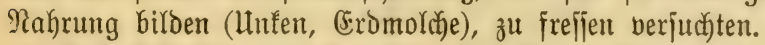

Dá̄ (Fidedjen, bei benen ja bie 3unge felten weiter als an Der Spize verhornt und oft jehr itarf entwicfelt ijt, einen wohl=

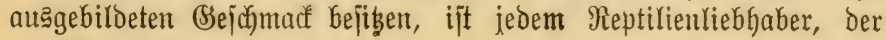
গ⿱一⿻上丨亅. A 16 $\mathfrak{B}$ erner II. 
Die gropen (SIattechjen Alujtraliens gepflegt hat, wohy befannt. Die

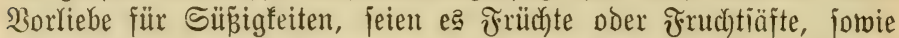

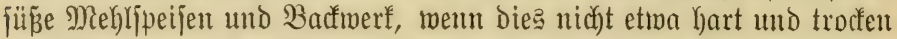
ijt, ift bei Den großenen 2(ujtraYien, der Stutzed)fe (Trachysaurus), Den

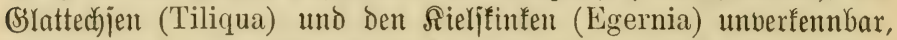
aber in bezug auf jübes Dbjt faum weniger aud bei ben gropent

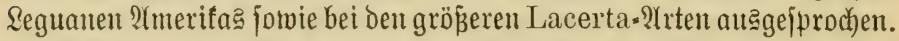

Ula bejondere Sinnesorgane müffen bie Scantjimnesorgane ber Banzerhurche, und 2 (mphibienlarven, bie Iajtflecten auf Den Sduppen Der Reptilien und bie 3unge Der Saflangen und mandher (sibed)jen (namentlich) Varanus) betrachtet merden.

Die erítgenannten, in regelmäß̄igen Sängsłinien an ben Seiten Des Rörpere und bes Schwanjes forvie in Sinien von ganz be=

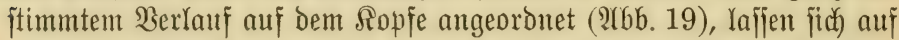

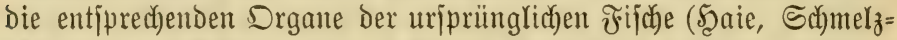
j(hupper) zurücfführen oder ę fömmen wenigitens dieje \&inienfyjteme

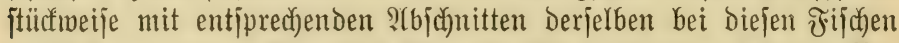
verglichen werden. Die alten $\mathfrak{P a n z e r h u r d f e}$ vermitteln in biejer $\mathfrak{B}_{e}=$

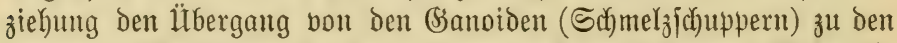
Sarven der $\mathfrak{A}$ mphibien, die dieje Drgane nod) Deutlid) zeigen (Irbb. 17), während fie bei den verwandelten Iieren nicht mehr erfentbar find. (5) handelt fich) bei biejen Sintesorganen jedenfalls um (Eimrichtungen,

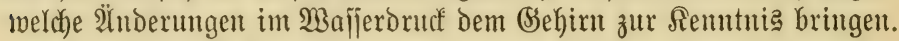

(5igentlidye Iaftempfindungen vermittelt bei unjeren Iieren ber ganze Rïrper, anjdeinend jogar nod) an gepanzerten Stellen. (Ein bejonders feines Iajtgefühl bejiżen aber alle zarthäntigen Ieile der

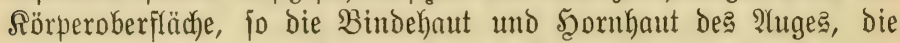

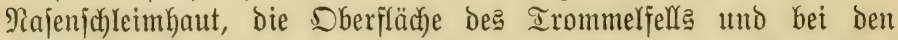

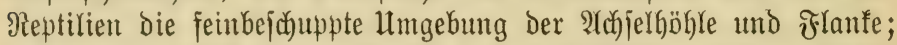
fogar groje, jtarf gepanzerte Iiere, wie firofobile, find an biejen

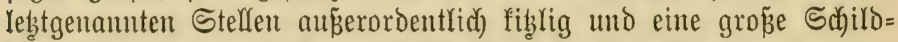
fröte, hier mit bem Finger gefikgelt, zieht igre Beine mit einer

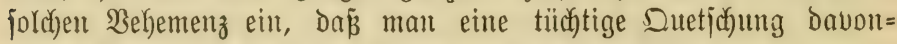
tragen faun, ehe man den Finger wieder herauafriegt.

Mëglicherweije find aud bie weid)en bejaduppten ober glatten Scönter, weld)e mand (bibed)fen (Ceratophora, Chamaeleon nasutus und Berwandte) uno Schlangen (Vipera ammodytes, Herpeton ten- 
taculatum) (2rbb. 20, 21) auf ber Sd)mauze tragen, alక Iaftorgane aufzufajןen. (Senaue Beobad)tungen barüber Yiegen nidat vor.

Als bejondere Iajtorgane Der Reptilientant find bie bei Rro= fodilen und vielen Sdylangen bejonders leidyt zu beobadatenden, aber

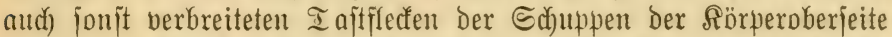
anjujeken. Die betreffenden Scornjaduppen (9̧b. 7) zeigen, im ourd)= falfenden sidst unter dem Miffroffop betrad tet, nabe dem Scinterende einen, bei Sd)langen vielfad) ztwei nebeneinanderftehende helle Flecten, two aljo die Dberhaut erheblich) bünner ift als jonjt auf der Sdyuppe. Unter jedem Diejer Fledfen

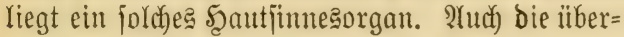
aus gebrechlichen Sdymänze der plattföpfigen feljenbetoohnenden Mauereidechjen tragen nad) Mé hell auf Den Sduppen Der Dberjeite ber= artige Simnesorgane (j.BD. I, S.73), während dieje an Den Sd)roänzen Der bicfföpfigen, meijt grünen, graßbetwohnenden Formen ber Mauereidedjen= gruppe fehlen oder jatroad entroidelt find.

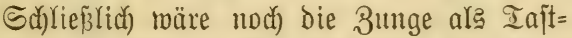
organ zu ermähnen. Die frotodile, bei denen bie 3unge auf Dem Boden der Mrumblöble feitgemad)jen ift, bie Sdyildofröten und manthe (5ibechjen benüben ilyre 3unge nidyt in biejer Meije, und man fiebt fie bei den lebtgenamuten Reptilien unr während bes Frefien und Irintens in Bemegung. Dagegen ftrecfen viele andere

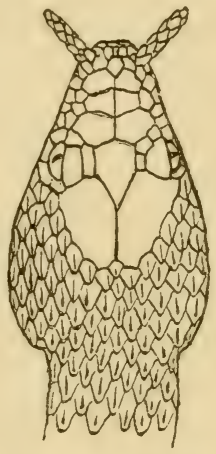

S(6). 20. Slopf won Herpeton tentaculatum (こiifwaffer=

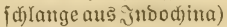
mit füblerartigen Sd)nauzenfortiätien. (5ibechjen die 3unge l)äufig, manche, trie die Warane, bei jedem Sdyritt แnd Iritt, und zmar fefyr meit vor, ofue dabei immer irgendeinen Siegenftand bamit zu betajten und ohne dấ man babei den (sindrua kat, als wäre überkaupt ein Betaiten Dabei beabjichtigt. Bei den Siflangen bejibt die meit nack binten über bie beiden Spiben hinaus verfornte 3unge (i. P(bb. 9) eine ganz auperorbentlicke Betweglidffeit, wie fie feiner (5idechjenart zufommt, eine Berweglidfeit, die jo meit gehen fann, daj man bie mit ben Spizen lebhaft auf und ab joftwingende

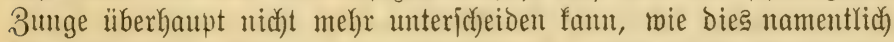
bei hod)grabiger (Erregung zu bemerfen ift. Scier ift die 3unge von 
auß̧erorbentlicher Wichtigfeit als das bei weitem am bejten entroicfelte

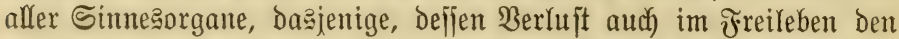
Şungertod natif fidf jieht, weil die Siflange ofne Bumge nidft mehr

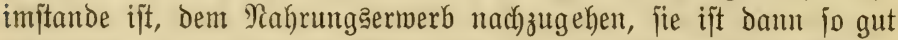
wie blind, "zungenblind". Man jieht bei aufmerfjamer Beobachtung, bã bie Shlange mit Scilfe ifyrer 3unge nicht mur erfennt, ob ein

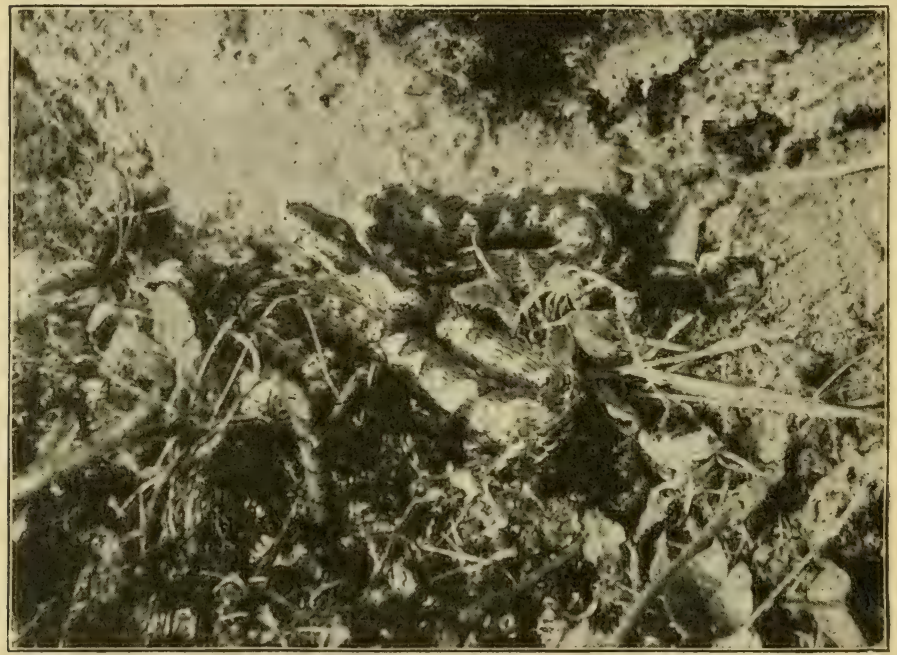

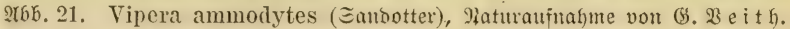

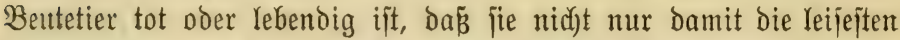

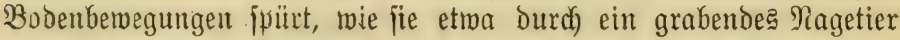

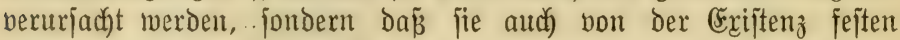
Bodens unter oder einer Wand bor jich, malyricheinlid burd den Widerfrall ber Durif die Bunge berwegten \&uft ebenjo mit Sidjerbeit Renntnie erhält, wie der Blinde, der ohne Şilfe und ohne auf jeinem Wege mit Şand oder Stod bie Wände zu berühren, nicht nur gerabeaus geht; jondern aud um (sifen biegt, offene und ge=

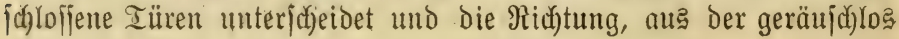


Kerannahenden Perjonen auf ifn zufommen, bejtimmt. - Währeno

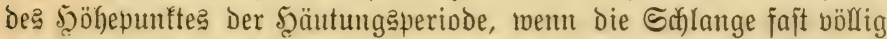
blind ift, ift bie 3unge iiberbaunt bas einzige mejentliche Sinnes= organ für fie uno mu[ aud) für da弓 2Yuge eintreten.

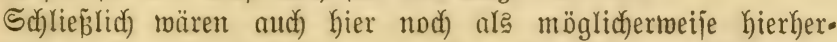
gehörig grubenartige Bertiefungen Der şaut bei verjobiedenen

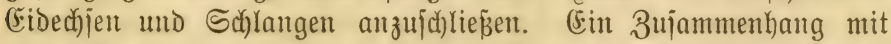

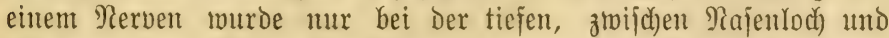

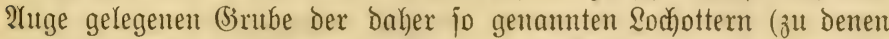
aud bie Silapperja)langen gehörent) won Wejt gefunden; wahr=

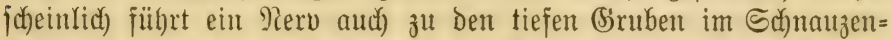

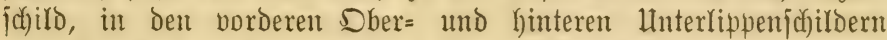

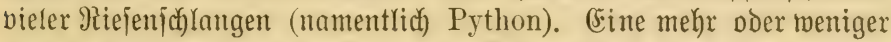
tiefe, mit jehr fleinen, farblojen ธ(d)uppen augefleidete Brube

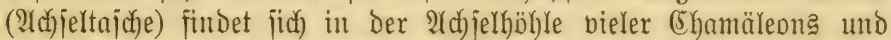
Des in mander Beziefung an bieje erinnernoen madagajifictien Blattja)ranzgectos (Uroplatus fimbriatus). RIaptocz, ber bieje

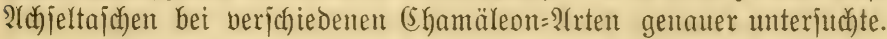
fonnte feinen zut biejen Iajchen Kintretenden Nerven auffinden, wie

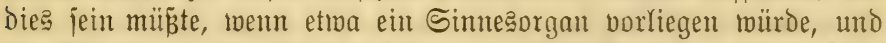

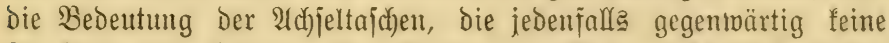

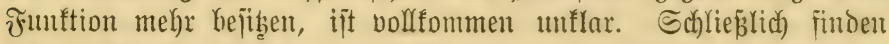
fich) jeiffte Crinftülpungen der şaut an Der Siehle und an Der

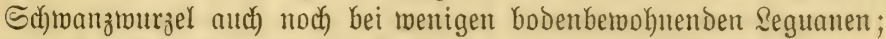
iiber jie ijt aber gar nidfte befannt gemorden.

\section{Bont Darm unt von ber Nafrumg.}

Bent wir die Reibeähöhle eines recht langgeĩtrecten Iiere马 aus einer der beiden Rlafjen, mit Denen wir uns hier bejwäftigen,

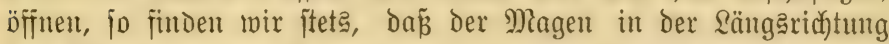
Des Sörpers gelegen ift uld der Darauffolgende Darmabidntitt int

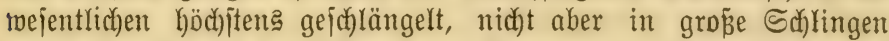
gelegt iit. Cis folgt aljo auf bie Mund= und Radhenthöhle eine Speijeröhre, due bei den ?tmphibien Łurz, bei den Reptilien aber im 3ujammenhang mit ber bedentenderen Sänge De马 Şalję meh)r oder weniger langgeítrect't ijt, darauf der Magen, mit bem ber 
3wölffingerdarm (dą Duodenum) eine U=förmige Sĭlinge bildet, in ber itets bie Baudfjpeicherorüje eingebett et ift und in weldye aud Der gemeinjame Âtüfüfrungagang der jtets mit einer Ballenblaje ver= jefenen Reber und ber Bautujpeicheldorijje ei umündet, dann Der eigent=

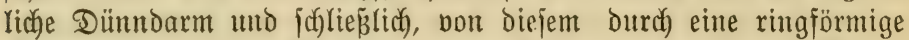

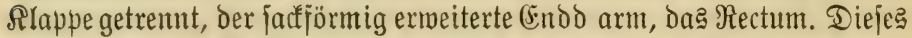

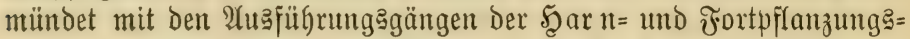
prgane in einen gemeinjamen Raum, Die Rloafe, ein, weldhe meijt

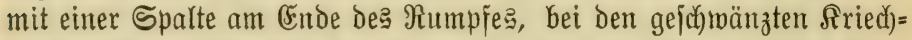
tieren und Surchen auf Der Unterjeite (längggeridutet bei Rrofobilen

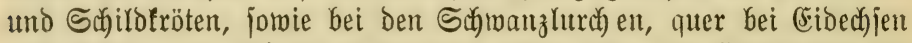
und Siflangen), bei den Safleidjenlurchen etwa am Şinterende be? Rörpers, bei ben Frojoflurd)en aber etwas nach) aufwärts non biejem (iid) D̈ffinet.

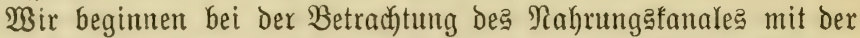
Mundhöhle, in ber wir ala bie auffallendften und widytigiten Drgane bie 3ähne und die 3unge erblicfen. Die erfteren murden bereitz

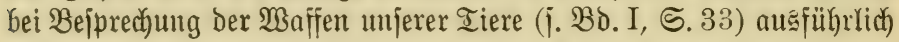
behandelt; es eriibrigt aljo nur noch, aud der mannigfachen (be= ftalt und Funftion der 3unge in Rürze zu gedenfen, mentugleich idi) jadon bei Belegenheit Der Bejprechung Der Iaftorgane Der Reptilienzunge (S. 35) einige $\mathfrak{B}$ orte gemiomet habe. Bei nur fehr

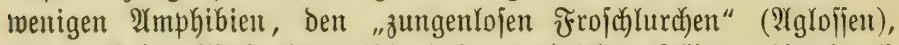
bie burch die $\mathfrak{B a b e n f r o ̈ t e ~ ( P i p a ) ~ i m ~ n o ̈ r o l i c k e n ~ S u ̈ b a m e r i f a , ~ b u r d ~}$ bie Srallenfröfche (Xenopus und Hymenochirus) im tropifacen

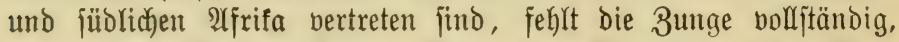
bei anderen ift fie auf Dem Boben der Mundhöble, mit 2Hus=

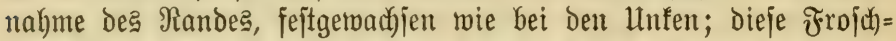
lurche, ob zungenlos doer mit feitgemachjenter 3unge, ergreifent ifre Beute mit Den Riefern; dies ift aud bei ber gropen 3ahl Der geidwänzten Rurche ber Fall. Bei anderen wieder if́t bie 3unge born am Rieferwinfel frei und am Şinterende feftgetwachjen, fann aljo etwa roie bei einem Säugetier vorgejtrecft merben; nur bie merifanijade Rajenfröte (Rhinophrynus) unter alfen ungeidgränzten Âmphibien bejigst eine Derartige 3unge. Soer es ift bie 3unge vorn am Rieferwinfel feitgewachien, hinten frei und fann aus bem Maul herauggeflappt werden (Y̛bb. 17); infolge ifres Drüjenreid)= 
tume ift jie jefrx flebrig und fungiert ale Fangapparat, ba fie nadd Injeften und anderen fleinen Tieren vorgefd) Yeudert uno mit der anraftenden (mitumter jogar mit ben 3ungenenden ummicfelten) Beute wieder in bie Mumbföhle zurüügetlappt werden fann. Da

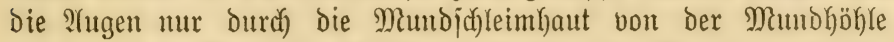

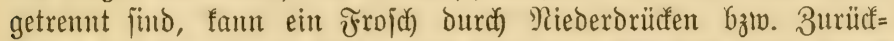

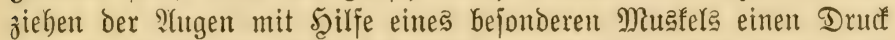

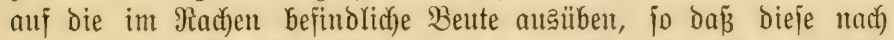

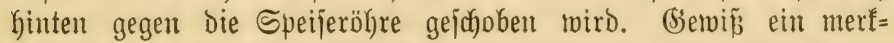

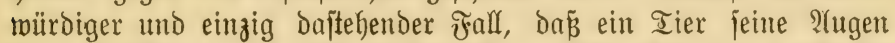
beim Beridhlingen Der Beute benübst. - Die Slappzunge ijt bei Den Frofidhturd)en eine überaus verbreitete 3ungenform, ob fie num freieförmig, elliptijad), herzförmig, Ginten ganzrandig, eingeferbt ober

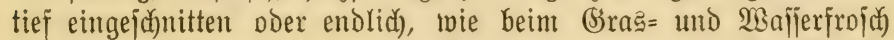
und jeinen Berwandten, in zwei Sappen ausgezogen ijt. Manche

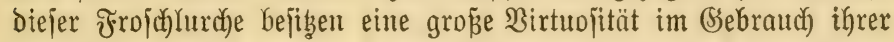
3unge, bie nidjt nur nad) vorn, jondern jogar nad) ber Seite vorgeid) (eudert werden fann, wie bejonders bei unjeren edften Sröten (Bufo). - Jn anderer Weije fangen bie Moldje aus ber vor= miegend amerifanijaden, in Norb = und Bentralamerifa artenreict)en (Sruppe der \$rlethodontinen (nur eine $\mathfrak{T}$ rt, Spelerpes fuscus, in Jatalien) ihre Beute mit Şilfe ifrer Bunge. Dieje ift hier pilzä̈rmig und bejteht aus einem muskulöjen Stiel, Dem eine flebrige Scheibe, bie eigentlidfe 3unge aufijizt. Der Bungenftiel fann bei Spelerpes, wie man jojon bei ber europäijd)en Ârt jehen faum, weit vorgejdyellt merden, und bie Ireffificherheit, mit ber biefe Molche z. B. Fliegent

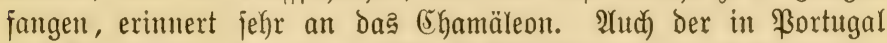
und Norbipanien lebende zierfiche (Soldifreiffalamander (Chioglossa) bejibst alfein unter ben altweltlict)en Salamandrinen eine berartige Schlenderzunge. - Die Reptilien Kaben bie 3unge entweder, wie bei Den Rrofobilen, am Boden Der Mundhöhle angewaddjen, meipt ift jie aber vorn frei und vorftreffbar (IYbb. 22a); Dod) wird fie bei vielen

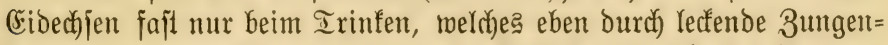

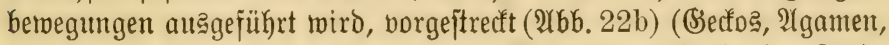
Segutane uim., aljo bei ben jogenannten "Dicfzünglern"); bei den Sano=

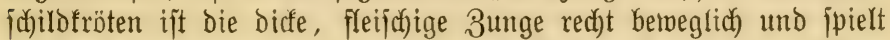

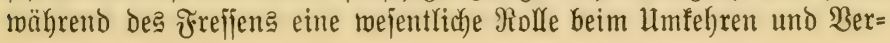




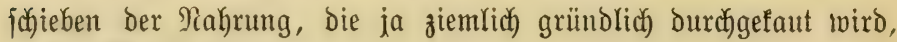
in Der Mundböhle.

Die Funftion ber 3unge als Iajtorgan bei gemifien (Fidechjen, namentlich) bei ben Maranen, in geringerem (5rabe bei ben Sacerten und Ieju=(5idechjen, aber auch bei allen übrigen Formen mit deut= Yich zmeifpaltiger 3unge, habe ich fidnon früher erörtert; ę bleibt nur noch bie Schleuderzunge der (5hamäleone zu erwähnen, eines Der merfmürbigiten Drgane biejer an fich) jo merfwüroigen (Eided)jen. $\mathfrak{B}$ ril cैe hat bie $\mathfrak{A}$ rt und Weife de马 Futfionierene der (5hamäleon= junge etwa folgendermañen flargemadyt, wie bie so Iorniex in jeinem Gübjchen $\mathfrak{A}$ uffałe "Wie lebt Das (5hamäleon?" miedergibt.

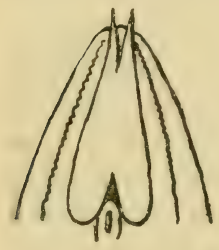

a

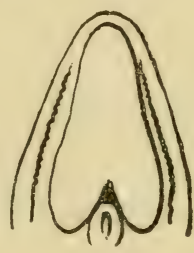

b

2(b6. 22. 3unge a) von Lacerta, b) von Calotes. Beijpiel cines Epalt= uno Iidjitngleris. "Dem ipiegelblanfen, jpik= fegligen 3ungenbeinförper jiģt bie 3unge in Der Pube wie eine Düte auf, während ithre flebrige Spiz̧e jul= jammengefaltet ijt; mit jtar $=$ fen Muafelringen umfapit fie babei ben 3ungenbein= förper, und foll jie hinate, Dann ziehen jich) Dieje Muaffel= ringe zujammen uno greiten auf Dem 3ungenbeinförper

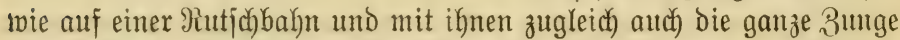
zum Munde heraus; an der Unterjeite der 3unge ausgebreitete

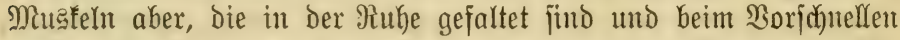

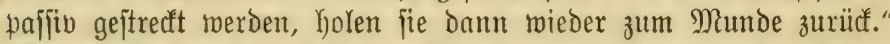
Mit welcher unglaublicher Schnelfigfeit uno mit weldyer Trefficicher= Keit die Chamäleonzunge vorgejolleudert wirb, bavon fann mur der= jenige jid) einen Begriff machen, der gejunde (Exemplare biejer interefijanten Iiere bei der Jago auf Frliegen beobad)ten fonnte.

3u Den Drganten ber Munbhöble würben autch nod bie Schall=

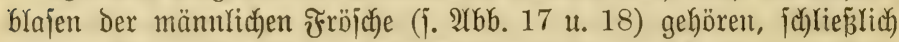
aber nod) eine $\mathfrak{2}$ nzahl von Mundgöhlendrïfen, welche bei den Pep= tilien bereit马 als Dberlippendrije, Unterfiefer= uno Unterzungen= ipeicheldriije (Submaxillaris und Sublingualiz) unterjojieden werden, mozu bei Den Dttern nod) eine Driife in Der 3ungenfdheide Kinzu= 
fommt. Bon ihnen ijt bie bemerfentwertefte bie Dberlippenipeidere briije, bie bei Bjiftnattern und Dttern in ihrem Ginteren 2(bja)nitt zur (Siftorüje getworocn ift, bie von einer jefnnigen Scheide umbüllt

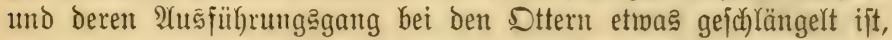
wodurdch er genilgenden Spielraum bat, um bei den Berwegungen Dez

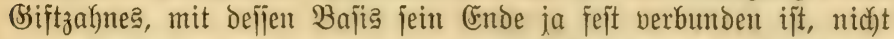
einer 3errung ober 3erreip̧ung auggejeşt zu jein; er ijt aud mit einem ermeiterten $2(b j d)$ nitt mit gefalteter Mandung (Şiftrejerboir) verjełen und leitet dą Bjift zu Der am Brnmbe Des von einer Falte

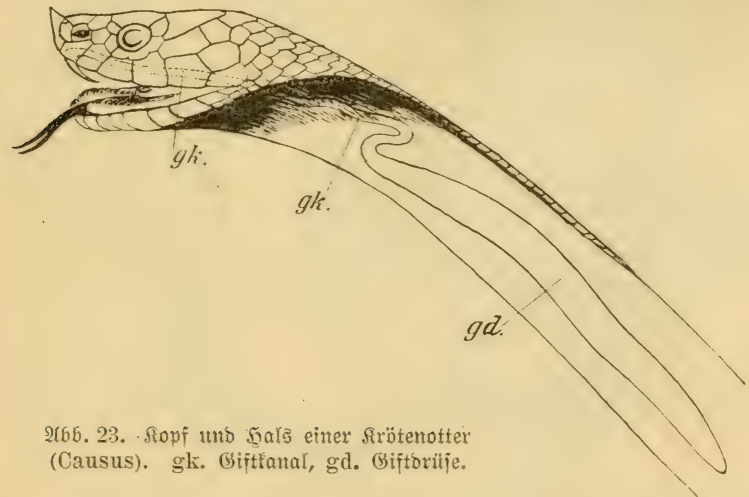

(Scheide) Der Mundid)leimbaut umgebenen (Siftzahnę befindrid)en

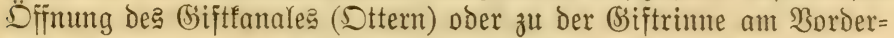

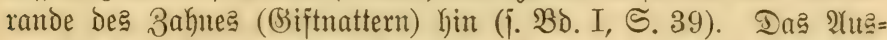

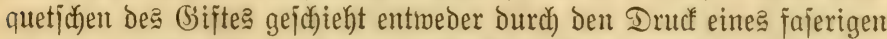

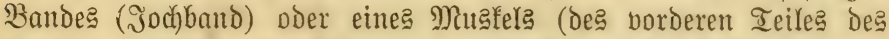
Sd)läfenmuafe(a). Die (siftorüje erreidyt bei mand)en S(f)langen eine enorme Sänge, fo reid)t fie bei den afrifanif(d)en Dttern Der (Sattung Causus (2rbb. 23) mehrere fiopflängen tweit unter Der Şaut deᄅ

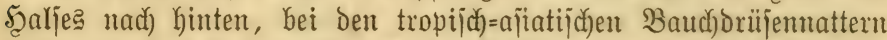

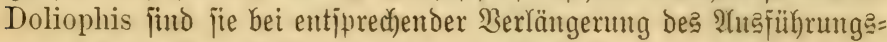

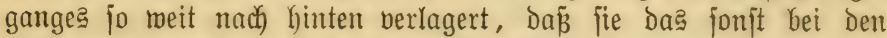
Sdiflangen etwa am Ende des eriten Sïrperorittels gelegene Şerz weit nach Ginten brängen. 


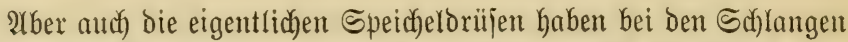

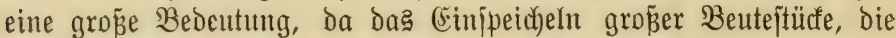
ja unzeritücfelt veridblungen merden, für bas Berichlingen eine un=

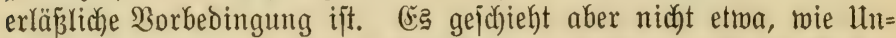

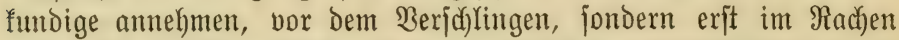

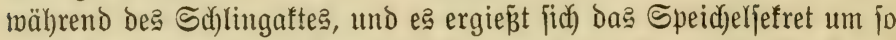

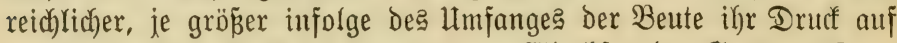
Die Drüjen ift. Daj bei den giffigen (Eidechjen der (Sattung Helo-

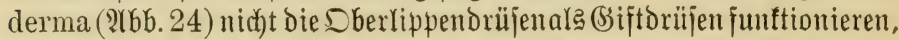
jondern bie der Unterlippe, mutrde bereita ermähnt (BDo. I, S. 38).

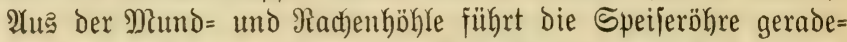
wege in Den Magen. Sie ijt bei firofodilen und Sdjildofröten

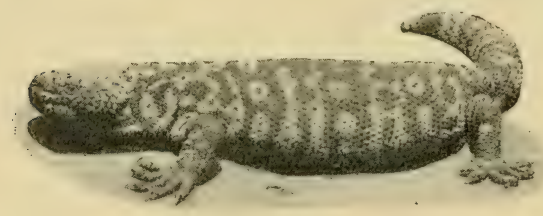

966. 24. Heloderma suspectum (พrizona). (Nacf) $B$ erg.)

relativ bicfmandig und in Sängesfalten gelegt, bei Den Seejchildofröten mit langen 3 otten, bie eine legelförmige ફ̧ornfappe tragen, bejebst, bei ben S(b)langen Dagegen oft auperordentliç) bünn= wandig uno ebenjo mie Der Magen einer enormen

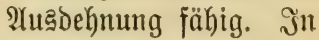
ganz bejonderer $\mathfrak{B e i j e ~ i j t ~ b i e ~ S p e i j e r o ̈ h r e ~ z m e i e r ~ S a j l a n g e n a r t e n , ~ d e r ~}$ afrifanifichen Dasypeltis scabra und bes indijunen Elachistodon

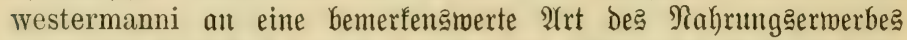

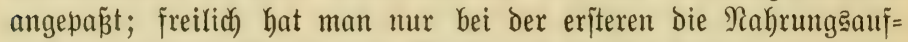

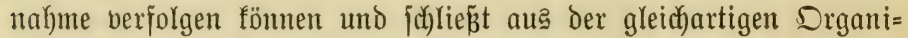
jation ber anderen auf greidye Rebengmeife.

Dasypeltis, eine in Affrifa meituerbreitete und nidst feltene fleine

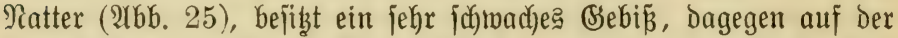
Unterjeite des 22. Gia 26. Wirbela jtärfer, an ben vorkergełenden und folgenden weniger beutlidy) ver(ängerte, nach hinten gerichtete sinochen= fortjäze, merche bie obere Wandung der Speiferöhre burchbohren und in bieje hineinragen. Die Schlange ernährt fich bon $\mathfrak{B}$ geleiern, bie, unverleşt beridhlungen, in Der Speijeröhre, an Den Sahlundzähnen vorbeigleitend, won biejen aufgeidnitten werden, wobei bie Sdylange 


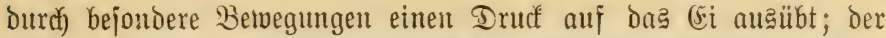

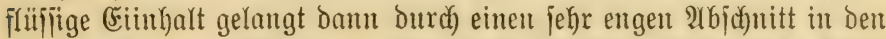

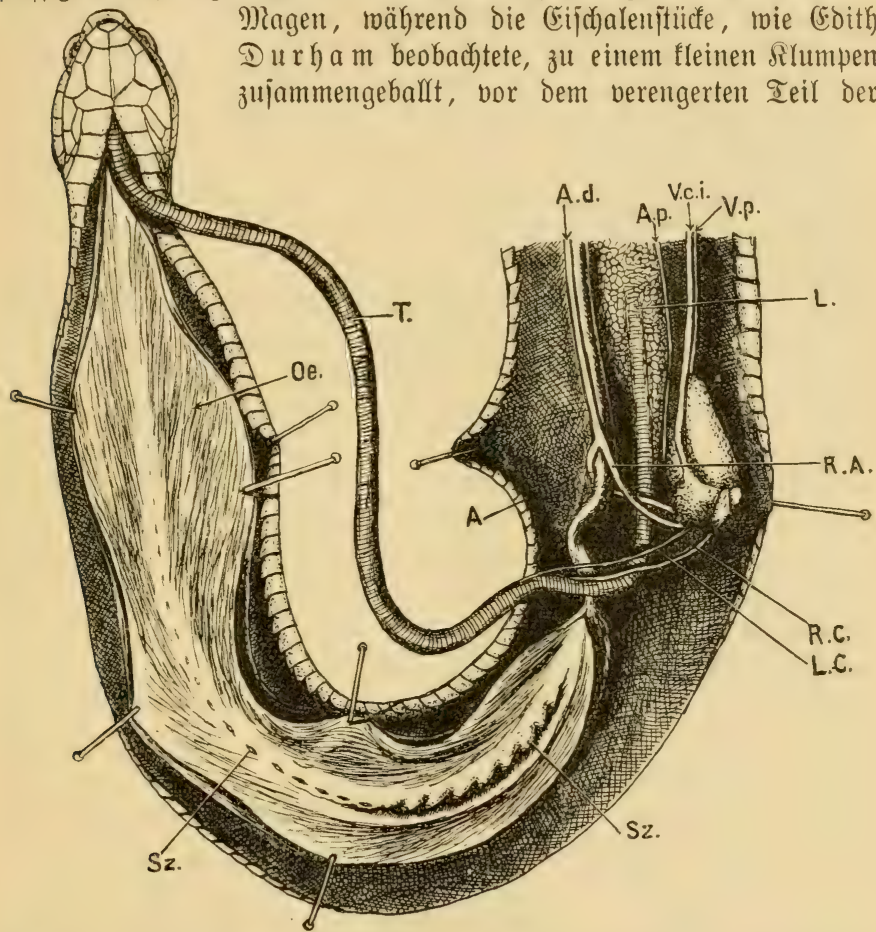

\{66. 25. Eierjalange (Dasypeltis scabra), Borberförper, von unten geöfnet, ebenjo aud) ber erweiterte Ieil ber Speiferöfre (Oe.); Sz. Ed)funozüfne, T. Irad)ea (Euft=

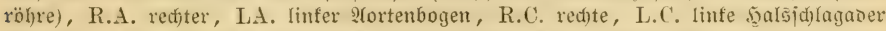
(Carotis), A.d. abiteigende Sorta (A. descendens), V.c.i. untere șohlvene (Vena"cara inferior), A.p. sungenarterie, V.p. \&ungenvene, - L. \&unge.

Speijeröhre fich aubäufen und burd̆ ben Mumb rieder autage= morfen merden.

Während ber Magen der langgejtrectten, job)langenähnliçen $\mathfrak{Y} m=$

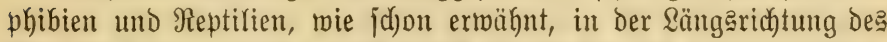
尺örpers Yiegt, romit wahricheinlich bie Seichtigfeit zujammentängt, 
mit Der Sdylangen bei ber geringiten Beunrufigung ihren Magen= inflalt erbrect)en fönnen, finden wir andererjeits bei georungen ge=

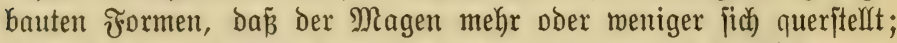

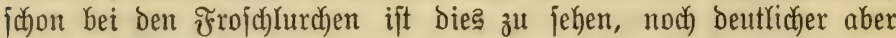
bei Den Schildofröten uno Srof́odilen; bei Diejen Yebzteren gleicht er in Der Beptalt jomie in ber Dicfe der muafulöjen Wandung dem Bogełmagen, und jo wie viele $\mathfrak{B}$ ögel verichlingen aud) bie frofobile

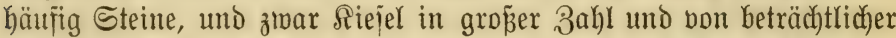

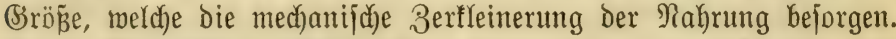
Solche Magenjteine (Bajtrolithen) fennt man aber nicht nur ( $a b=$

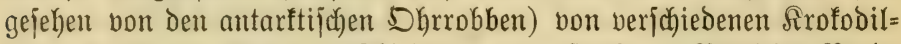

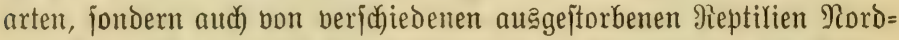
amerifas, uno zwar aus ben Dromungen ber Dinojaurier und Plejio= jautrier. Die Bajtrolithen ber Dinofaurier find aber Durch bie lang= Danternde atbrollung im Magen in einem hohen Brade abgeichliffen

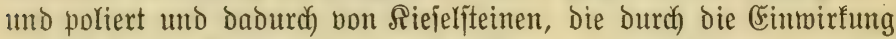
von Wind oder Majjer gejchliffen jind, Yeicht zu unterjacheiden; ourdh bie

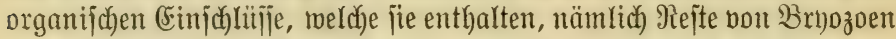

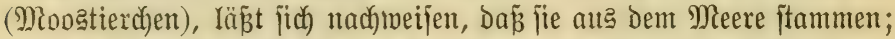

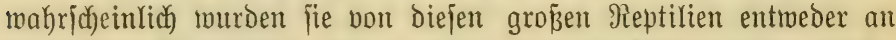
einer alten Strandinte doer an einem bieje burdjidneidenden ơlujie, Der bieje Siejel mit fich führte, aufgelejen. WBielan b hat über

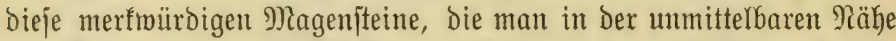
non Dinojaurrier = und ßlejiojautrierffeletten in veridjedenen Ieilen Tordamerifas gefunden hat, ausführlich berichtet. Miidgt zu ver= med)jeln find Damit bie jog. Roprolithen, fojitil getoordene errfe= mente veridjiedener Wirbeltiere, bon denen namentlid bie fpiralig gejurchten Soprolithen gemifijer, namentlid) permijacher Stegocephalen und ber Jaththyojaurier bemerfenamert find; bieje Spiralfurche beutet

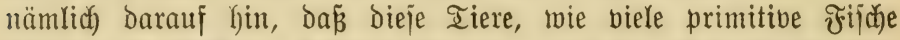

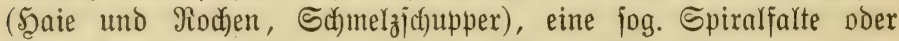
Spiralflappe des Endoarmes bejefien haben, die ebenjo eine $\mathfrak{B} e r=$

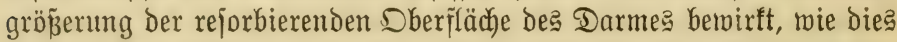
bei mandjen Sd)langen burd) boripringende Rängg= und Suerfalten Des (5nodarntes und bei den pflanzenfrefienden Reptilien burch) einen

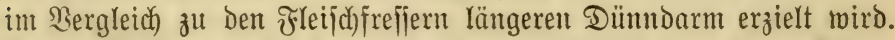

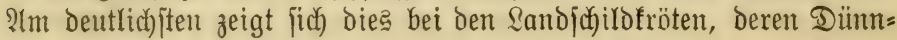




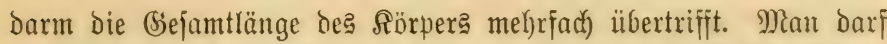
aber meder bie Sandjujildotröten für reine $\mathfrak{B}$ egetarier nod) die ïbrigen

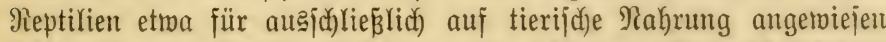

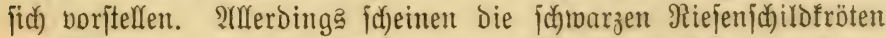

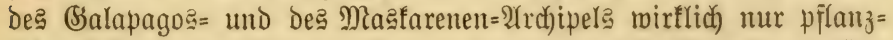

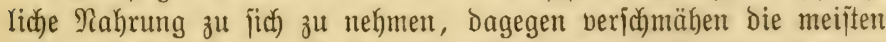
ïbrigen 2(rten, wie gerade bie europäijoben, Regentwürmer und jogar

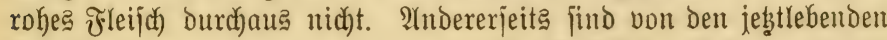
Reptilien im ganzen genommen nur bie Rrofodile, Sa)langen und

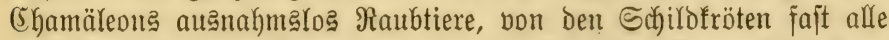

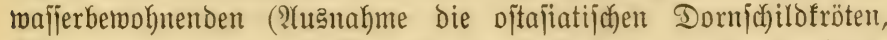
Heosemys spinosa, häufig verzehren auch) bie indijache Kachuga tectum, bie norbamerifanijachen Schmucfichild fröten, Chrysemys, it. a.

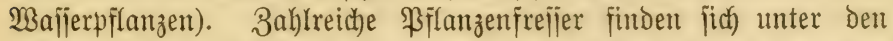

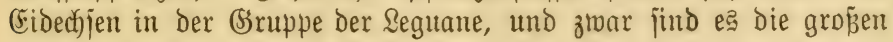
$\mathfrak{Y}$ rten, bie, wie Iguana, Metopocerus und Ctenosaura, vorwiegend Frü̈bte und faftige $\mathfrak{B l a ̈ t t e r ~ v e r z e h r e n . ~ W e n i g e r ~ v e r b r e i t e t ~ i f t ~ d i e ~ v e g e = ~}$ tarijache Sebensmeije bei Den Ilgamiden, Sacertiden, Ieiiden und Scinciben, und jtets jefen wir, daz̃ nicht mur ïberall gerade bie größ̄ten $\mathfrak{A} r t e n$ - jo bei Den 2Ygamiden Liolepis und Uromastix, bei Den Sacertioen Lacerta viridis, ocellata, galloti, simonyi, bei Den Ieiiden Tupinambis, bei ben Scinciben Trachysaurus, Tiliqua,

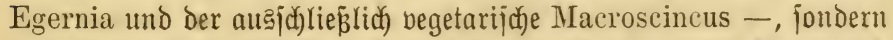
non ben gropen vielfad) aud wieber mur bie ganz ermadjenen jich von Bflanzenifoffen ernähren, in ber Jugend aber Injeften frefien (Lacerta). - Inter den ausgejtorbenten feptilien merden nament= lid) manche ber groß̌en Dinojaurier, wie Iguanodon, Diplodocus, Brontosaurus, ala Bilanzenfrejer angejehen. Diplodocus foll nach

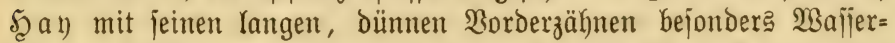
pflanzen (Çharaceen) abgerauft haben. Neueroinge bringt aber

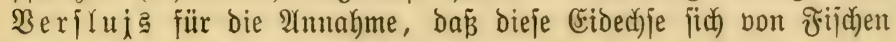
ernährt habe, einleudtende Bründe vor.

Unter den 2 (mphibien gibt e马 im vermandelten 3 ujtande feine Pilanzenfrefifer; im Sarvenitabium find alle Moldhe, ebenjo bie Irallenfröiche (Xenopus) Raubtiere, bei ben Raulquapppen ber übrigen

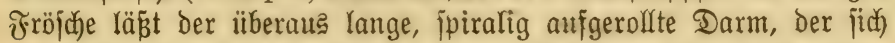

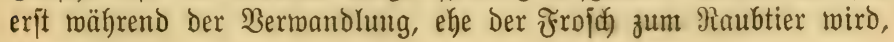




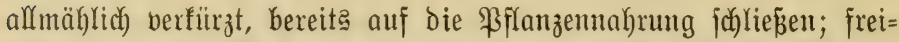
lich) nehmen die Saulquappen neben biejer oft betrüct)tliche Miengen

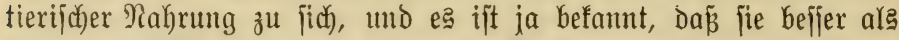
jeder menjallidje \$räparator, großje Raulquappen jauber zu jeflet= tieren bermögen.

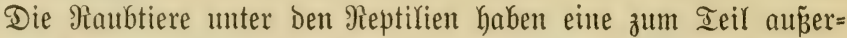
ordentlid) grüntliche Berdaum

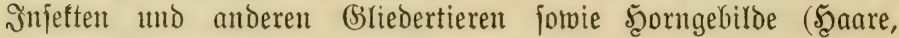
Federn, Sd)uppen) zu wiberftehen vermögen.

Spridywörtlich) geworden ift in biejer Beziefung Der Schlangen= magen, und zivar mit Rect)t. (Eine Riejenja)lange von etra $2 \mathrm{~m}$ Sänge vermag zmei Sanind)en im Bejamtgetwicht von etwa $1 \mathrm{~kg}$ Durchidnittlid) binnen fünf Iagen volfitändig zu veroauen, und ein 3eitraum von adyt bis neun Iagen genügt in der Regel zur $\mathfrak{B} e r=$

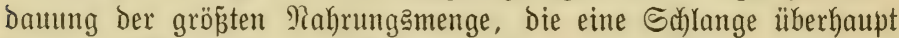
bei einer Mablzeit zu veridjlingen imjtande ift. Dabei erjojeint $e$ es

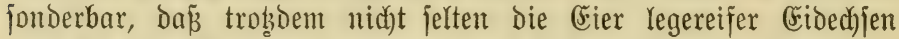
oder $\mathfrak{B o ̈ g e l ~ v o l f f o m m e n ~ u n v e r b a u t ~ b e n ~ \Re a h r u n g a f a n a l ~ p a j f i e r e n . ~}$

Bie bas Berzefren ber Nafrung vor fich geft, ift fo allgemein

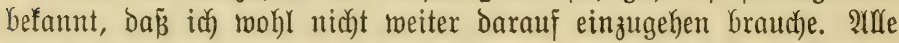

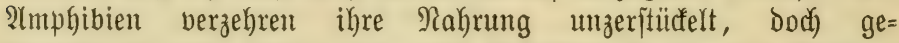

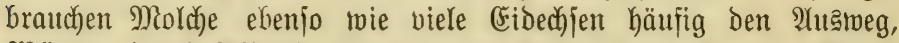
Würmer burd) 2 rborehen (wobei zwei Tiere, bie z. $\mathfrak{B}$. einen $\mathfrak{W u r m}$ an ben beiden Enden gefapat uno fo meit himuntergetwürgt haben,

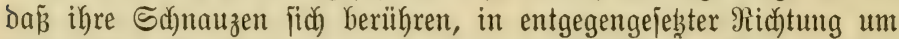
ihre Qängsadjje fidy brehen) zu teilen. (Eidechjen zerfleinern ihre Beute burd) heftiges S(d)ütteln und 2 uffid)lagen auf ben Boden, Schildofröten mit Şilfe der Borberbeine, indem fie den Bifien ent= meder mit biejen fejthalten und Stürfe bavon mit dem Maul $a b=$ reipen, oder indem fie, wie bie Süpmafieridjirbfröten, mit ben fä)arfen Srallen Stücfe bon bem im Maule gehaltenen $\mathfrak{B i j i e n ~} a \mathfrak{b}=$ tremnen. Die Srofobile berid)lingen fleinere Rahrungsbroden un= zerteilt, grö̈pere werden burch heftigee S(h)ütteln und 2(njo)lagen an Den SBoden zerfleinert; groß̉e Srofobile fönnen aud Stü̈fe einer Bente direft abbeiß̄en. Die gröpte Ârbeitzleiftung beim Frefijen volfbringen bie Sdalangen, und jwar namentlid) biejenigen unter ifnen, weldye Sätgetiere doer Bögel verzehren, Deren Durchmefjer 


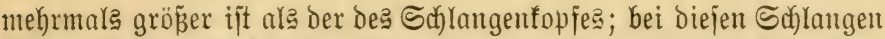

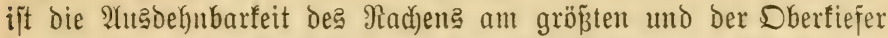

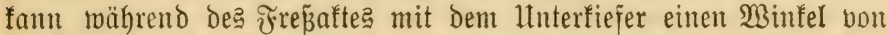

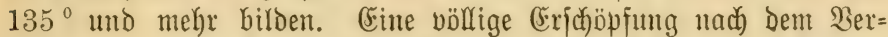
jablingen einer nody jo gropen Beute tritt bei Sdylangen nicht ein, twohl aber legen fie jid), wenn fie gejättigt find, zur Ruke, ohne ihre Berwegungäähigteit volftändig zu verlieren. Bei höherer Tempe= ratur tritt bie 3erjebsung ber im Dagen angejammelten Tiere und bamit ftarfe Basentwicflung früher ein als die Beroaunng, moburd die Schlange oft in unglaublicher Meije aufgebläht und genötigt tvird, einen Ieil deక Mageninhaltes roieder zu erbred)en. SInderer=

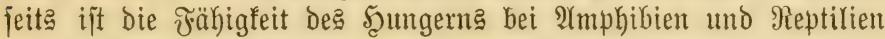
auperorbentlicf) ausgebildet, was ja mit bem weniger regen Stofï= wechjel zujammentängt. Mandhe Sdbildfröten und Sd)langen fönnen, twenn fie nur volfommen gejund futo und Irintivajier er= Galten fömnen, ohne Shaden ïber ein Jahr fungern; nach biejer

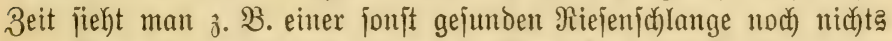
von ihrer Şungerperiode an, wie id midh mefrifach überzeugen fonnte. Im ßarifer Pflanzengarten joll eine Madagaßfar= Boa jogar vier Jahre gefungert haben, twas idf freilid etroa bezmeifeln möchte. Bei Mangel von Irinfmajier erliegen alle Reptilien viel janeller bem Scunger; (siderbjen halten aud), wenn jie Irinfigelegentheit Gaben, faum

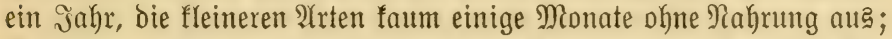
IImphibien zeigen nad) mehrmonatigem Scungern jehr beutliche $\mathfrak{2} b=$

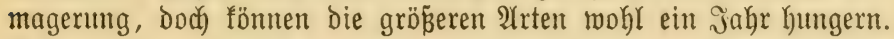
Befannt ijt der im Bolfe meit verbreitete SSlaube, daj man lebende Sröten in Stein DDer in Bäumen rinģherum eingejchlofien gefunden habe, benen bemnad) ein ungebeueres arter zugeidyrieben murbe.

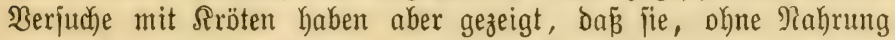

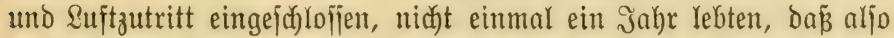
fold)e Funde ungenau geprüft worden jeit mü[jen. Wabrjacheinlich baben joldye Tiere aus irgendeinem (Srunde ein aftlod od oer eine Felahöhle, die ihnen als Sd)lupfmintel dienten, nidyt mehr verlajien

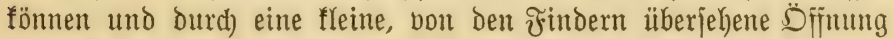
dennoch Rahrung erbalten. 


\section{Die Ruftröbre und bie Rungen ber Reptilien: AYtumng, Somuter $=\Perp 10$ Winterjd)laf.}

Menu roir bei einem Frojid doer Salamander verjuchen, bie Suftröhre aufzufinden, fo merden mir bamit menig ssłüc haben. 2łuf bie von Sinorpelipangen, Den Borläufern de Reflfopfę Der höłeren Wirbeltiere, Gegrenżte, läng马 gerichtete Stimmrib̨e (216b. 17), bie in ber Iiefe der Rachenböble auf ber Bauchjeite gelegen ift, folgt eil jo furzer und weiter, als Suftröhre (Irachea) zu bezeidnender

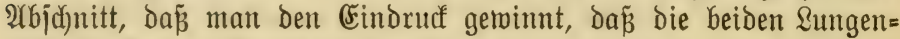
jäcfe bireft bem Borberbarm anjizzen.

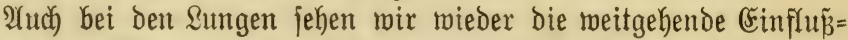
nahme ber Sïrpergejtalt auf die Frorm biejer Drgane. Bei den Frofichlurchen mit igrer georungenen, breiten Sejtalt jind beide Sungen gleich) grop̉e, anjefnliche Säcte, weldje burd ina Jnnere voripringende

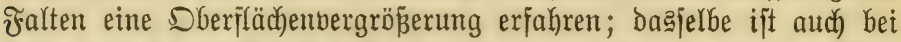

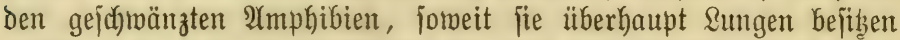
(j. Bb. I, S. 10), im allgemeinen ber Fall, bodf find hier bie Sungen

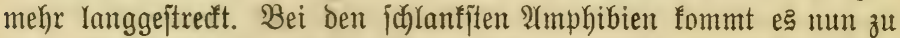
einer $\mathfrak{B}$ erfürzung der Cinfen Sunge bį zur Scälfte Der rechten (mie bei (Brottendim, Proteus) oder zu einer noch weitergekenden $\Re e=$ Duftion (bei ben Błindwühlen); in biejem Fall ijt bie längere

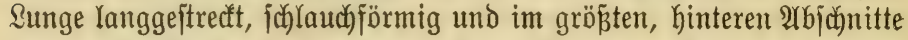
glattwandig, Gat aljo feinen eigentlichen Bezug zur 2(tmung, jondern dient ale Suftrejerboir.

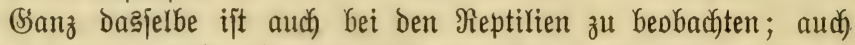
Kier haben bie mehr gebrungenen Formen furze, im Umriß̄ eiförmige

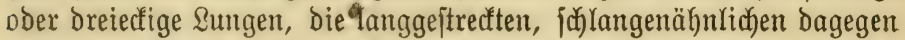
auch langgeftrectte Sungen, bon benen bie eine entweder berfïrzt Dঠer vollfitändig rüügebildet ift.

Die Reptilien haben aber bereite einen gut entwičelten Refltopf

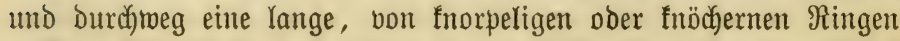

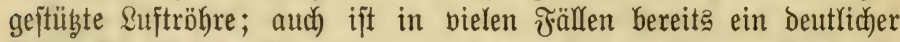

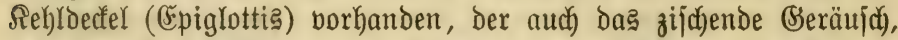

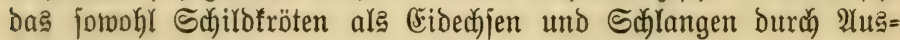
ftoken bon \&uft burch bie fpaltförmige Stimmrike herborbringen fönnen, erhebliç veritärfen fann. 


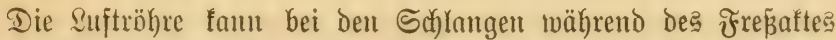
unterfhalb bes zu verjd)lingenden Tieres, weldyes ja bei bedeutenderer Bröß̧e bie ganze weit auzgedehnte Mantohöhle ausfült, vorgeftrectt

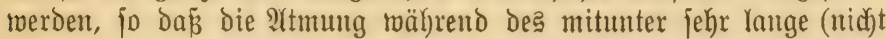
felten über eine Stunde, aushahmameije jogar mehrere Stunden) dauernoen Freßaftę feine Unterbred)ung erfährt. - Bei einer

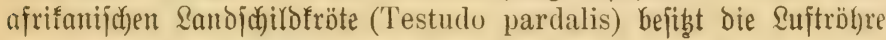
ebenjo wie bie Brondien eine ganz gewaltige \&änge uno bildot

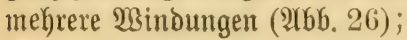
oas ift audi) bei einer anderen ałrifanijachen Sandichildofröte, Cinixys crosa, Der ₹all, während bei eimer zmeiten afrifanijonen Testudo= 2 rt (T. oculifera) bie suftröbre auserordentlich furz ift. Ütberafl, wo zwei beutlicke sungen vorhanden find, fpaltet jidi) bie Suftröhre in zwei meift furze siffe (Bronddien), bie bei Rrofodilen und Schild fröten ver= Gältnismäß乃ig am iveitejten in Das Sungengemebe jidi) eritrecten. Die sungen jelbjt entbegren entroder eines beiten inneren Şohfraumes und find burd)

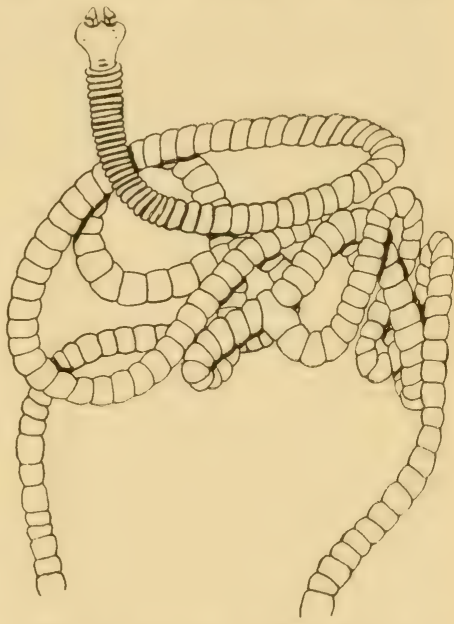

9(6b. 26. ¿aftröhre uno Brondien won Testudo pardalis. (Pad) ङ iebentod.) ein fomprizierte? Syjtem von Balfen und Bänden in fleinere, twabige oder zelfige 5̧ohltäume geteift (Sd)ildfröten, Strofobile) oder es fpringen twie bei den Umphibien nur an den. Wänden Falten vor, während der innere Szohlraum erfalten bleibt (ङFidechjen, Schlangen). Die Âtubildung Diejer von der Mand dez Sungenjačę vorjpringenden Göheren

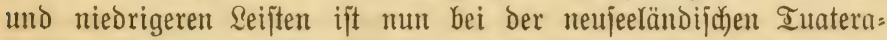
(5a)je und einigen edften (sibechjen nod) jehr primitio uno erimmert an bie Berbältnifje bei ben IImphibien, bod̆ finden twir alfe über= günge bis zu einem red)t fomplizierten Syjtem von burd) Seiften getrennten größ̈eren (2̂lveolen) uno fleineren (Rrgpten) 2(bteilungen, 
in meldye bie bei den Baraniden jogar gegabelten Brontefien ein= treten.

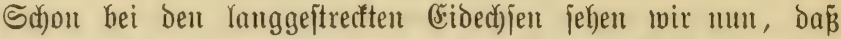
genau fo wie bei den entfpred)enden ?tmphibien nidft mur bie eine (meijt bie red)te) Sunge bą übergemids)t ïber bie andere geminnt, jo

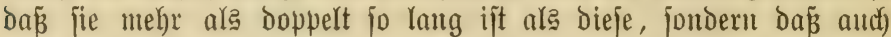
wieder ber Gintere. 2(bidanitt einfac), glattwandig ift und ein \&uft= rejervoir voritellat, weldyes aud beim Schmimmen gute Dienjte leiptet. Die linfe Runge ber Riejenichlangen ift noch bolfommen erhalten, zroar nicht mehr als halb jo lang als bie rechte, aber immerhin funf= tionafähig (nur bei den fleinen tropifac)=amerifanijden Ungalia=2(rten feh)lt fie); jonft aber finden wir bei ben S(d)langen eine Rüufbildung Der linfen sunge bis zum völigen Schiwunde, dagegen ift bei bell Murmidalangen gerade nur die linfe erhalten.

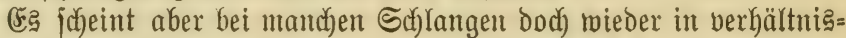
mäß̧ig neuerer 3eit bas Bedürfniz nad) Wiederheriftellung ber zreiten

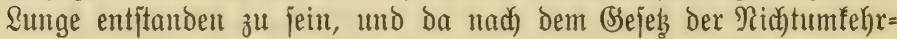
barfeit der (Entwidflung bie einmal verloren gegangene Sunge nid)t

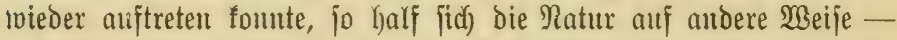

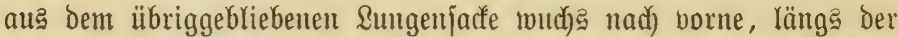
Suftröhre bis zur Siefle, eine neue Runge Kerbor, bie in ihrem Baat volfytänoig mit ber ïbriggebliebenten red)ten übereinjtimmt. (Eine folche Irachearlunge, die mit ber Ruftröhre ifrer ganzen Ränge nadh

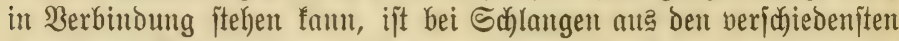
Familien (Wurmid)langen, Nattern, Bipern) gefunden worden und wabricheinlid) jedesmal jelbjtändig entitanden (\$lbb. 27), Bei der indifach Scamabrijasja)lange (Naia bungarus), bie mit über $4 \mathrm{~m}$ Marimallänge bie größ̄te befannte (sififtichlange ift, joll bie Suftröhre nach Bed dard mit 30-40 Suftääfen in Berbindung ftehen.

Während mun bie langgeítrectte Sdylangenlunge, ob jeb̧t die red)te oder bie Yinte, in ifrem ganzen Ginteren 2(bichnitte glattwandig und für bie Yltmum! jelbjt bedeutungelos ijt, jehen wir bei den

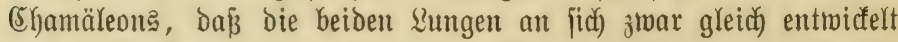
und entiprechend dem georungenten Rörper jelbft wentg mehr ale Doppelt jo lang wie breit jino, Dá̃ ferner dą Balfenmerf der

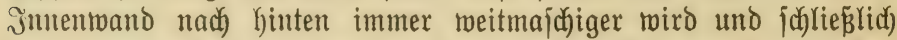

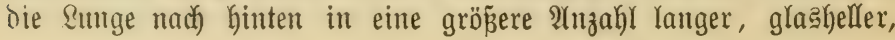




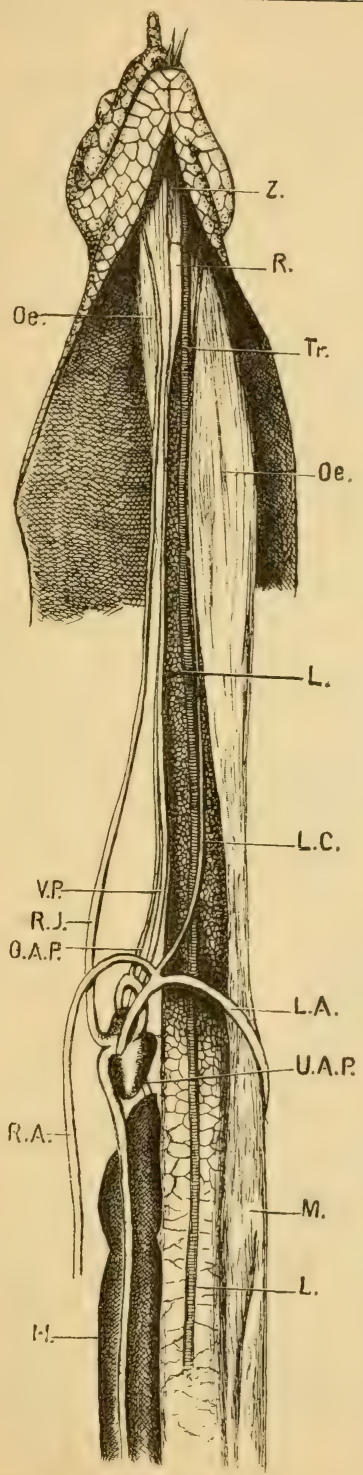

)66. 27. Eanootter, Vipera ammodytes, Borbertörper non ber unterjeite geöfinet.

L. Worberer Bipfer ber sunge (Irad)eallunge), in offener Werbindung mit ber suit= röbre (Irachea, T.),

L' die eigentlid)e sunge, einen blop̃en \&uftbebälter bildend,

Z. 8ungenbafis,

Oe. Speiferöhre,

M. Miagen,

H. Reber,

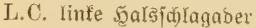
(Earotis),

L.A. linfer I rortenbogen,

V.P. \&ungenvene,

R.J. red)te Sugular $=$ (Drofiel $=)$ Bene,

O.A.P. obere sungenarterie (fitr bie Tradjeallunge),

U.A.P. untere sungenarterie. 
idhlaud)artiger Bipfel ausgeht, meldhe ebenfalle als \&uftbehälter an=

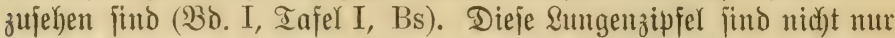
bei ben (Shamäleons, jondern autud) bei einer madagaijitichen, gectoähn= lidenen (sidechje (Uroplatus) gefunden morden, bie in bemerfensmerter

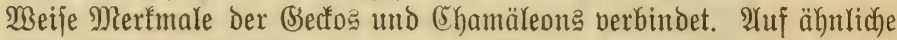
(d)lauchförmige Fortjäbęe ber Sungen ift man geneigt bie bie in bie Sberarmfnod)en fid eritrectenden und für ben Flug jo widftigen

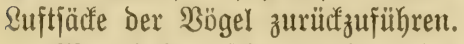

Mir Gaben idjon früher, Gei Belegenheit der Befpredfung ber ßanzerbildungen Der Peptilien, auch) Der P(tmungäbetwegungen Der= jelben gedadyt (j. B. I, S. 56). Bei allen denjenigen, Die entweder

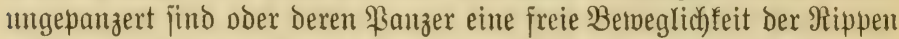
zuläpat, wiro der Suftwed)jel in ben Sungen burd) bie Betwegung

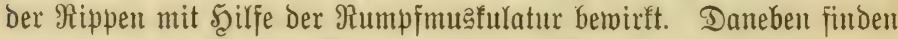
wir aber ganz ähnliche Bemegungen Der Rehlhaut, wie fie von ben lungenatmenden und lungenlojen 2(mphibien auggeführt werden, bei Den Bectonen und zum mindejten den jungen Rrofodilen, Dod) find bieje fatringenten Betwegungen tweder io idnell nod aud jo gleiç)mäßzig wie bei Fröichen und Mold)en. Die Rrotodile bejiţen

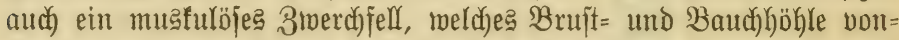
einander tremut und fdjon bei ber YYtmung wie bei den böheren Mirbeltieren mitrirft, während bei ben Schildofröten durd) dą $\mathfrak{B o r}=$ ftrecten und 3urürfieken Der $\mathfrak{B}$ orberbeine bie Suft in ben Sungen getwectjert wird. - Die 2(mphibien, bei Denten niemals lange Rippen vorfommen, fondern höcdjten furze Stummel von fold)en an Den Querfortjäzen aller (Schmanzlurche) ober ber vorberen

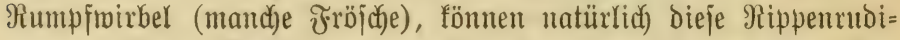

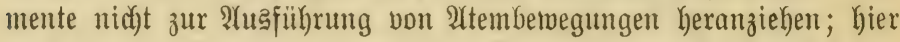
geidjelgt bie (sinatmung Durch bie Betwegung ber fehlmusfulatır,

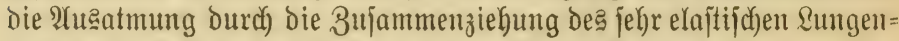
gemebes und burd) Den Drucf der Baud)muafeln und Der inneren Dr=

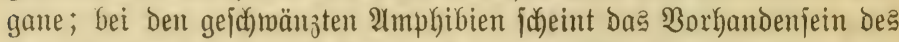
vom Borderrande bes Becfens nach vorn geridyteten "upillonfïrmigen Sinorpels" mit Der Sungenatmung in 3ujammenlyang zu jtehen, Da man beobacktet hat, daj er bei allen lungenlojen Salamandern ferylt.

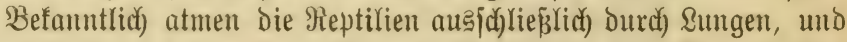
die wajןerbewohnenden unter ifnen müifjen baher nad) fürzerer oder 
längerer 3eit an bie Dberflüd)e fommen, um \&ujt zu job̈pfen. (5己 wäre aber verforene Müthe, wollte man auf ber Jago nadi) irgento= cinem aquatifaten Reptil etwa warten, bis ę fid zum 3rocfe des

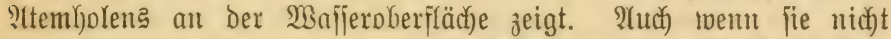

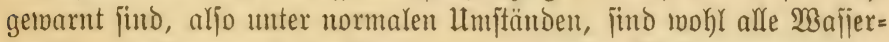
reptilien imftande, viełe Stunden lang unter Majjer ausullyalten, tobbei Den Saflangen ify \&uftrejerboir ebenipo midutige Dienjte reiftet mie beim Sdumimmen an ber Dberfläd)e; fie fömten unter $\mathfrak{B a j p e r ~ e b e n j o w o h l ~}$ ruthen wie frejien.

(52) gibt aber zroei von ber Natur bejonders zum Iauchen ausgeriijtete Reptilformen, dą find bie $\mathfrak{B e i d})=$ jufilofröten (Irionychiben) und bie Seejdlangen (Şyorophiinen). Bei

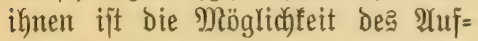
enthaltes unter Wafjer durch eine IYrt Riemenatmung ganz bedeutend vergröpert. Der Sefhluno Der Meidy=

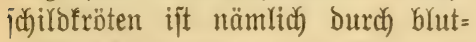
gefǟreid)e 3otten zu einem $\mathfrak{A}(t m u n g s=$ organ umgeitaltet, das imjtande ift, Der im Wajjer berteilten atmojphä= rifichen Suft ben Saueritoff zu ent= zieken, und ebenjo ift bie Mumb= id)leimthaut der Seeja)langen, nament= lidi) Das 3ahnfleijod, iiberaus reid) an fein veräjtelten Blutgefäß̈en, melche

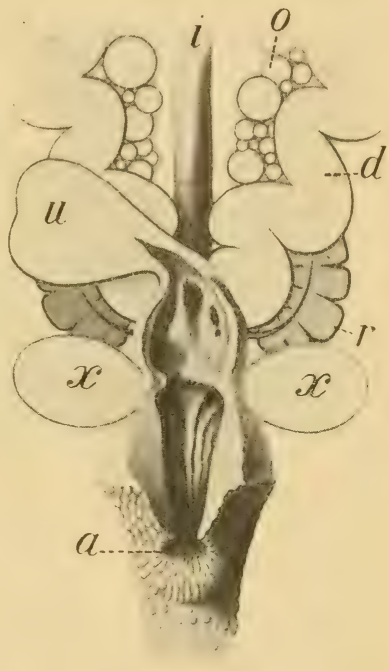

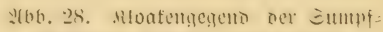
idulotröte (Emys orbienlaris).

$x$ Efnalbajen, 1 Sarnblaje, d Darm, $r$ Mitere, o Evarium, a Mifer. (Yiad)

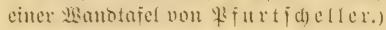
diejelbe Bedeutung haben. Benn wir bedenten, dẩ e

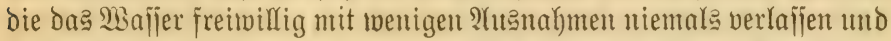

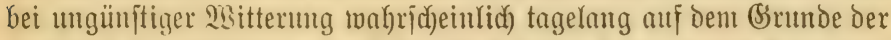

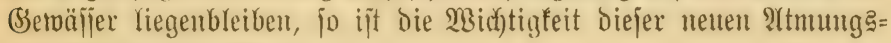
einrid)tung einlentidtento.

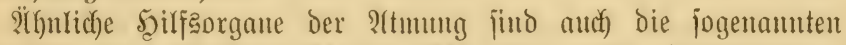

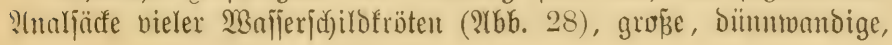




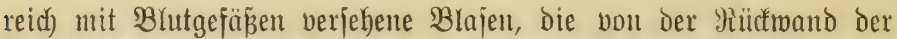
Nloafe entipringen und bei mandjen 2 rten weit in bie Seibeahöhle vor= fpringen, ja jogar mit ben sungen in Berbindung fithen follen. Sie fömen von Der Rloafenöfinung aue mit Wajfer gefüllt werden, weldies oft getwedjelt wirb, und ber Wajjeritrabl, ben frijch gefangene

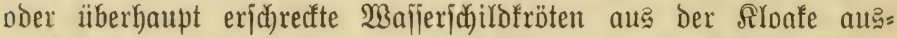
fpriben, fommt nidjt, wie man getwöhnlich glaubt, aıt der Scarnblaje, jondern aus diejen ?alnaljäcten.

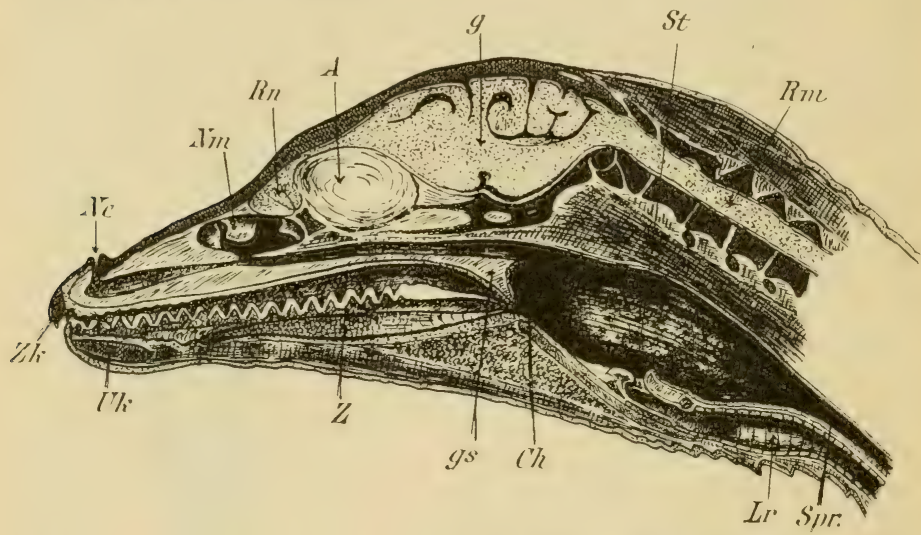

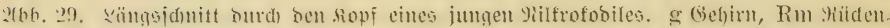

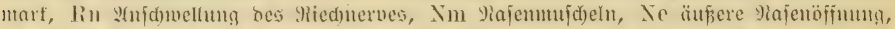

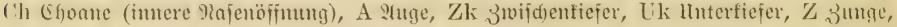
gs Baumenjegel, St Stimmriz̨e, Lx \&uftröhre, Spr Speijeröhre.

2Yuf eine (ङigentümlidffeit ber frofobile foll noch) hingemiejen werden, weldye es ifnen ermöglidyt, unter ßajjer beim atmen den

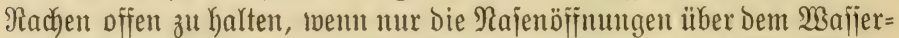

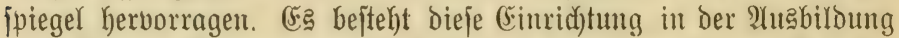

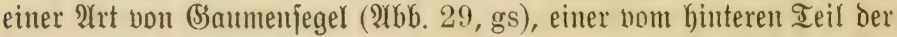
Munoböhle bis zum 3ungengrumbe voripringenden Scautfalte, meld be

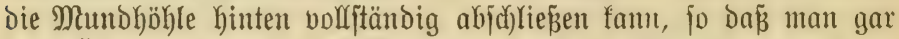
feine S̈ffmung bemerft. Die Suft geht Durdh bie Rajenöffumgen, Den

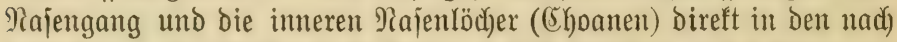

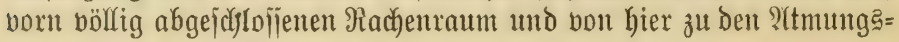




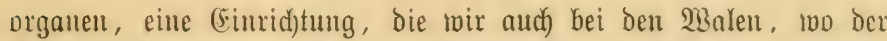
Rehlfopf bis ju den Shoanen vorgeidoben werden fam, wieder antref̃en.

Wir haben aljo auber den Rungen nod) verjachiedene Artmunggorgane waijerbetwohnender Reptilien fenten gelernt, die für die das Sï̈prwajier แnd das Meer berobnenden, aber nidht in bedeutende Iiefe taudjenden Iiere ausreidten. Wir fennen mu aber verjofiedene, burdyneges ausgeitorbene Reptilien, die jweifello in bedeutende Meerestiefen Ginabtaudjen fomnten, ja vormiegend in tieferen Regionen Des Meeres lebten; bei biejen ift zrar auber ber Sungenatmung feine andere bor=

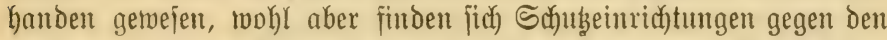

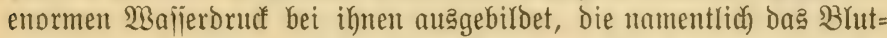

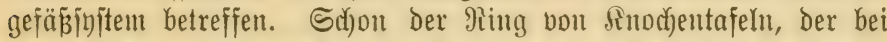

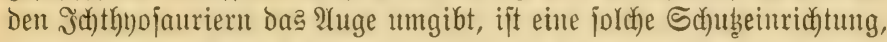
aber bejonders bemerfensmert ift es, daß̄ bei biejen Reptifien, ganz wie bei den eine ähnlidłe Rebensmeije fübrenden Walen, diejenigen

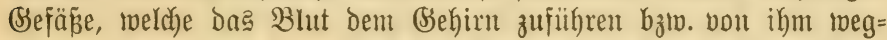
leiten, fo gelagert find, Daj burdh Den beim Iauchen in gröpere Iiejen außjerorontlich) gejteigerten Wajjerbrud feine Störung in Der Blutverjorgung des Behimes eintritt. Bei den Zahnmalen (Del=

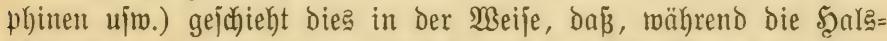
joflagabern (Carotis interna), die jont dieje frunttion haben, fid

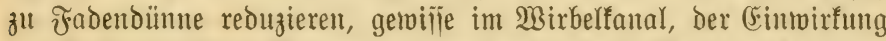

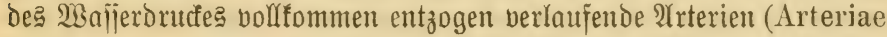
meningeae spinales) bejonders itarf jich) entwicfeln und in Der Berjorgung Des Befirnes mit Blut die Stelle Der Carotiden ein=

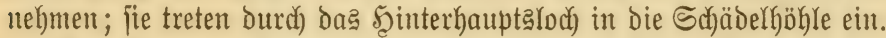

Nun finden wir, geradejo wie twir gejegen haben, daj̃ bei den Walen, bei dem judthtyojaurier Ophthalmosaurus und dem Moja=

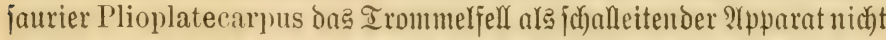

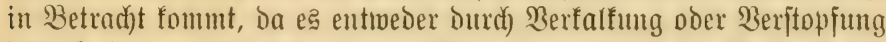

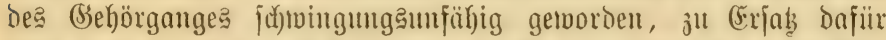
aber eine molefulare Sdfalleitung burd) dic ïbermüpig entmicfelte

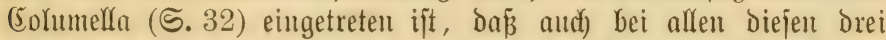
taud)enden Meeresbetwohnern in gleid)er Meije bie das (Sebirn wer: jorgenden Blutgefäpze ourd) Berlegung in die Iiefe, in Den ber

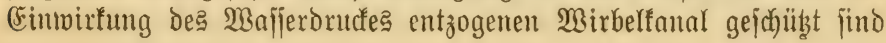


und Durd eine fleine (Finferbung Des oberen Sृinterbauptabeine (Occipitale superius) in ben Schäbel eintreten fönnen (DorYo).

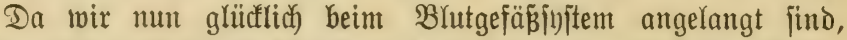
wollen mir noch einige bejonders bemerfentwerte, in diejes Sebiet fallende (5richeinungen betrachten. Wenig befannt ijt es wohl, da

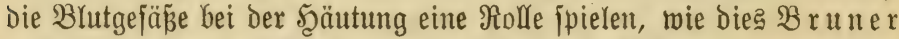

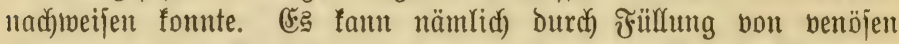
Bluträumen im Ropf biejer zu einer berartigen IYnjohnellung ge=

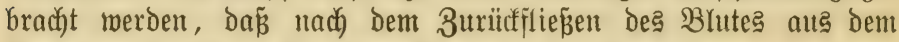
Sopf eine Socferung ber alten Şaut angebafnt wirb.

शuch) eine andere mertmürdige (sridjeinung, die oft bejdrieben, chenio oft aber wieber ins Fabelreidf berwiejen morben ift, twäre

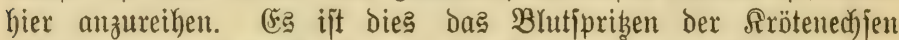
(Phrynosoma), das id jăon in B̉o. I, S. 53 erwäbnt habe.

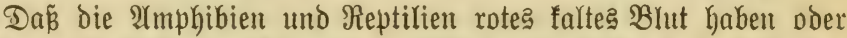

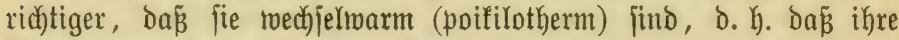
Bhttemperatur nur menige Srabe über bie ber Umgebung fir erkebt, ift wohl jedem sdulfind befannt.

Meniger befannt Dürite bagegen aus ben Unterjuddungen von

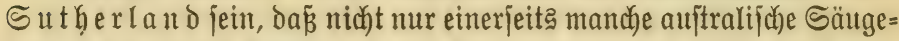
tiere ein geringes Sdfwanten ber Rörpertemperatur entjpredjend dem

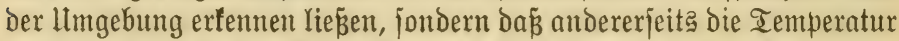
getwijfer aujtralijober (sidechjen, die dell bereits mehrfach bei ver= fđjiedenen Selegenbeiten ermähnten Ssattungen Tiliqua uno Trachysaurus angefören, geringeren Sdfwanfungen unterliegt, als $e^{2}$ nad)

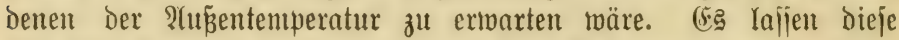

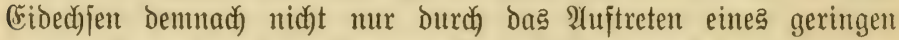
3ahnwed)jels (ein 3ahn in jeder Rieferbälfte wiro bei den Siungen gemedjjelt) jomie die Srt und Weije ber Ernährung ber Şungen in Mutterleib Säugetiermerfmale erfennen, wenngleidy dieje ütber= einfimmung natürlid nicht auf eine nähere Bermandtichaft zurüct= zuführen ift und die dą Mittelmeergebiet bemohnenden Stinfe der

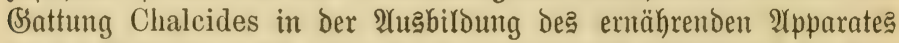
für bie (Fmbryonen jich viel mehr jäugetierähnliç verhalten (j. ธ. 72).

Scier wäre auch ber Drt, einer regelmäßig auftretenden (5rid)einung

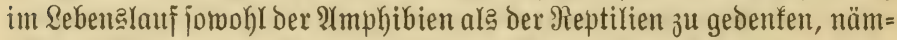

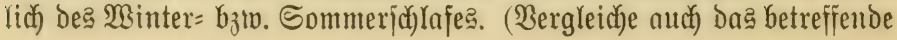




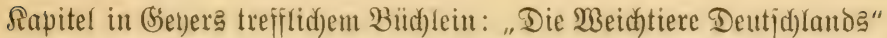

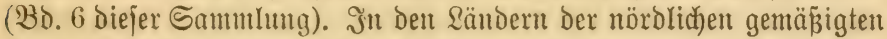
3one tritt befauntlid) mit Dem Sinfen der Iemperatur im Şerbft und

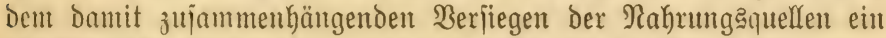

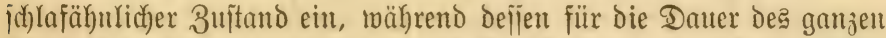

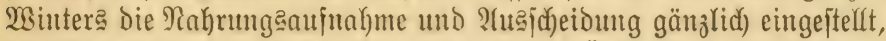

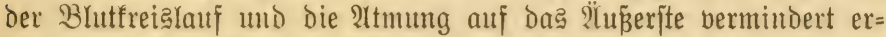
icheinen. Diejen Minterjallaf verbringen bie Tiere an Drten, bie nor Froft gejoujibt fino, da jie jugrunde gehen, wenn bie Bluttemperatur

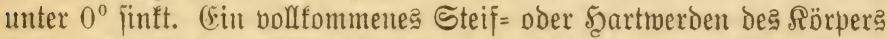

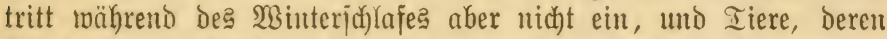

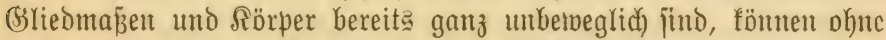
weiters als erfroren betrad)tet werden. 2(mphibien verbringen bon

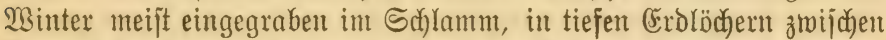
Baumıurzełı oder von Säıgetieren gegrabenen uno verlajienen Qöd)ern,

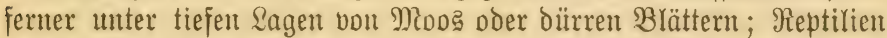

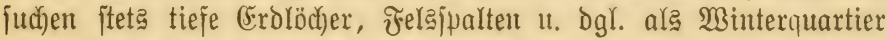

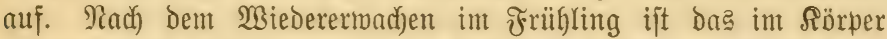
aufgepeicherte Rejervematerial an Fett aufgebraucht; getwöhntich er= folgt bann zuerit eine (Entleerung Deß Darmes und der Şarnorgane, eine Şäutung getoöhulid) erift nad) ber erften Mahlzeit.

In Den Tropenländern, aber fodon im lumfreis bes Mittelmeeres tritt eine andere, äbnlid)e (eridjeinumg auf, die ale Sommers, ridjtiger Iroffenzeitj)laf bezeidnet twirb. In den Mittelmeer= Yündern begimen fich) Die meiften Reptilien, namentlid) aber Sdylangen,

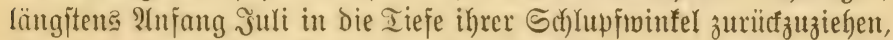

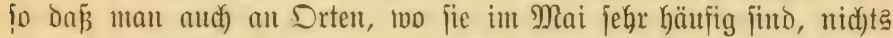
bon ifuen zu fefjen befommt. Diefer Sonmeridglaf ber Mittelmeer= reptilien ift aber nidyt unuterbrod)en, fondern man fann in ben

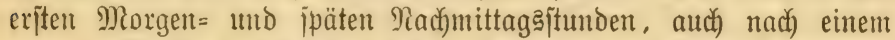
warmen Regen immerhin einzelne Erremplare zu jeken befommen. Dabei ift aber ein edjter Minterichlaf, menigitens für Sablangen,

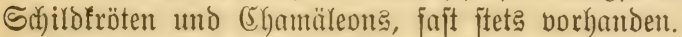

2Inders liegt bic Sad)e bei bem Irocfenzeitid)laf Der Meptilien in getviffen Iropenländern. (Ex entjpricht dem Minteridalaf ber ge= mäṕsigten 3one, Dod) ift or feine alfgemeine (5rid)einung, indem

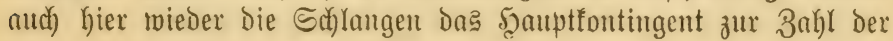


Schläfer ftellen, nebit den in Den Sd) Iamm fid) eintwüglenden Srofo=

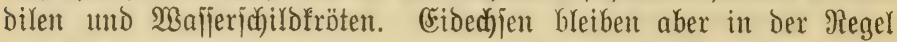
aud in ber regenlojen ßerido munter. Der Natur der Dinge ent=

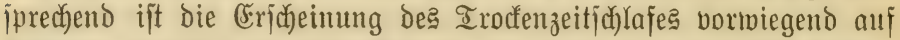

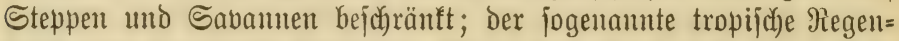
wald mit jeinem feutd)twarmen Slima beherbergt bas ganze Jah)

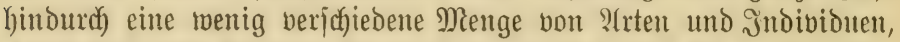

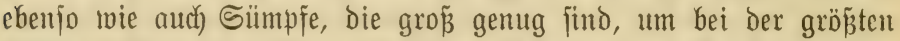
Dürre nidgt ausautrodinen, in ihrem Iierleben zur Iroctenzeit eher noch) 3uwad) aus Der Itmgebung erhalten. -

\section{Bont ber Bermelynutg mto Regeneration.}

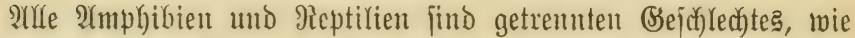
dies normałerweije überhaupt für alle Wirbeltiere gilt, bagegen iprect)en aud bie wenigen Fälfe hermaphroditif(c)er Frortpffanzungas=

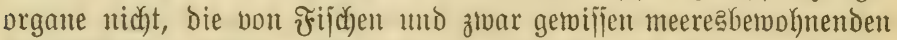
Stachelfloffern (Chrysophrys, Serranus) befaunt jino, da auch bieje ibrer Funftion nach) ridytige Mämuchen ober Weibchen fino, dic

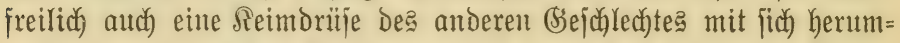
tragen; ein äfnlidyes Borfommnis ift aud das Bidoderidhe Drgan

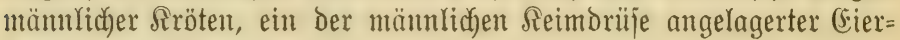
ftodrejt ohne frunftion.

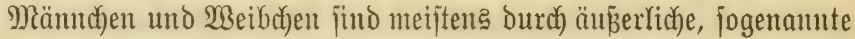

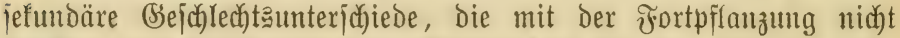
Direft zu tum haben und beren Mannigfaltigfeit eine überaus groß̋̄ ift, noneinander mehr oder weniger leicht zut untericheiden. Bir wollen bavon abjeken, bieje vielen Formen hier Revue pafijeren zu laffen, da wir ïber ifre eigentliche Bebentung twentig ober nichtes wifjen unt id eine ziemlid) nollytändige 3ujammenftelfung im Biolog. (5en= tralbratt XV 1895 gegeben habe. (Einige auffalfende Beifpiele mögen aber hier wenigitens burd) ?tbbildungen norgefiilfrt inerben.

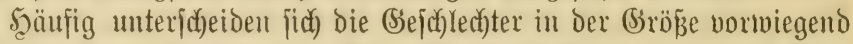

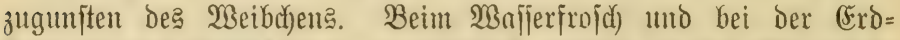

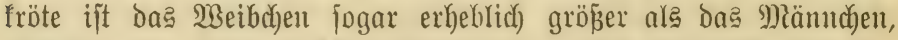

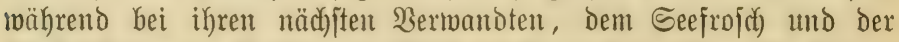

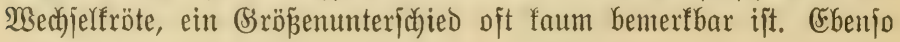




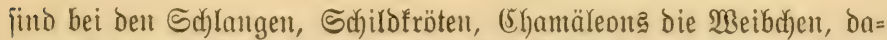

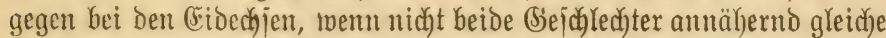

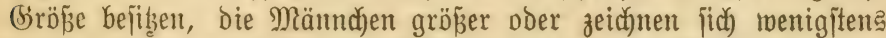

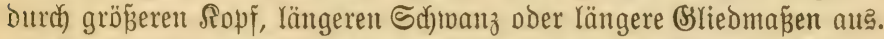

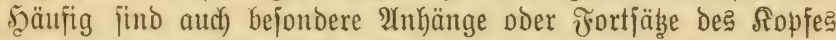

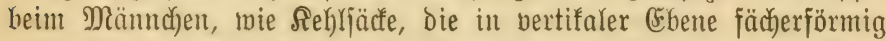

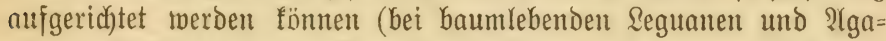

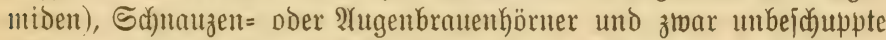
(Ceratophora stoddarti, 2rbb. 30) uno mit Schuppen bedectte (Cha-

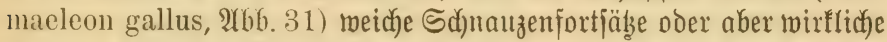

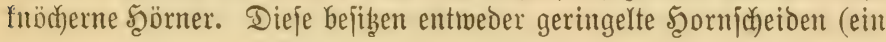
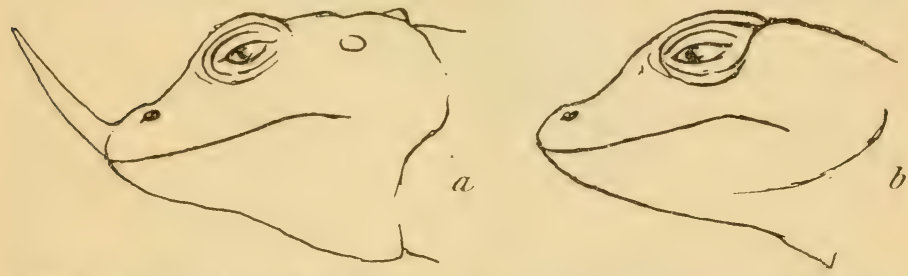

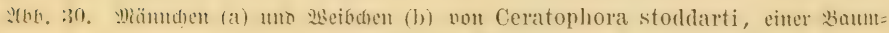
agante aus Eenlon.

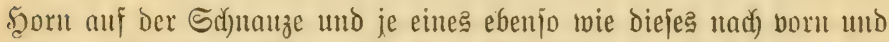
ctwas aufrörts geridatet am vorderen 2 Augenbrauenrand bei bem wejt= afrifanifichen Chamaeleon owenii mo mehreren siftafrifanijuden $\mathfrak{B e r}=$ wandten; zmei Schnauzenfjörner nebenteinander bei bem wejtafrifani= fiden Chamaeleon montium; vier S(f)nauzentyörner bei Ch. quadricornis, wie voriges aus Ramerun) Dber fie find fantig und mit S(t)uppen bedectt (Chamaeleon fischeri von Ditafrifa, Ch. bifidus von Miadagasfar u. a.). Dagegen find bie Şönter berjdiedener Sd)langen (bei Langaha, Ilerpeton, Vipera ammodytes, Bitis nasicornis, gabonica auf der S(f)nauje, bei Cerastes cornutus, Bitis cornuta und caudalis und anderen Dttern ïber jedem $\mathfrak{\text { Huge) }}$ fajt manafmelos in beiden Bejejlechtern in gleidjer Weije vor= Kanden, Daher nidgt in bieje Rategorie gehörig.

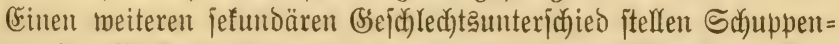
fänme der Riačenfirfte vor, bie entweder beim Männd)en allein 
Dobr in bedeutent ftärferer Entrofflung vorfommen; fie bejtehen aus

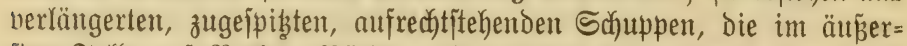
ften Falle auf Racfen, Rüffen und wenigitens dem vorberften Ieile bes Sthwanzes ftehen und nach Ginten immer fleiner werden. Diejer

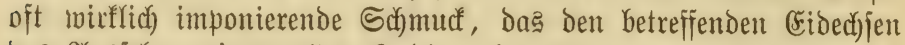

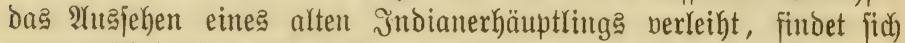
namentrich) bei Den grïnen Seguanen (Iguana) Des tropijichen PImerifa? (2166. 32) und Den Santenföpfen (Gonyocephalus), den Bertretern

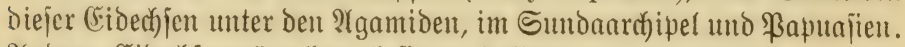

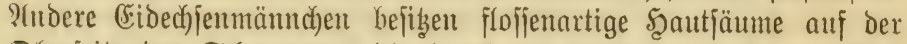

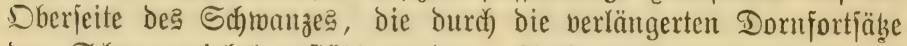

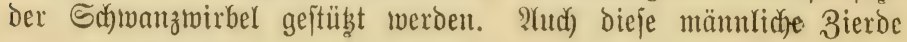
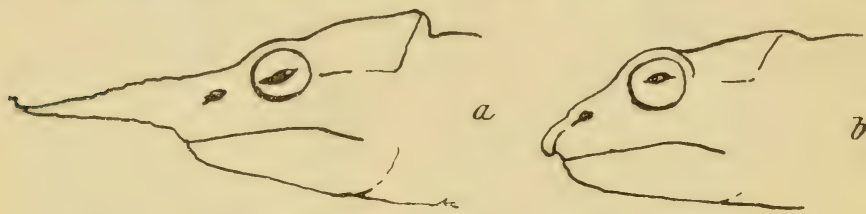

Yab. 31. M(ämud)en (a) unઠ खeibdjen (b) won Chamaeleon gallus vout Mabagastar (vergr.)

fonmt jowohl bei einem neumeltlidyen Seguan (Basiliscus) ale audd) ciner altweltrict)en ?Igame, der Segelecthie (Lophura) bon den Mo=

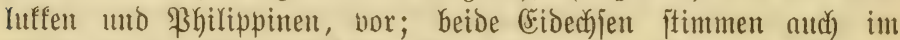
Befitz eines gejägten Sd)uppenfonmes an Den Seiten ber Finger

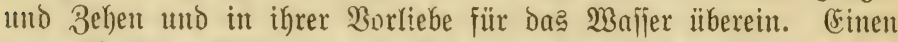
ganz ähnlid)en follifenfaum auf der vorderen Sdymanzhälfte bejib̨t

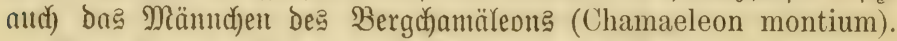

भ(ber Şörner, Rämme und Floffenfäımte find nicht bie einzigent

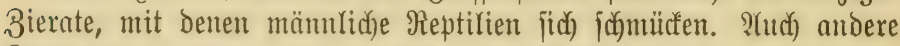

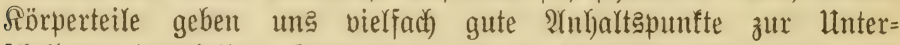

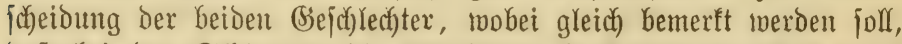

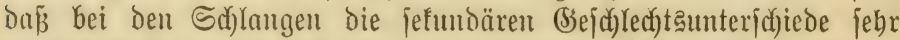
jpärlich) finto und jich) auf gelegentrict)e Farbenberjodedentheiten (Sreuz=

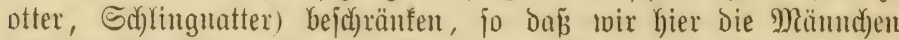

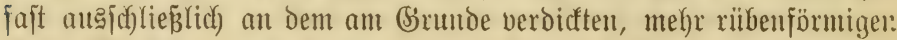

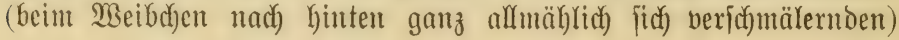




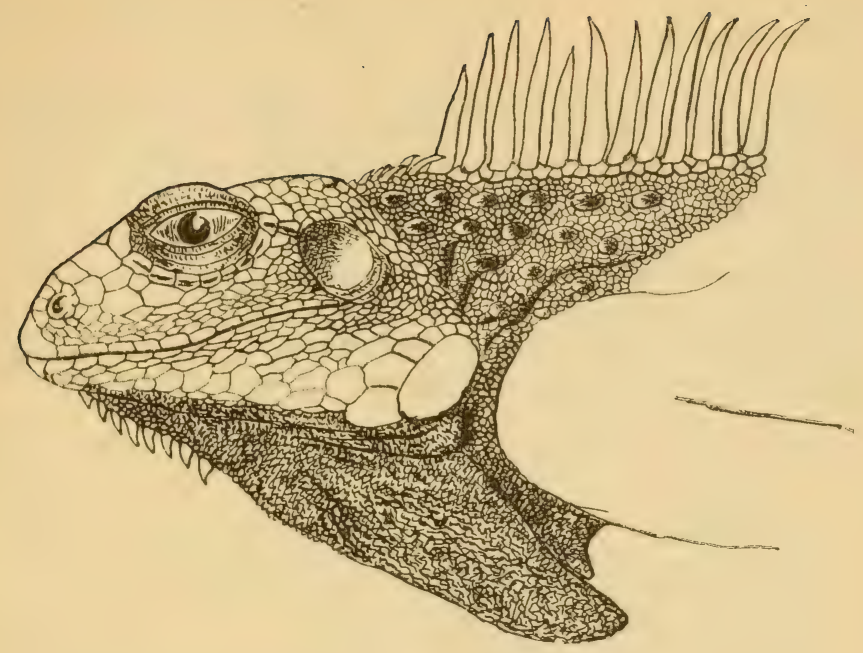

a

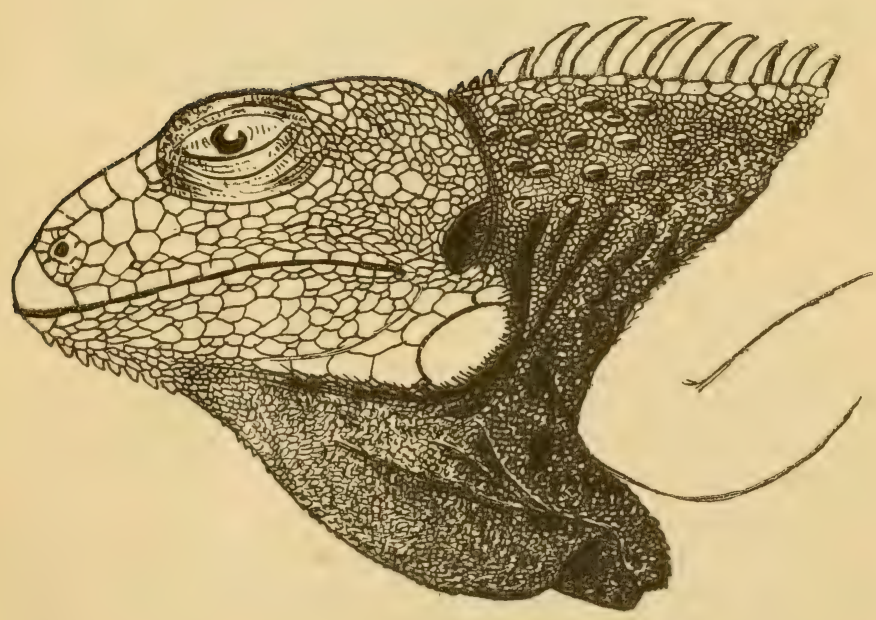

b

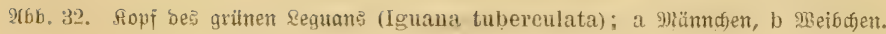




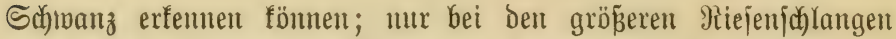

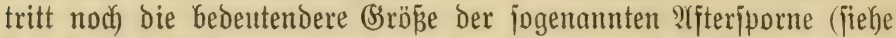

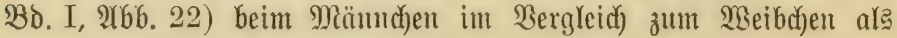
Unteridjeidung smerfmal hiuzu.

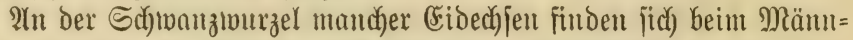
(j)en entweder fegelförmig nad) Der Seite wegitehende Sृöcfer, ent= rweber einer ober mehrere in einer Sängareike an jeder Seite ber angejdyollenen Sifmanzmurzel vor bem ?(fter, wie bei mandifen (Sectonen, oder aber lange, ftachelförmige Sporne, wie bei ben

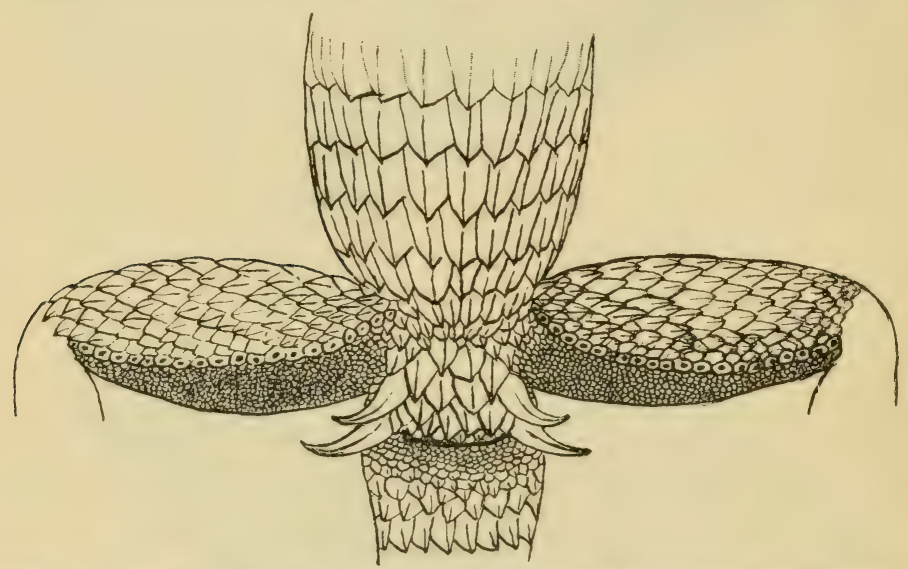

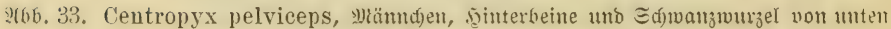

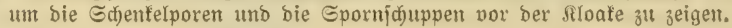

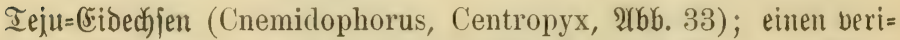
tabeln Birpapparat, au je einer gerieften hornigen Blatte am Dber=

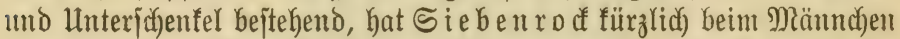

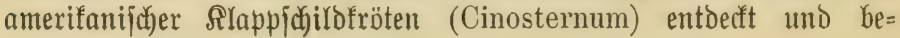
jarieben (2rbb. 34).

Bei dem aujtralijojen Flofjenfū (Pygopus) und bei bem twie biejer langgeftrecften, jó)langenförmigen Dibamus, ciner von ben Sundainjeln bią Neuguinea berbreiteten (Fibechje, find die einzigen

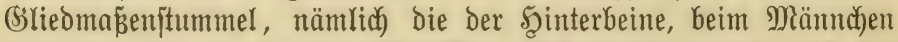

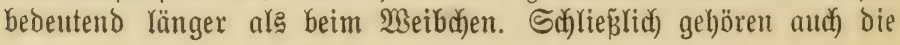




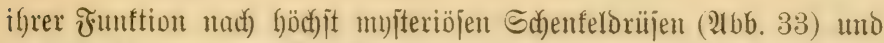

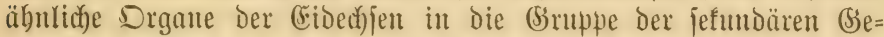

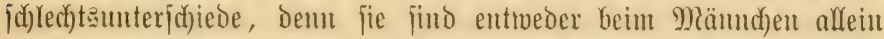

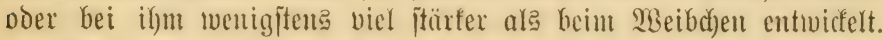
stber man barf nad) obiger 3ujammenjtellung, die ja mur bie

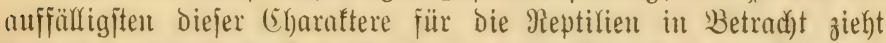

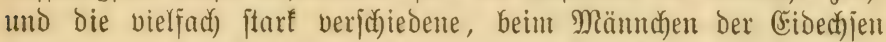
häufig vieł buntere uno lebhaftere Färbung eben mur erivähnen

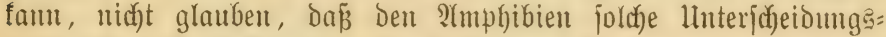
merfmale nicht jutonmen, fie jint fogar fuum toentiger mannig= faltig ale bie ber erfteren. $2(b=$ gejeken von ber bereits eingangs erwäbnten bäufig ftarf́ veriơdic: denen (Srö̈ß̈e, der jeltener beridjies Denen Färbung (Bufo viridis, Pelobates fuscus $\mathfrak{u}$. a.) wären nod̆ zunemen die Shallablajen ber

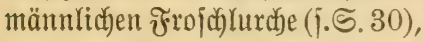
die ebenfalla bei verictiedenen Fröidjen verbreitetenßrumifiajowie. len bes Männchents an ben Fin= gern, namentlidú) an dem fälichliç) Daumen genaunten inmeren Fin= ger (f. Trbb. 4), am $\mathfrak{A r m}$ und an

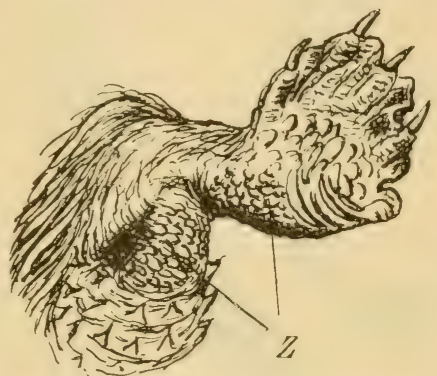

2t66. 34. Dinterbein non Cinostermum odoratum (\$2ojd)usj(filsfröte), Miämonen, non unten. Z jirporgan. Der Bruft, ferner bie beident zroei=

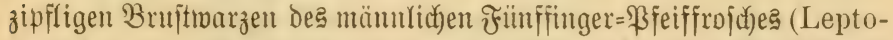
dactylus pentadactylus), deı auß̈er biejent furiojen Brujtidymutf

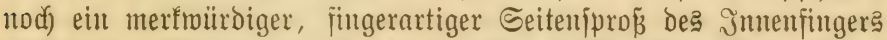
(baher fein ?(rtname) und die enorm verdicften Borderbeine fent=

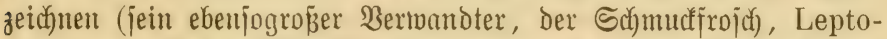
dactylus ocellatus [?(6̧. 35], trägt auß̃erdem einen mächtigen Sporn

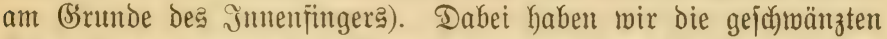

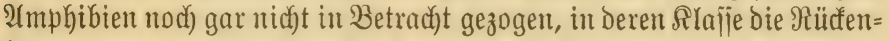

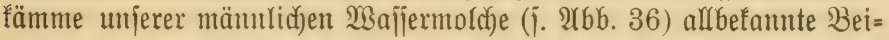

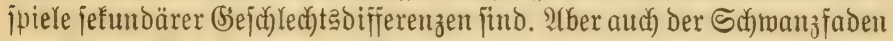

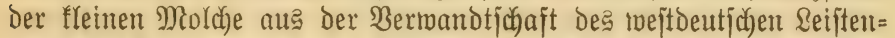

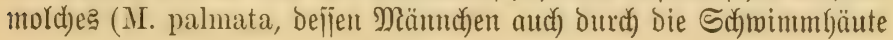




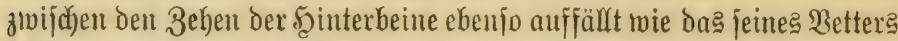
M. vulgaris burd) den Sappenfaum der 3ehen), bie verid)iedenen Antjänge und Fortjäbe am Şinterrande bes llnteridjenfele bei ber=

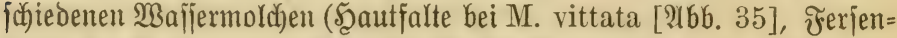
iporn bei M. rusconii, Ferjenjacheibe bei M. montana), jogar Brumjt=

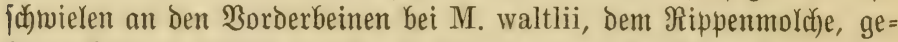

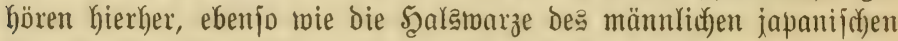
Fenerbaudfymolde)e (M. pyrrhogastra) und ber nad) vorn gerid)tete Fortiaks auf ber Sd)twanjtwurzel dę Männ=

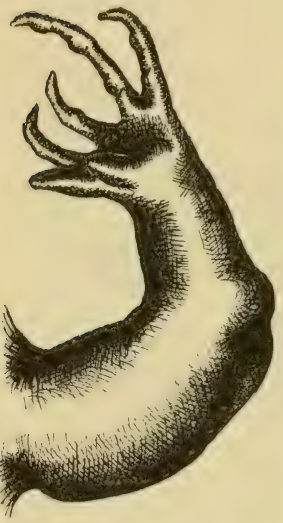

26b. 35. \$orberbein bes Miämut)enis von Leptodactylus vcellatus. d)ens ber beiden mejtafiatijoden Salamander (S. caucasica und luschani).

Freilich find mand be biejer Merfmale

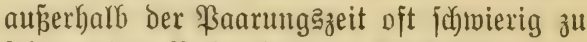
\{ehen, toie z. B. Die bäutigen Pä̈cfenfämmme der Mämudicn, bie bann zu einer ganz niebrigen Seifte einjodrumpfen fönten; in biejen శällen jind bie bic angejatwollenen SToafenlippen De马 Mäundyens dą einzige fidjere Merfmal

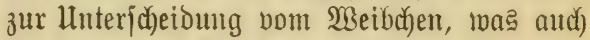
für biejenigen M(oldye zutrifft, die überhaupt feine jefundären Unterjobiede erfennen lafjen, wie 3. 3. unjeren Erojalamander, bei bem

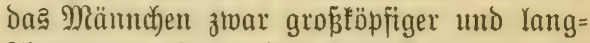

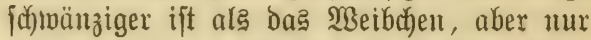
banu merfbar, wenu man beide (Sejod lechter nebeneinander vergleidyen fann.

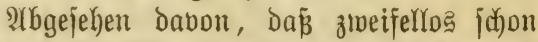

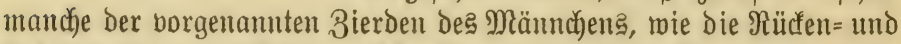
Sdhmanzfämme der $\mathfrak{B a j j e r m o l d h e , ~ B a u m l e g u a n e ~ u n d ~ B a u m a g a m e n , ~ b i e ~}$ Reflllappen Der vorgenaunten Baumeidedjen, bie Şb̈rner gemiffer männ= licher (5hamäleons, jowie bie präd)tigeren Farben bę Männd)en an

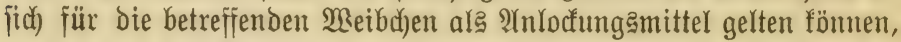

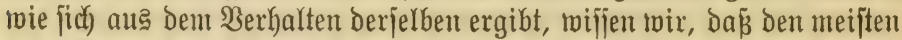
männlichen Frojohlurchen jogar eine aftive $\mathfrak{B} e r f$ tändigung, ein scerbei=

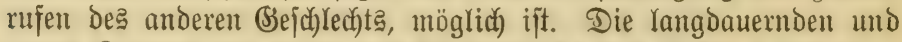
lauten Ronzerte Der $\mathscr{Q} a u b=$ und Bajierfröiche und Unfen haben żwar burdfaus nidyt immer bieje Bedeutung, wie biez fodjon aus bem 


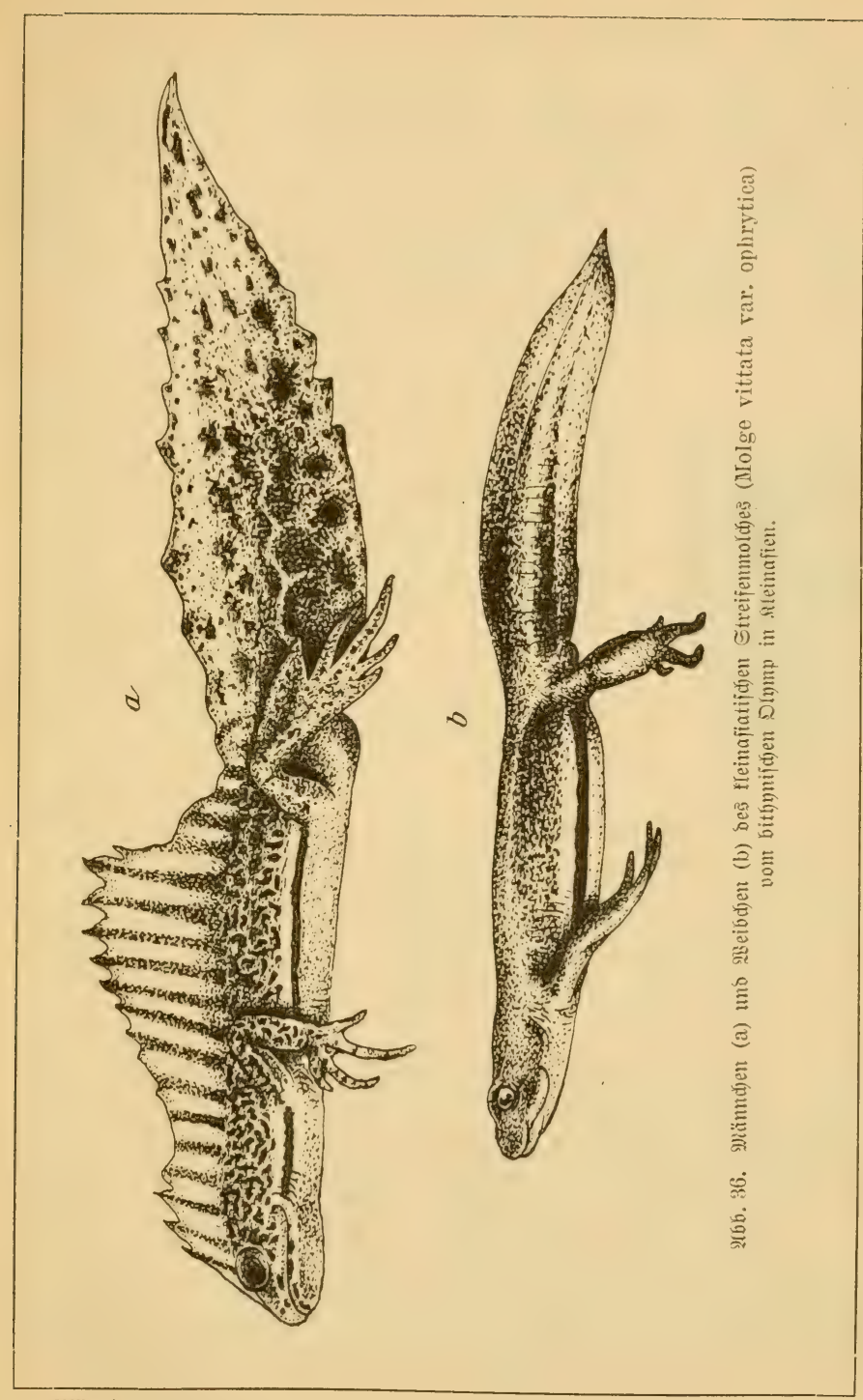

9.2. A 16 3erner II. 


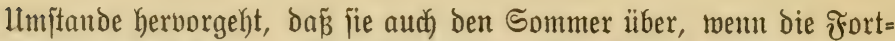
pflanzungszeit lange vorïber ijt, mit demjelben (sifer fortgejebt werden

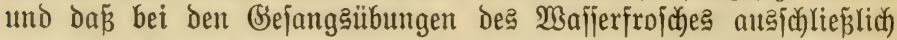

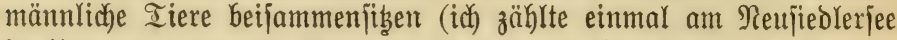
in Ungarn gegen 60 Mämochen auf einem (Sebiet von faum mehr ale 4 Duabratmetern); im Frühling fönnen bieje Sänger bagegen

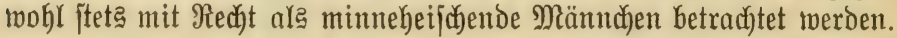

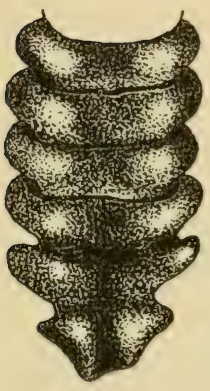

a

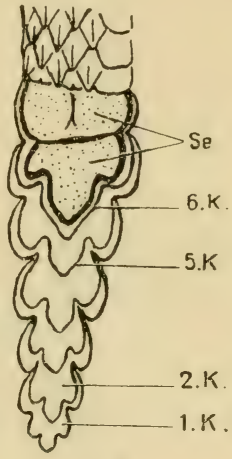

b
צ66. 37. Hafiel einer Rlapperfdalange. a Enne Der Rlapper einer erwadjienen Rlapperidjlange (Crotalus), h burdjidjeinende Mlapper eines jüngeren Exemplares, Se. Sd)wanzende, 1.K. erites (ältejtes), 6. K. fed)ftes (ältejtes) ßlapperglieo ; bas erfte wiederholt bie form bes Sduwangendes bei her erften, bas fedjpte biejenige bei ber leb̨ten föutung uno fik̨t nod) birelt bent ङd)wanzenbe auf.

Daß̄ß eptiłien mitStimm = begabung, wie Brectos und

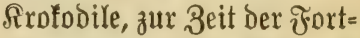
pflanzung von ihr (Sebrauct) madyen und einamber rufen, ift roohl mit Sidjerheit an= zunehmen. IYber aud bie Srimanzrajel ber Rlapper= joblangen, ber man bie in bie jüngfte 3eit bie vers fodiedenjten $\mathfrak{B e d e u t u n g e n ~ z u ~} u=$ gejchrieben hat, ijt höb)jt= wahridjeinlidis nidjte anderes ale ein beiden (Sejh) lewtern zufonmende? Mittel Der $\mathfrak{B}$ er= ftänotgung zum Behufe leid. = terer gegenjeitiger 2Huffin= bung. Daḱ ein joldhes hier beiden(sejejledytern zufommt, bei anderen Schlangen aber gar nidut, ift fein Bsegen=

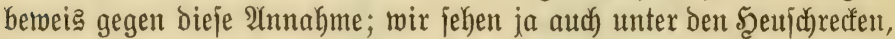

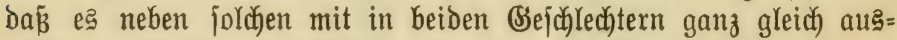
gebildoten 3irporganen (Ephippiger) auth joldhe mit 3irporganen

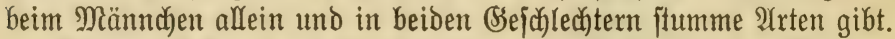

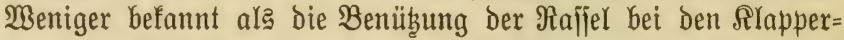

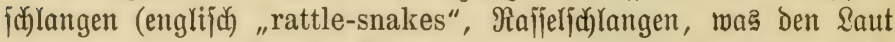

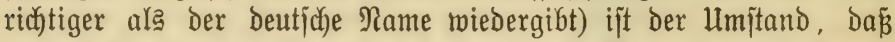
viełe Sdalangenarten, benen ein berartiger 2rpparat am S(d)wanz Durchaus fehlt, in ber crrregung ben Schmanz überaus fonnell bin 

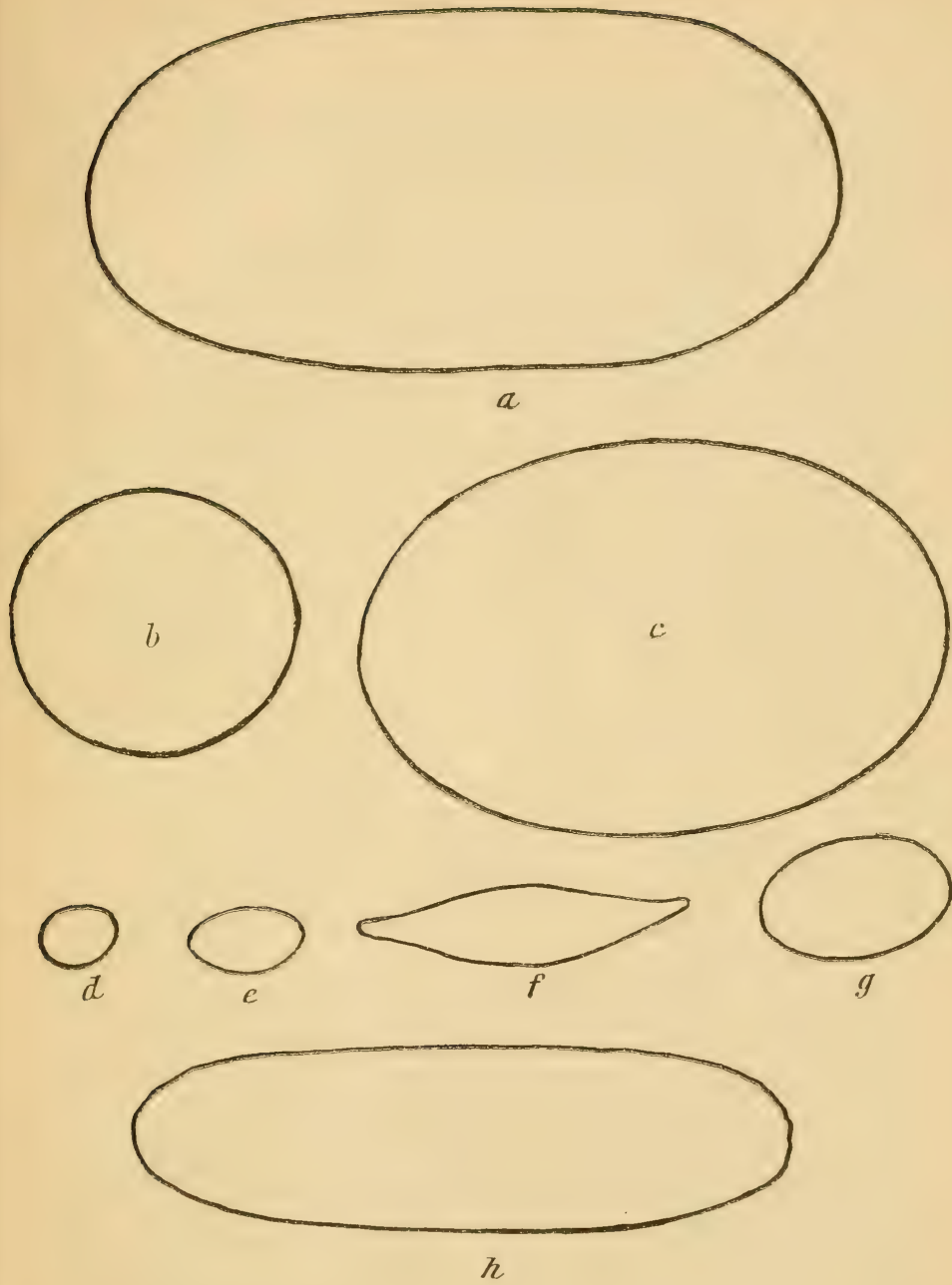

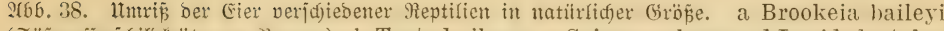

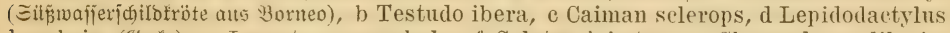
lugubris (Gedfo), e Lacerta oxycephala, f Calotes jubatus, g Chamaeleon dilepis, h Coluber leopardinus. 


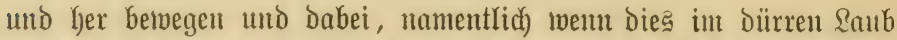

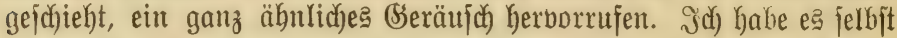
bei der brajilianijðen (5aninanha (Spilotes pullatus), bei ber Setten= natter (Coronella getula), ja jogar eimmal bei unjerer ïlfulap= ichlange beobachtet.

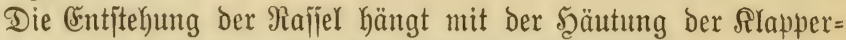
fit)lange eng zmjammen. Die Sdytwanzipitze diejer Sdylangen ift mit einem groß̌en, etras zujammengebrüctten Scornichild fuppenartig beDedt, weld)es eine tiefe ringförmige (Finjchnünung aufmeift. Bei ber

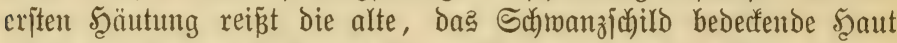
ab und bildet, am Sdhrwanze bängenbleibend, bas erjte flapperglieb; hei jeder folgenden Şäutung gejchieht başjelbe, indem das Sdhwanz= foctld inmer wieder ein nete Slapperglied erzeltgt, meldyes das vorkergehende, innerbalb defien ę entjtanden ijt, etwas nach Ginten

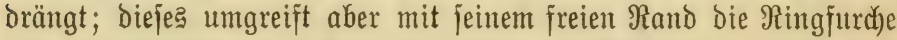
Des neugebildeten, jo Dá̧ ę mit diejem in Berbindung bleibt, uno jo entiteht mit der 3eit eine ganze Rette von Rajjelgliedern, die, wenn unverjehrt, Die 3ahl Der überjtandenen Şäutungen angeben würde.

Somohl die $\mathfrak{A m p h i b i e n ~ a l s ~ b i e ~ \Re e p t i l i e n ~ f i n d ~ b o r w i e g e n d ~ e i e r = ~}$ regend, boch gibt ę unter Den jekstlebenden Şauptgruppen beiber

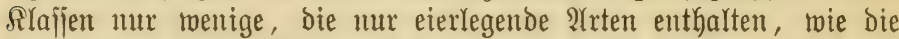
Rrofodile und Schildofröten. Die Eier der Amphibien find meift

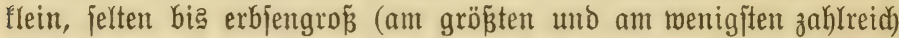
die der brutpflegenden mit Brutfäcfen) und bejizen eine glähelle, im

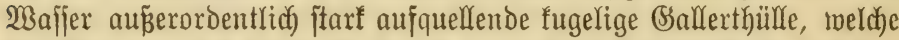
jotwohl gegen das (sintrocfnen als gegen viele Jeinde jodüht ınd ben ausfriechenden Sarben anfanģ zur Rafrung bient, vielleicht jogar wie ein Brennglas die Somnenftrablen auf bas (5i fonzentriert. Dic bedeutend Dotterreidjeren (Fier Der Reptilien find Dagegen ftete Durch eine zäke pergamentartige ober falfige Sabale auggezeichnet. Ralf= jobalig find z. B. Die Eier Der Rrofobile, Sdhildtröten, Sectonen und mancher (Slattedjen. Die Anzahl Der (5ior eines Beleges ift unter

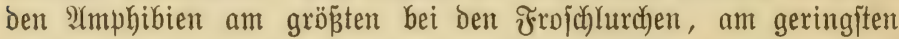

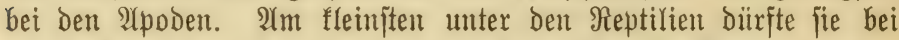
ben Biecfonen feil, die immer mur 2 sier ablegen, während anderer=

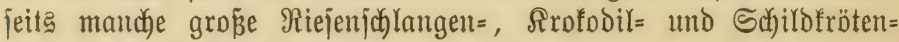
arten bis 100 Eier ablegen. 
(Ein eigentümlid)es Srgan, das als (5izahn bzw. (Eija)miele be-

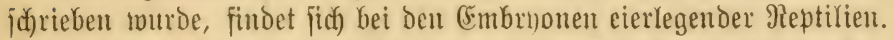

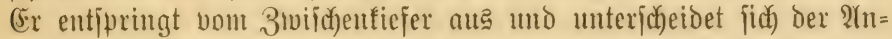

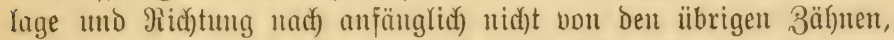

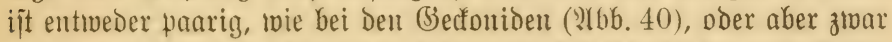
faarig angelegt, aber ber rech)te $3 a$ hn entwicfelt fich ftärfer und facheint, obwohl er immer im rechten 3mifa)enfiefer verbleibt, in der Mittel= linie gelegen zu jein; Der linfe (rizal)n bleibt flein mo ift nidat

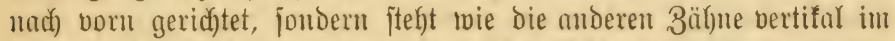
Siefer; bies ift bei mieren einheimificten (sajpen, wie bei ber 3aun= eided)je uno $\mathfrak{B l i n d}=$

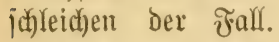
(Enolid) findet fide) bei ben Sd)langen und manthen (Eidedjfen, twie bem jabanifichen Calotes jubatus, ber (ङizahn unpaar genau in Der Mitte De? 3mijonentieferes ge= Yegen. Bei Schillo= fröten ııı Srof́p= bilen ift anjtatt be?
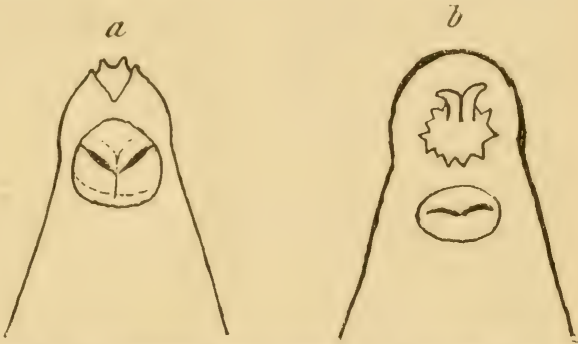

?(b), 39. Eijitniele non ('rocodilus niloticus (a) umi porosus (b), rahinter die ipaltörmiģen Vhajenöfïmugen. (b) nad) $\subseteq$ luiter.) (5izalne eine

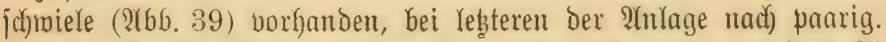

Der (Eizahn ift bas Jnjtrument, mit meld)em bie aus dem (5i

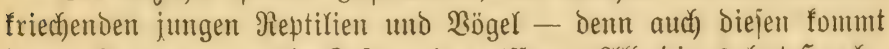

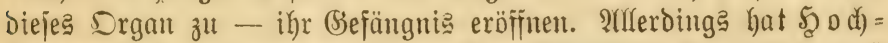
jtetter bei umperer europäifichen Sumpfichildofröte beobachtet, Da bie Jungen zuerit mit den firallen Dez redyten, Dann mit benen

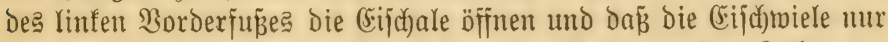

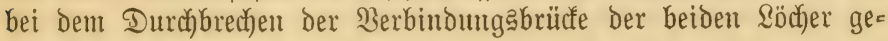
brautidyt miro.

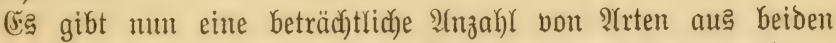
Slafjen, bie ifre Jutngen lebend sur Melt bringen, und jmar gehören bieje Yebendiggebärenden \{rten den verjaciedenjten Battungen mo Familien an; in allen F̈̈lfen bürften bie äuñeren Itmittünde, unter 
Denten bie Tiere leben, bie Urjadje des Rebenogebärens jein, obrobl unter anjdyeinend gleidyen $\mathfrak{B}$ erbältnifjen nicht jelten lebenogebärende und eierlegende Formen nebeneinander leben. Unter Den Ämphibien finto joldche, die entfernt bon Betwäfjern Yeben, in Denen fie ihre Sier ablegen fönnten, twie der jd)twarze AYlpenjalamander (Salamandra atra), ber hod) an Eichen in Rindenipalten haujende falifornifide Baumjalamander (Autodax lugubris), ber italienijache Şöblen= jalamander (Spelerpes fuscus), freilidy aber aud) der jeine Larben ins Wajjer ablegende fatwarzgelbe Freuerjalamander Yebenogebärent. Der (Brottenolm (Proteus) ift nach) mehrfacten Beobachtungen mit=

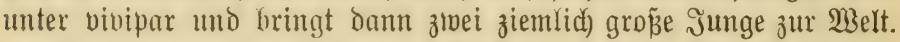
Auch ein lebendiggebärender Frojid $)=$

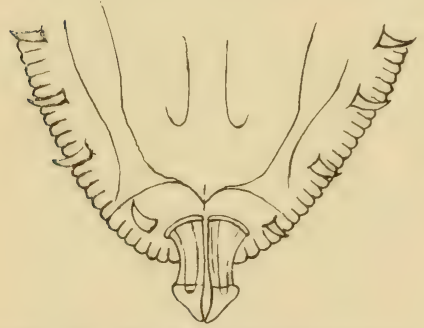

2(bo. 40). Eijabn won riecko rerticillatus. (Yact) $\Xi l$ uiter.) lurch), Pseudophryne vivipara, ift in jüngiter 3eit in Deutich) $=$ Ditafrifa gefunden und bon Iornier be= jurieben worden, jeither nod) weitere Durdid Rrefft.

Unter den Reptilien find e? vormiegent Şodjgebirgștiere, Denen bie Sommertemperatur ihrer Şei= mat nicht genügt, um bie (5ier jur Reife zu bringen $(z . \mathfrak{B}$. Die zen =

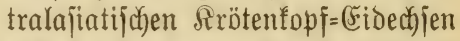
[Phrynocephalus]), won Denen bie Scod)gebirgarten Yebendgebäreno, bie aus tiefer gelegenten (bebieten eierlegent find); ferner aber aud) jolche, die von (Bebirgabetwohnern abjtammen, fid) aber niber niebriger gelegene Bjebiete verbreitet Kaben (mie vermutlich) die afrifanija)en (c)langenähnlidyen Chamaesaura=?(rten), ebenfo joldhe, bie in ben nörblicheren Ieilen ber (Frbe ihren Uriprung genommen haben, Deren

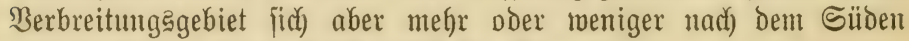
ausgedehnt hat (jo mahricheinlich bie $\mathfrak{B} i p e r n$ ).

Bei manden tropijdyen Reptilien ijt ber 3ujammenkang zwijd)en

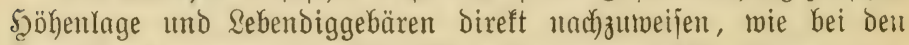
(5hamäleons namentlic) Sifafrifas (von denten Ch. bitaeniatus, jacksoni, fuelleborni, werneri uno andere im Berglano bzrw. Şod $)=$ gebirge Yebende ?(rten vivipar jind); die ed)t jübafrifanija)en (5.hamäleons aแ๖ der Bertombtichaft des ('hamaeleon pumilus 
Dagegen jind lebenogebärend, ohne immer B̧ebirgabemohner zu jein.

Sebenogebärend find auch fajt alle Dttern ber Alten und ?euen Wert, viele (Siftnattern (ङrapiden), ausnahmalos ifre im Meere Yeben=

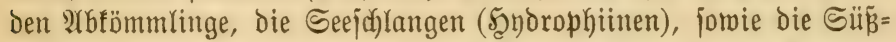

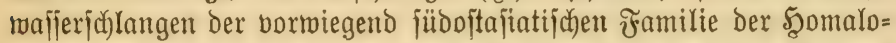

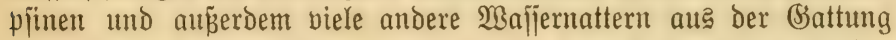

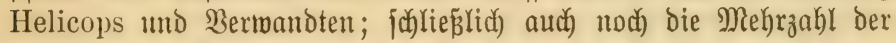

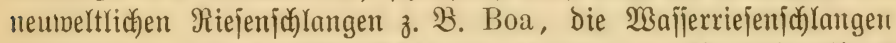
(Eunectes), Die Szundafopfifid)langen (Corallus) und Schlantboą (Epicrates). \$3ou Boa uno Corallus find aud) bie madagajiifiden 2(rten vivipar. Bei Den Seeja)langen uno Scomalopjinen ift dię von

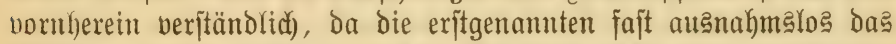
Wajijer niemale verlafien, daker ifhre (rier nidgt ablegen fömnten, was aud für bie nahez̆ rein wajןerbetwohnenden Scomalopjiden gilt. 2quß̄er biejer in ganzen Battungen und Familien auftretenden Biviparität treffen mir einzelne Yebendgebärende $\mathfrak{A}$ rten unter eier= Yegenden, unter Den fleinen Baumleguanen der Battung Anolis (z. B. cristatellus), eine einzige in ber Battung Lacerta (bie be= fannte Bergeidedjje, L. vivipara); ferner bei den (Shamäleone (jiehe oben), bei nordamerifanijajen Tropidonotus=2(rten, Den grünen Baumidilangen Sübojtajien (Dryophis mycterizans); andererjeits fommen in Familien mit vorrwiegento lebentogebärenden $\mathfrak{A}$ rten einzelne

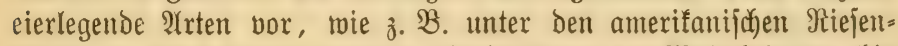
joblangen, bie fajt ausnaf)mslos lebende Junge zur $\mathfrak{B e l t}$ bringen, bis auf Epicrates cenchris, eine im nörblichen S̈̈bamerifa vorfommende

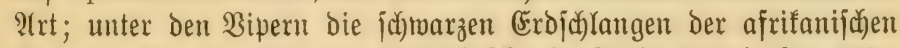
(Sattung Atractaspis, bie norbindijithe Lachesis monticola, unter Den (Sitattedfjen (Scinciden) bie afrifanifanen $\mathfrak{2}$ rten Mabuia quinquetaeniata uno occidentalis; außnabmatweije find jogar in mandjen Sändern andertwärts vivipare $\mathfrak{A}$ rten eierlegend, wie anjafeinend ber befannte Chalcides ocellatus in 2 Igypten, und mitunter fommt $e^{\zeta}$

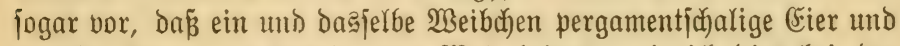
lebende Junge gleichzeitig zur Welt bringt, wie idf bies bei ber fubanifajen S(f)lanfboa, Epicrates angulifer, beobachten fonnte.

Im allgemeinen erfolgt nidyt nur bei den eierlegenden, fondern

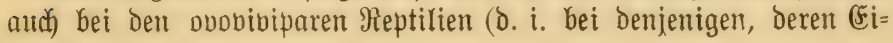


fachaten bünnbäutig find, bei ber ablage fadjon ein bollfommen ent= widelelte Junges enthalten, Dą entweder nod) ehe bas (5i abgelegt ijt

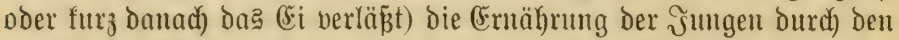
im (5i befinoricken Dotter. Der Dotterjact wiro mit zumehmender

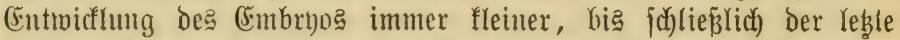
Rejt Durde) eime Spalte an der Bauthjeite (an ber Stelle, wo ber Dotterjact mit Dem Rörper be马 Tieres zujamment)ängt und bie er=

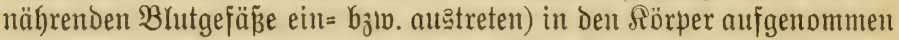

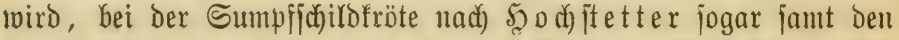

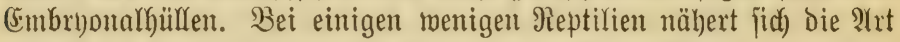

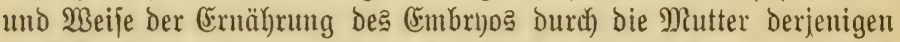
wirflich lebenogebärender Iiere; und zwar wirb bei ben aujtrafij(j)en Riejenffinfen Tiliqua und Trachysaurus ähnlid) wie bei dem (Slatthai Dę Arrijtoteles (Mustelus laevis) Durd) eine jogenannte Dotterjact= placenta bie crnährung bemerfitelligt, indem der Dotterjact des (5m= bryos burch jeine Blutgefäß̧e mit der Wand des miitterlidjen, zu einem Fruchtbehälter (Uterua) ertweiterten (sileiter in innige Berbindung

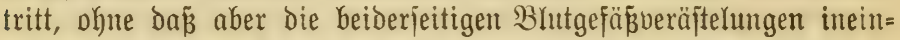
ander übergehen. Bei ber Battung Chalcides bagegen, foweit jie rebendiggebärende $\mathfrak{2}$ (rten entfält (aljo vor allem Ch. tridactylus) ijt eine edy)te Irlfantoigplacenta borfanden. Die arlantoia, ein mur

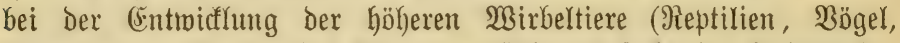
Säugetiere) borfommendes Drgan, entifteht ale fact= oder blajenartige 2(usftülpung auf ber Bauchjeite bes (smbrnos hinter Dem Dotterjacf, breitet jid) inmerhalb ber (eifaut immer weiter aus, bia jie aud ben (5mbruo felbfit vorn und hinten ummäd)it. Shne uns weiter in bie Erörterung Der Rolle biejes Drgans in Der Entwicflungägefofichte einzulaffen, wollen mir uns mit dem Şinmeife begüigen, dẫ bei Chalcides bie r(nantois burch) ein reid) entricfeltes (Siefäprnebs eben= jo mit ber Hterustonono in enge Beziełnng tritt, wie bię bei ber ßlacenta Der Säugetiere Der Frall ift.

In ber Regel johlïpfen Die Jiungen im Jahre Der (Fiablage, oder genauer gejagt, nodi imerhalb berjelben $\mathfrak{B}$ egetationaperiode aus,

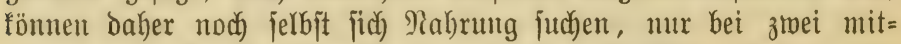

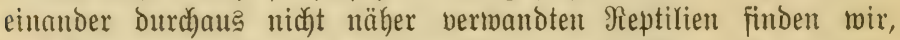
daß bie ipät int Seerbit bereiţ volfitänoig entwicfelten sumgen ent=

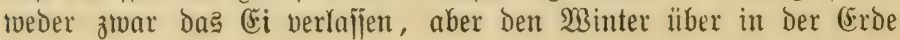




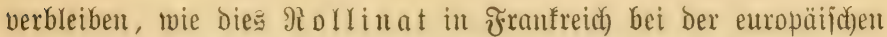
Sumpfichilofröte Genbad)tete, ober aber überhaupt in (5i ̈̈bermintern; bies ift ale normal jomohl für bicje Siffildoföte ala für bie neu= jeeländijcke Iuntera oder Brïcfened je (Sphenodon punctatus) ge=

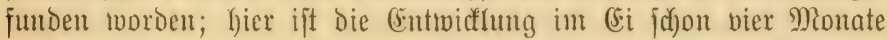

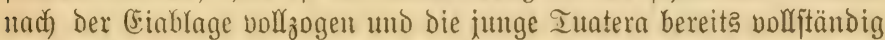

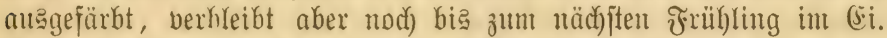
Dieje (5rja)einung ift in beiben ₹ällen are Sofalampajinng an be= jonbere flintatijche Berlyältuitje zu Deuten.

Bäbrend von Fijd)en, namentlid) aus der Rarpfen= แnd Iad) familie zablreidse freilebende Bajtardformen befannt jund, ijt Baftardienung bei Den Smphibien im Freileben jelten, bei Reptilien fanm jemals mit Sid)erbeit beobar)tet morben. Der befanntefte freilebende PImphibienbajtard ift Molge blasii, ein in Der Pormandie neben feinen Stammeltern, Dem Ramm= mo Darmorntold), vorfommender, von Drendeuf De I' J̧ Peracca und fpäter $\mathfrak{B}$ orterstorff l̈berzengend nachgetwiejen

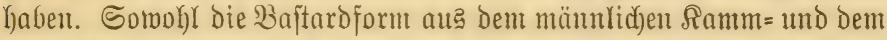
weiblidyen Darmormold), wie aud bie aţ umgefehrter freuzung Gervorgegangene twurde bon ifm gezüd)tet und ber Jiad) weis der

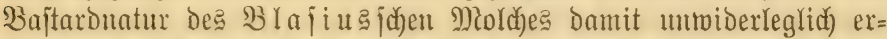

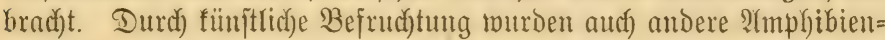

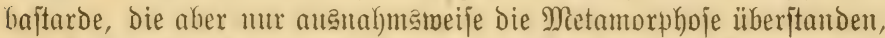

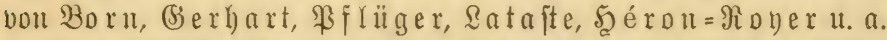
erzielt; mögliç) ijt $e$, da (Bombinator igneus und pachypus) an den Brenzen ihree $\mathfrak{B e r}=$

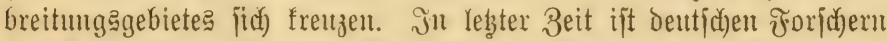
die frenzung verj(d)iebener Mold)arten volntommen geglïit.

Bon freilebenden Reptilbajtarben fenten wir mit Sidjerkeit

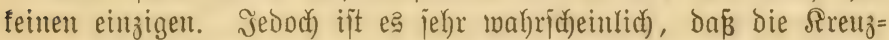
otter und die Sandotter, tov jie nebeneinander vorfommen, gelegent= lidf fich und zmar frudthar freuzen, আn dieje Sreuzungprodufte jind von Vipera aspis, bie in jeder Beziehung zmifhen beiden Mrten die Mitte bält, faum ju unterjacheiden. Soldye Bajtarde fund in Rärnten (Jriejach), in Bosnien (Sola Jahorina) und in Der Tïrfei (Ronjtantinopel) jebesmal in einem einzigen (5xentlar gefunden worben. Die angeblichen Baptarbe von Piiejenichlangen (Epicrates 
striatus mit inornatus), bie im Sondoner 3oologijatyen (Sarten zur

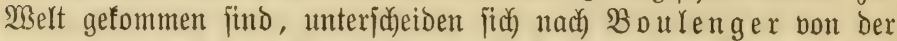

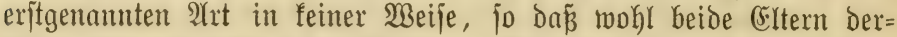

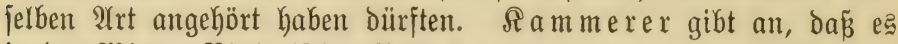

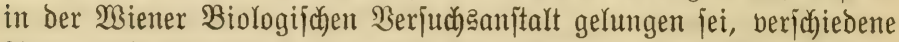
Irrtel und Barietäten von (Eidechjen (Lacerta) zur fireuzung zu bringen, was um fo bemerfenamerter ift, als im Freien Lacerta= Bajtarde niemals gefunden worben fein bürften.

Fine Bermefrungarart, bie in Der niederen Tiermelt eine groß̧e Rolle jpielt, bei den Wirbeltieren mur mehr als Erjabs verloren ge= gangener Rörperteile auftritt, ift bie Regeneration. Sein Mirbel= tier ift mehr imitande, als einem abgetremten Ieir Des förpers ein nelte Tier zu erzengen, wie bię bei einzelligen Tierell, ferner bei \$olnpen unঠ S(f)rämmen, $\mathfrak{B u ̈ r m e r n , ~ S e e j t e r n e n ~ u j w . ~ v o r f o m m t ; ~}$

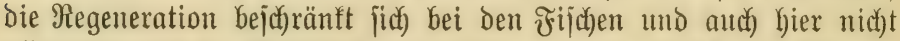
allgemein auf bie Fühigfeit, verloren gegangene Stü̈fe ber 尺örper= haut uno ber frlofien zu erjeken.

(5röperer ift die Regenterationafähigfeit bei den 2(mphibien, too

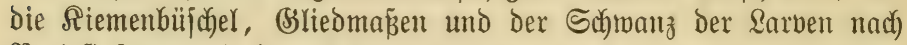
Berlujt jogar mit bem 2ldjenfifelett erjekst merben fönnen; auf biejem hohen Brabe erbält jie fich aud noch im vermandelten Buftande bei

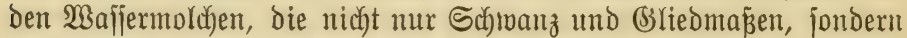
aud) Unterfiefer und $\mathfrak{A}$ ugenlinje neu zu bilden vermögen; geringer ift bie Regenerationääbigfeit bei ben ungeja)mänzten ?tmphibien entwicfelt, too im erwackfenen 3ujtande feine Regeneration mehr ftattfindet; $\Re a m m e r e r$ hat nad) den (Ergebnifjen feiner (Experi=

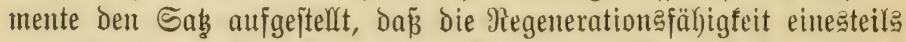

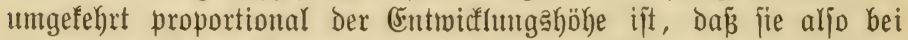

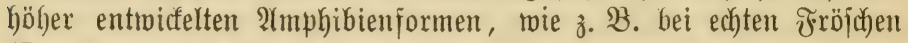
(Rana) geringer ift als bei nieberen (Discoglossus, Pelobates) uno dấ fie um jo geringer ijt, ie meiter bie Rarvenentwieflumg vor=

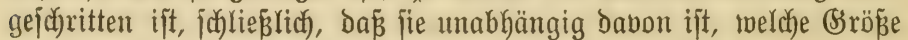
bie $\mathfrak{A}$ rten im erwadjenen 3ujtand erreicfen.

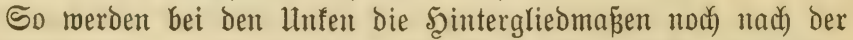
Berwandhng regeneriert, wenn bie 2(mputation noch an Rarben vorgenommen wurde, bie eben vor der Berwandlung ftanden; bei

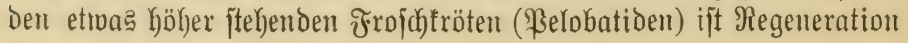


Der Scinterbeine żwar twährent Der ganzen Metamorphoje, aber nidj)t

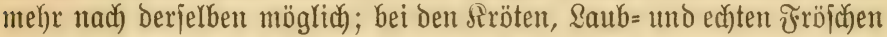
(Rana) Dagegen tritt Regeneration aud bei Sarben mur jo lange ein, als Sher = und Unterid)enfel nod) einen ftumpfen Binfel bildon.

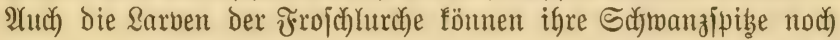
regenerieren, aber in ber Regel nur, jolange bie Borbergliebmañen noch) nidht burdjgebrod)en jind; neotenija)e (zmei= bis mehriommerige) Sarben regenerieren ihren Ruberfatwanz ebenjo wie normale, bie Scinterbeine jedod in einem Stadium nidat mehr, in weldyem bei normalen bie Regeneration nod) eintritt.

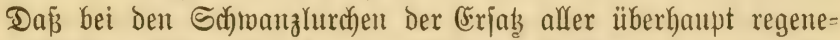
rationsfähigen Rörperteile bei ausgebildetem 3ujtande langjamer vor fich) geht als bei Sarven, ift nach Dem $\mathfrak{B}$ orhergejagten ju erwarten;

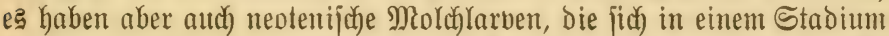
befinden, in bem normale Sarven nod) fegr rajd) regenerieren, nidat bie Regenerationggejdymindigfeit biejer, jondern von verwandelten Iieren gleidjen 2(lters.

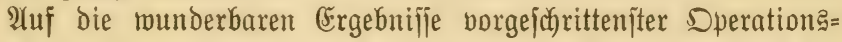
tedunif, bie, auggefend von ber Regeneration ber 2 ugenlinje bei Fröithen und MRoldien, in Den fompliziertejten Berpflanzungen der Simje und Behörblaje an entipredbende Stellen anderer Tiere derjelben 2Yrt oder jogar verjodiedener 2Amphibienoronungen, Bertaujachung ber beiderjeitigen Drgane derjelben $\mathfrak{A r t}$ und bon $\mathfrak{A}$ ttgen = und Dhrblajen gipfeln (Sewis, Spemann), joll hier nidht näher eingegangen weroen,

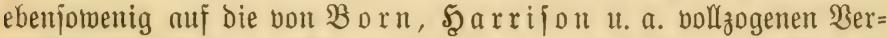
wad)jungaverjuche von Raulquappen, wobei zmei Iiere mit Borber=

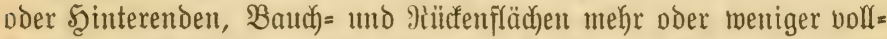
fommen zur Bereinigung gebracht twerden fonnten; in Scempel m a n lehrreidjem Büd)lein "Der Frojd" findet Der Sejer barïber bas Widytigite auf S. 154-162 zujammengeitellt. Bon den vielfact)en geglüctten (Experimenten von Iornier, ber burd) beftimmt geridytete

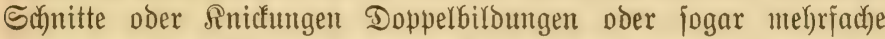

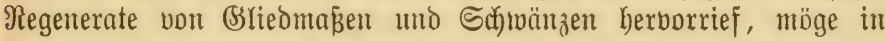

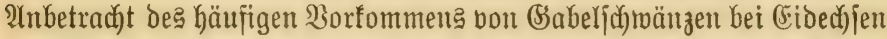

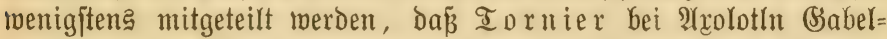

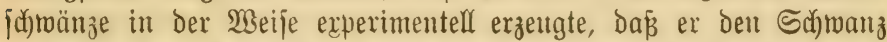

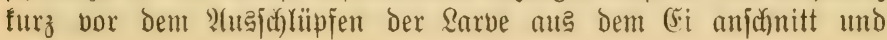




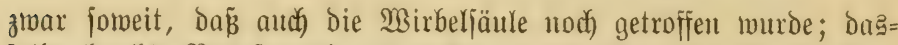
felbe brad)te Barfurth am Sdymanz Der Sarve Des (Srasfrojches

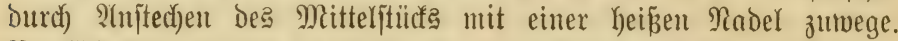

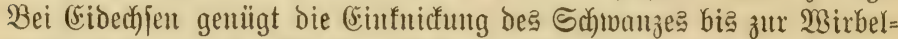

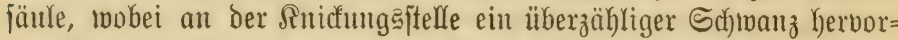
fpropst, ein in Freiłeben gar nidd)t jelten eintretender Fall; auf bie=

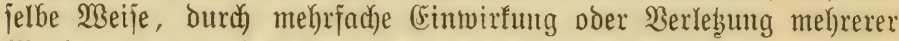

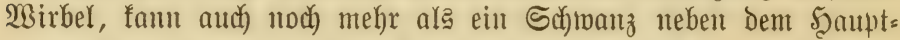
j(f)wanz fproffen ober bei Berluft des urjprünglichen Schwanzes von der Brucbjtelle ein ganzes Bündel Schwanzregenerate entipringen (j. BD. I 2(bb. 29). Doppelgliedmaßen bei $2(m p h i b i e n$ wurben in ber $23 e i j e$

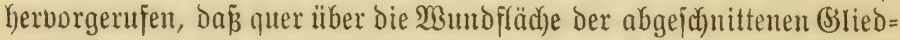
mazen ein Faben gejpannt wurbe; an biejer bedecften Stelle wiro

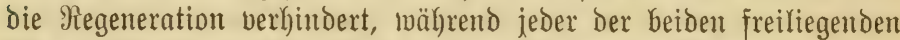
Wumbabjannitte unabyängig vom andern bie ganze (extremität jut re= generieren ftrebt; audf) andere bom jelben Berfaffer angegebene Me= thoden führen zu demjelben 3iele, ebento gibt er audd an, in weldyer Beife man beim Rammoldh, einem zu foldchen Berjuct)en wegen jeiner gerabezı unglaublicken Regenerationafraft bejonders geeigneten Iier, überzählige Beken erzettgen fant.

Si a merer bat Berjuche ïber die Pegeneration der fogenannten

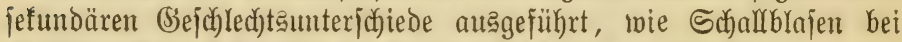

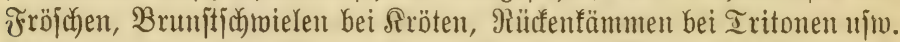

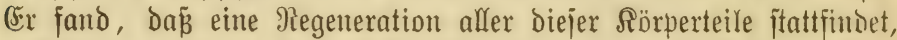
und zwar entweder in berjelben Form oder unter bejtimmten 1 m= ftäuden entweder provijorija) doer bauterno von unbolffommener

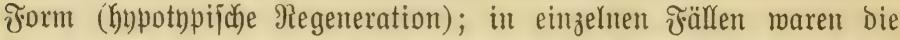
Megenerate vollfommener ale die urjprïnglichen Drgane (hypertupif(h)); babei werden mitunter Stadien wieberholt, Die in ber Ent=

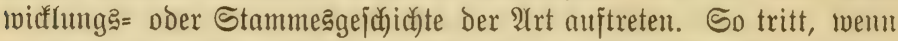
man bie den gelben Rürfenmitteliftreifen De马 weiblidfen Rammold)e马 tragende Şautffelle abpräpariert, Derielbe bei Der Regenteration inten= jiv hervor (rwie bei Den Jungen). (Ebenjo entipricht dą FehYen ber

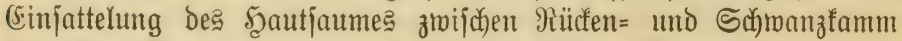
bei Den Rammregeneraten be马 männlichen Rammoldyes einem frïheren Stadium der Stammesentwicflung bieję Moldjes; Der

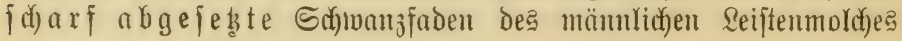




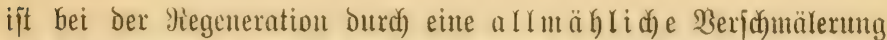

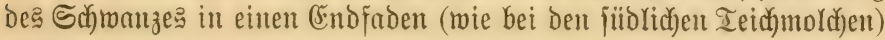
erjebt.

Bei Den Reptilien finden wir, wie f(d)on früh)er (BZb. I, S. 66 here

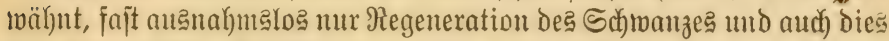

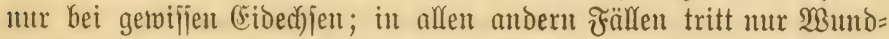
heilung auf, teilweije allerbings in jehr auıgedef)ntem Maßje, wie namentlich) bei S(f)ildofröten zu beobachten ift, bei benen großße Stücfe

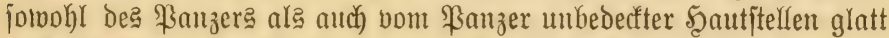
werbeilen; auf den Narben treten bäufig nad) einiger Beit wieder

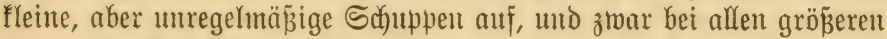

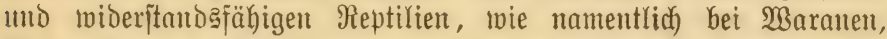

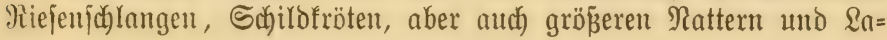
certen. -

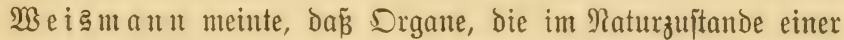

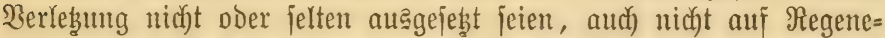

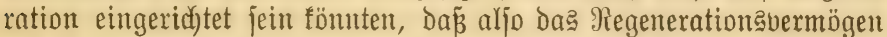
auf 2Ynpajiung an Berletzbarfeit ber betreffenden Ieile beruhe, und

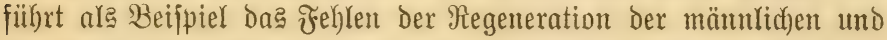
weiblicken Reitunggorgane forwie Der Rungen bei Triton an. Muftić fand aber bei beridyiedenen 2 mphibien, ant jownädjiten allerbings bei Triton, Die sunge regenterationäfähig.

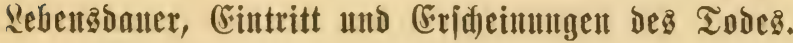

(5es ift überrajachend, zu beobachten, in wie weiten Bsrenzen bie

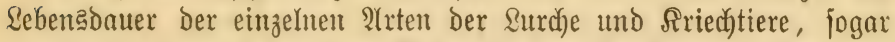
innerbalb ein und derfelben Battung fobwanfen fann. Man fan

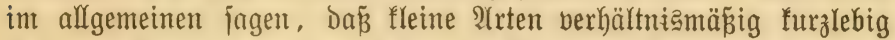
find, im Berlaufe wentiger Jahre ihr $\mathfrak{B a d}$ gatum beendet haben und imjtande find, jich) fortzupflanzen, dẩ aber andererjeits großje

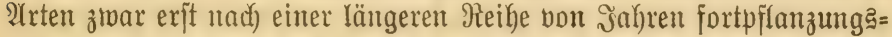
fähig werden, aber Dod) noch) bis an ihr Rebensende weiterwadjfen

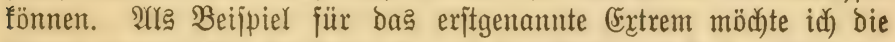

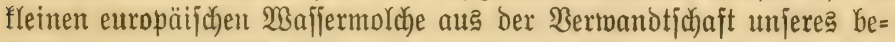
fanten Ieiddmold)es (Molge vulgaris), bie fleinen Steppenlacerten 
Beftafien (Lacerta parva, Ophiops elegans) anführen, bie im äuß̌erften Falle zmei Jahre nadbem fie das Ci verlajfen Kaben, wölfig erwachjen und fortpflanzungesähig find; andererjeite bie

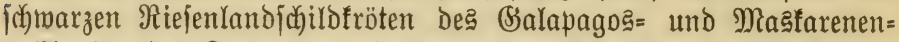

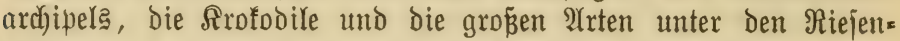

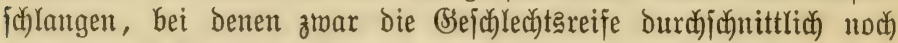
vor cinde dę zweiten Dezenniums eintritt, eine Alteragrenze hin= gegen gar nidjt fejtzuleben ift, auch ein 3ujtand, ber mit 2ylters= faftwäche zu bergleidyen wäre, im Freileben faum je beobachtet

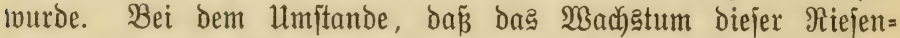
reptilien unjerer heutigen 3eit zwar in ben erjten Jahren jehr rajic) bor fich geht, twie an gefangengehaltenen Riejenjichlangen

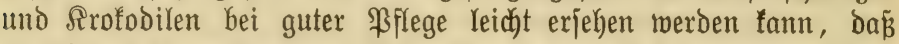

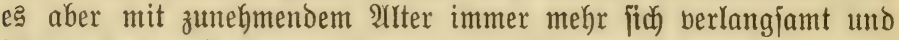

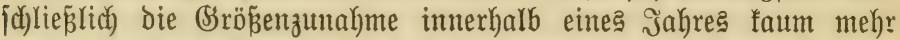

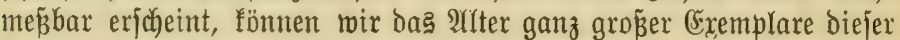
Reptilien auth bann, wenn feine genaueren IYngaben borliegen (nur

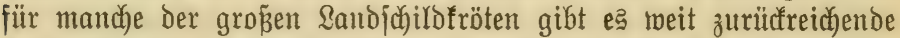

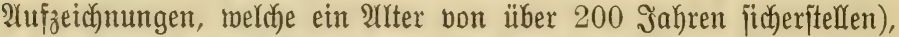
auf mehrere humbert Jahre veranjahlagen. Crocodilus porosus, baz Reijtenfrofodil der indopazifijachen Rüjtenländer und Injeln, foll biß $10 \mathrm{~m}$ erreichen; biejelbe Sänge wiro audh für dą madagafijiche Riejenfrotodil (Crocodilus robustus), wahridjeinlidi eine furzichnauzige

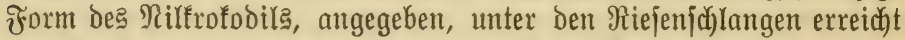
die 2̂nafonda (Eunectes murinus) jicherlid gegen $10 \mathrm{~m}$ und fajt ebenjoviel die beiden jüboftajiatijenen \$nthonjalangen (P. bivittatus und reticulatus), dagegegen $\mathrm{P}$. Sebae, die afrifanij(d) Sziero= gluphenjulange jelten mehr als $5 \mathrm{~m}$, während unter ben übrigen

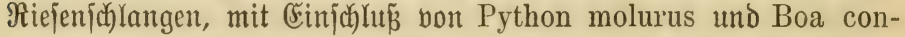
strictor, nur relatib wenige über $4 \mathrm{~m}$ lang werden, eine \&änge,

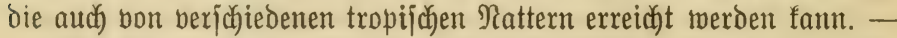

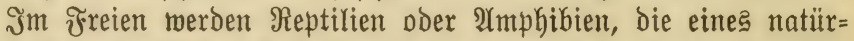
licken Iodes geftorben find, fo gut wie niemale angetroffen, zweifel=

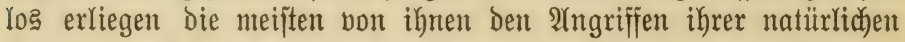
Feinde, und bie wenigen Exemplare, bie biejen entgehen, jobeinen im Berborgenen ihren $\mathfrak{I} D d$ zu erwarten. Daker find Die Borboten

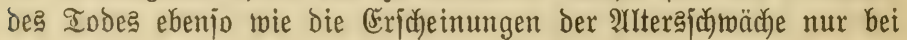




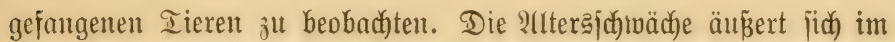

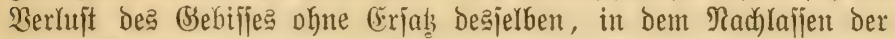

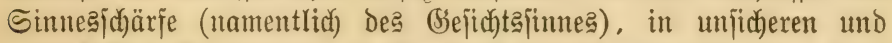
ungejdifften Bemegungen (z. B. Gäufigem Danebenja)nappen beim Frefien), bei Meptilien vielfad in auffallendem 2lbfteben ber Sahuppen,

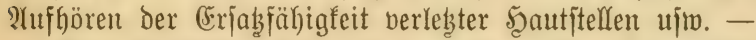

Dem Cintritt des Iodes, wenn er nidjt auf gemaltjamem Wege

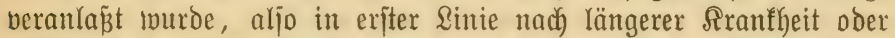
infolge hartnäcfiger Nahrungsverweigerung, gehen beridjiedente $\mathfrak{P n}=$

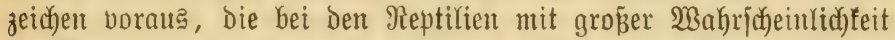
die Boratsjage des creignifję gejtatten. So verlaffen Baumbetwohuer das Bezlmeig, um auf Den Boden herabzutommen, ebenjo fommen grabende, im Boden eingetwilglte Iiere auts biejem herbor; bie farben= medhjelnden (Fided)jen erhalten eine auffallen helle Färbung; Sajlangen, bie fich lange Beit fehr rufig verhalten haben, Durdhandern in ber Racht vor ihrem Iode bäufig rubelos igren Räfig; Dieje Untuhe

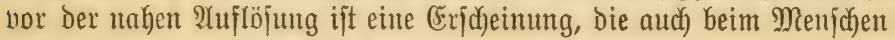
nicht jelten zlt beobachten ift.

Uuf bie darafteriftijaten Stellungen, die bon unjeren Tieren Gäufig im Iode angenommen werden, will id nidjt näher ein= gehen; bemerft möge nur werden, daß̧ fie ber natürlidjen Schlaf= ftellung um fo näher fommen, je ruhiger ber Iod eingetreten ift.

\section{S(d)lüronert.}

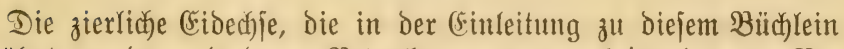
ermähnt murbe und beren Betradytung uns nacheinander zur $\mathfrak{B} e=$ fpredfung Der Sdjuţfärbung, Der Scaut ıno der inneren Drgane Der Bermefrumgas und Todęarten geführt hat, mag nod) immer im (Braje liegen und jich fonnen, wenn ber Sejer jeine Reftüre be= endet und bas Bud zugej(c)lagen hat. Und nun fönnen wir une

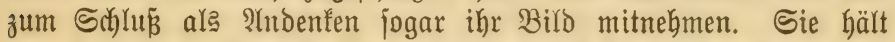

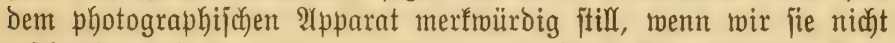
eriunreffen und beunruhigen. Sogar bie flinfe Mauereidedje fann in voller Freiheit auf bie \$rlatte gebannt meroen. Wer als Freund Der Reptilien = und IImphibienwelt unjerer Şeimat gleidzeitig über 
cinten geeigneten Appatat berfügt, wiro in ber Samterajago eine

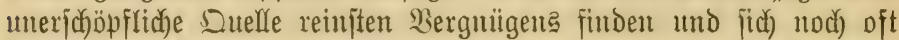
Dakeim im Minter in ber Erinnerung an bie gelungenen 2 ufnahmen ergöben, einer (5rimmerung, bie burd) den Umitand, daßj fich dą Iierdyen vermutlich nod jeiner Freiheit erfreut, natürlid) nod erhöht

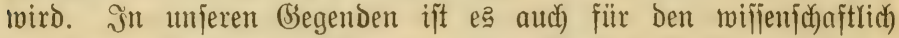
arbeitenden 3oologen nid)t mehr nötig, für bą Borfommen jedcr

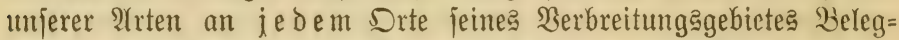
exemplare zu jammeln; bie \$hotographie, am natürlid)en Standorte aufgentommen, wirb in viełen Fällen jogar wiffenifhaftlich) mertwoller

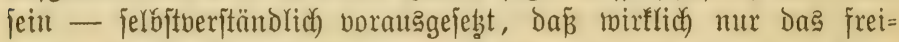

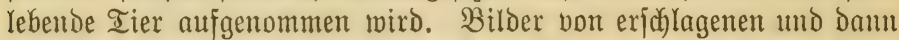
ins Freie gelegten Tieren haben feinen, Bilder von fold)en, die aus Dem Ierrarium in Freie mitgenommen uno in einer aus= getwäblten Stellumg photographiert wurben, nur einen jefr he= bingten $\mathfrak{B}$ ert. Mëge aud niemanto glauben, Daß̃ man do

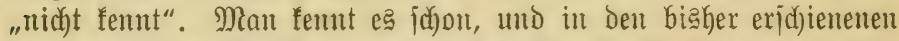
photographifichen 2rbbildungen von Reptilien (子. B. Ditmar bie photographierten Sd)langenleichen trobs affer gutgemeinten $2(n=$ orbmung jtets fofort auffälfig, die "geftellten" aber immerfin nod) in viełen Fällen.

Mögen bie Freunde unjerer beiden Gier heljandelten Iierflaffen, Deren Deutiche Bertreter bieher in fo vielen Taujenden von Exem= plaren im Ierrarium dem Beobachtungatriebe zum Dyfer gefallen

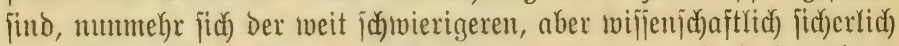
mertwolleren Beobad)tung im Freileben wiomen uno dabei ihnen interejiant erjacheinende Borfommuifie auf photographifdem Bege fejtbalten! 


\section{Riteraturuadi)weiz.}

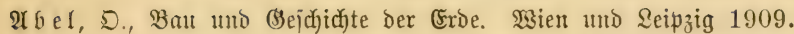
Зе๖ऽ

Nature LXVIII (1903) 497.

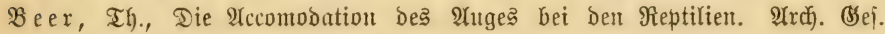

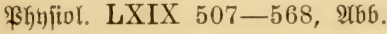

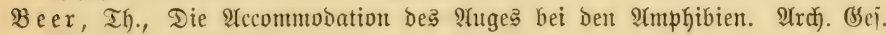

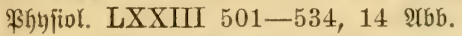

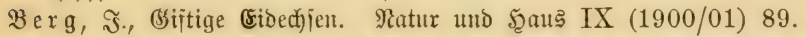

Bo〔a

6. Unjere Efefantenjuhilotröten. 3ool. Barten XXXVII (1896) 353-357.

$\mathfrak{B}$ ou $\mathfrak{l}_{\text {euger , (S. }}$., Les Batraciens (Encyclopédie Scientifique, Paris 1910).

3̧oulengex, (3. 2 ., Further Notes on the African Batrachians Trichobatrachus and Gampsosteonyx. Proc. Zool. Soc. London 1901, II 709.

$\mathfrak{B}$ runer, $\mathfrak{5}$. $\mathfrak{Q}$., On the cephalic veins and sinuses of reptiles, with description of a mechanism for raising the venous blood-pressure in the head. Amer. Journ. Anat. Baltimore XII (1907) 1-117, 3 Tafeln.

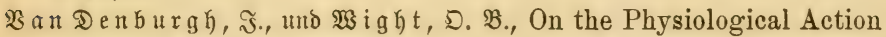
of the Poisonous Secretion of the Gila Monster (Heloderma suspectum). Amer. Journ. Physiol. IV (1900) 209-238.

Dollo, \&., L'audition chez les Ichthyosauriens. Bull. Soc. Géol. Bruxelles XXI (1907) 157-163, 2xbb.

Durfam, Edith, Notes on the mode of feeding of the egg eating Snake (Dasypeltis scabra). Proc. Zool. Soc. London 1896, 715, Iajel XXXII.

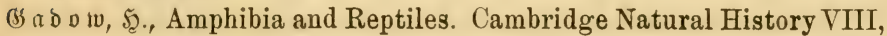
Sontoon 1901.

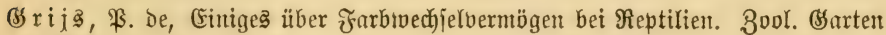
XL $49-58$.

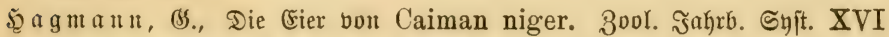
(1902) 405-410, Tafel XIX, XX.

Szempermann, F., Der Froid. Leipzig 1908.

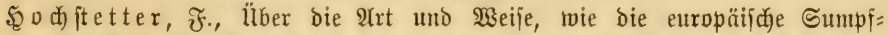
fafildofröte ifre (Fier ablegt und wie bie sungen biefes Tieres bas (Fi ber=

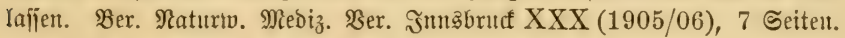
Mas. A 16 merner II. 


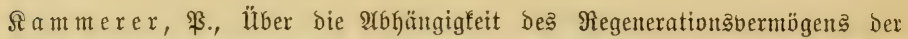

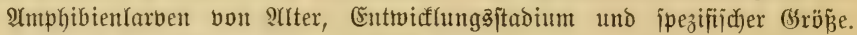
Ýchio f. Enttvidflungsmechanif XIX (1905) 148-180, Infel VII.

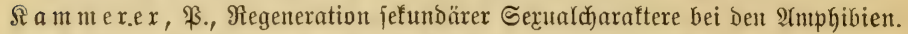
Irchio f. Cintwidflungsmect)anif XXV (1907) 82-124.

Iathariner, über ben Berbaungäanal und bie W̧irbelzähne von Dasy-

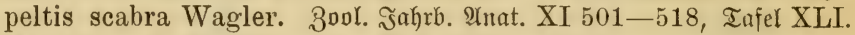
Rathariner, L., Die Raje ber im Waafjer lebenden Sdylangen als \&uftweg und (Berud)songan. 3oor. Sahrb. Syft. XIII 415-442, 2tbb., Iafel XXVII uก๖ XXVIII.

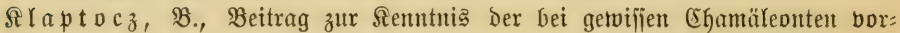
fonmenden 2̂djeltajchen. Bool. Sahrb. 2Anat. XXIII (1906) 187-206.

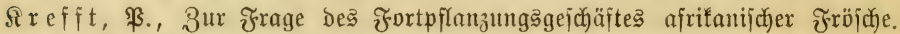
BI. IYq. Terr. Sunde XXI (1910) 463.

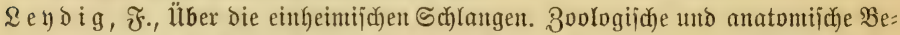
merfungen. 21bł. Senffenbg. (Sei., Franffurt $\mathfrak{a}$. M. 1883, 1-54, Iafel I-II. $\mathfrak{M a g} \mathfrak{n} \mathfrak{n}, \mathfrak{A}$., Extraction des pigments chez les Batraciens. Comptes rendus Ac. Sc. CXLIV (1907) 1068.

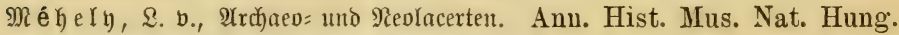
Budapest $\nabla$ (1907) 469-493, Iafel X.

Menex, $\mathfrak{A}$. $\mathfrak{B}$., über Den (Siftapparat ber Sdjlangen, insbejondere ïber ben

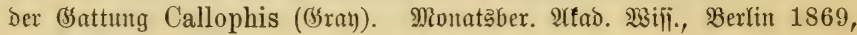
28 Seiten, 2 Iafeln.

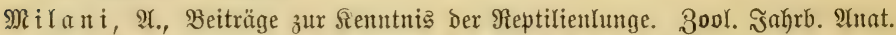
VII (1894) 445-592, 18 abb., Iafel XXX-XXXII.

Mopdie, R. \&., The lateral line system in extinct Amphibia. Journ. Morphol. XIX (1908) 511.

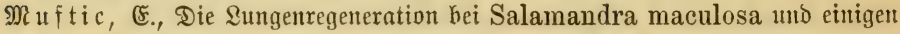

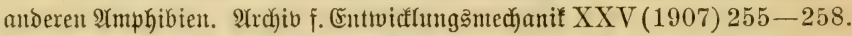
$\mathfrak{N} u \mathfrak{B} \mathfrak{b} \mathfrak{a} \mathfrak{m}, \mathfrak{J} ., \quad$ Fin $\mathfrak{F} a \mathfrak{l l}$ von $\mathfrak{B i b i p a r i t a ̈ t}$ beim Proteus anguineus. Biolog. Centralblatt XXVII (1907) 370-375.

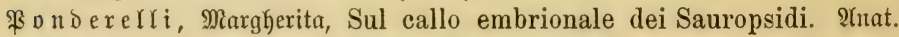

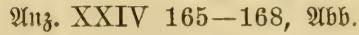

ฐొuef d), The Boa Constrictors of British Guiana. Ann. Mag. Nat. Hist. (7) I (1898) 296-308.

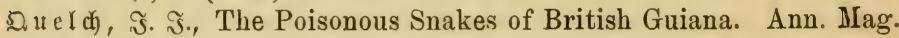
Nat. Hist. (7) III (1899) 402-409.

$\Re$ olri nat, $\Re$., Sur l'accouplement automnal de la Cistude de l'Europe.

Bull. Soc. France XXIV 103-106.

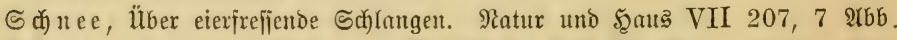

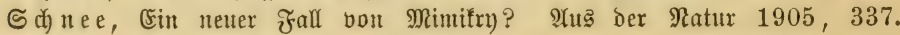


Siebenrodf, F., über den Siehlfopf und bie \&uftröhre ber Schildoföten.

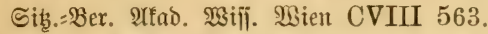

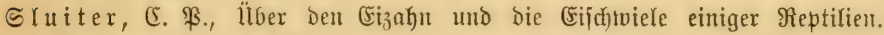
Morpholog. Jahrb. XX (1893) 75-89, aafel VI.

Sterufeld, R., Mimicry bei afrifanijden Schlangen. Sib̨:=Ber. Bei.

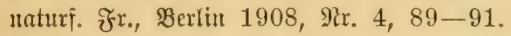

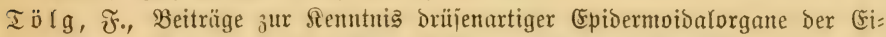
Dechien. 2trb. 3ool. Init. Mien XVI 1-36, Iajel I-III.

Iornier, (Ss., Sdntwanzregeneration uno Doppelidntwänze bei Eibechjen. Sib̆.=Ber. Bej. naturi. Fr., Berlin 1897, 59-64.

Iornier, (\$s., l̈ber experimentell erzeugte oreijchroünzige (Eidechjen und Dopper=

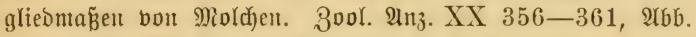

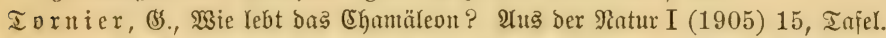

Iornier, Bs., Pseudophryne vivipara n. sp., ein lebendig gebärender

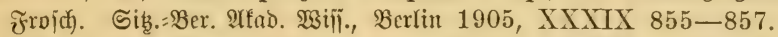

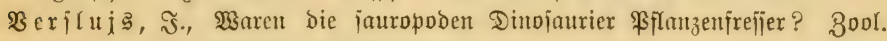
ฐałrb. Syjt. XXIX (1910) $425-450$.

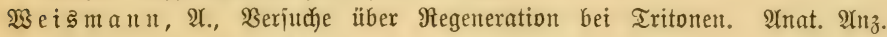
XXII $425-431,2 \mathfrak{2} 6$ b.

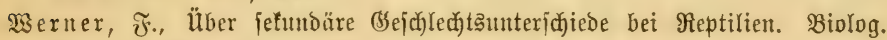
Centralbr. XV (1895) 125-140.

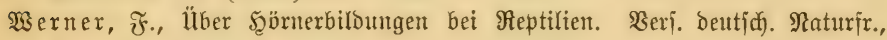
Meran 1905, 202-204.

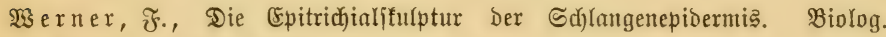
Centralbl. XII (1892) 277.

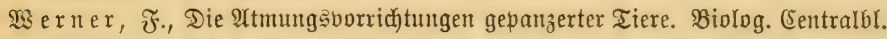
XIII (1893) 83.

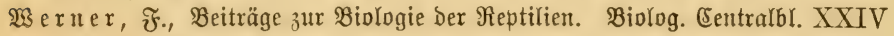
(1904) 322.

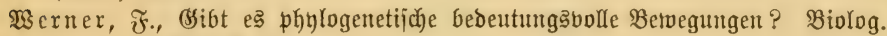
Eentralbl. XXIX (1909) 318-328.

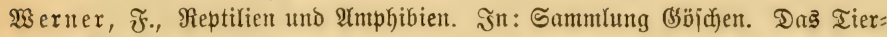
reid) III (1908) গr. 383.

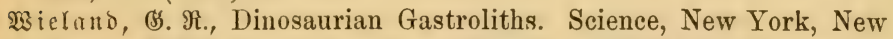

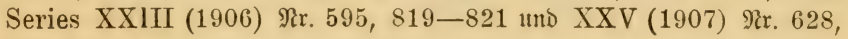
$66-67$.

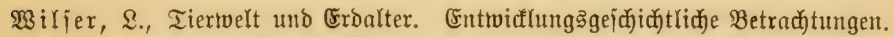
Stuttgart 1909 (Strecfer \& Schröber).

פisorteratorff, M., über Triton blasii de l'Isle uno den experimentellen

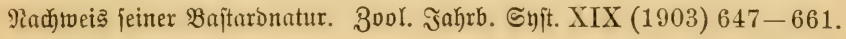




\section{Megiiter.}

Ablepharus 26

Irccommobation 28

Aelurodactylus 27

IrIantois 72

அnariäde 53

21ugenliber 25

2rtemberegungen 52

Autodax 69

Basiliseus 60

Baftarbe 73

Bombinator 73

Callophis 10

Causus 41

Centropyx 62

Ceratophora 59

Chamaeleon 5, 59, 70

Chioglossa 39

Chromatophoren 14

Cinosternum 62

Cnemidophorus 62

Coluber 7

Corium 13

Coronella 66

Eutis 13

Crocodilus, (5ijdymiele 69

- Rebenşbauer 78

Cylindrophis 10

Dasypeltis 42

Dibamus 62

Doliophis 41

Dotteriact 71

Dryophis $3,6,10,24$

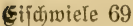

Eizahn 69

Elachistodon 42

Elaps 8

Epicrates 73

Epidermis 12

Eremias 25

Erythrolamprus 10

Eumeces 5, 7

Eunectes 78

Garbenwedjel 4

Jemoralorilfen 15
Gaftrolithen 44

Saaumenjegel 54

Gecko 29

(Sejd)(ed)tsunteriffiese, jefun= bäre 58

(siftoritien 41

Gonyocephalus 60

Guanin 14

Samabryasfdylange 50

5autfinnesorgane 34

ร̋̈utung 18

Heloderma 42

Herpeton 35

5örner bei Яeptilien 59

Hydromedusa 19

Iguana 28, 60

Inguinalorilien 15

รrī 24

\section{Saltjäcfdjen 32}

Rlapperja)langen 66

Sioprolitben 44

Lacerta 4, 26, 73, 77

Leptodactylus 63

sipodirome 14

Lophura 60

sungen 49

Lygosoma 7

Mabuia 7

Mimetozoon 3

Mimifing 8

Melanome 14

Molge 73,77

ophiops 26, 27

Ophthalmosaurus 55

Oxybelis 3,10

Paludicola 31

Barietalauge 27

Sigmente 14

Platurus 10

Plioplatecarpus 32, 55

\$räanalorüfen 15
Pseudophryne 70

Ptenopus 27

Ptychozoon 3

Bupille 23

Pygopus 19, 62

Python 37, 78

Rana 5, 31

Regeneration 73

Rhinoderma 31

Rhinophrynus 39

Sacei endolymphatici 32

Salamandra 4, 64, 69

Stballblajen 30

Edienfelorilfen 15

Sc)uppen 15

Sc)uppenifulptur 18

Gd)uถ๋färbung 2

Spelerpes 39, 70

Sphenodon 28, 72

Spilotes 66

Etatolitfen 32

Sumpfídilsfröte 24,72

Eaftfledfen 35

Testudo, \&uftröłre 49

Iradieallunge 50

Trichobatrachus 11

Irodfenzeitid) Iaf 58

Typhlops 10

İbermintern im Ei 72

Uroplatus 3, 5, 37, 52

Varanus 28

Begetarier 45

Biviparität 69

Vipera (2aftarbe) 73

gointerjd) laf 57

Xenopus 45

כ゙=förmiger finorpel 52

Birpapparat 62

3unge 35 


\section{Der Mensch der Urzeit Kunde über ter Lebenweise,}

Sprache und Rultur des vorgeshichtlichen Menschen in Europa und Fsien von Heinrich Driesmans. Mit 9 farbigen Tafeln und 60 Textabbildungen. Oktav. 236 Seiten. Geheftet M 2.-, gebunden M 2.80 .

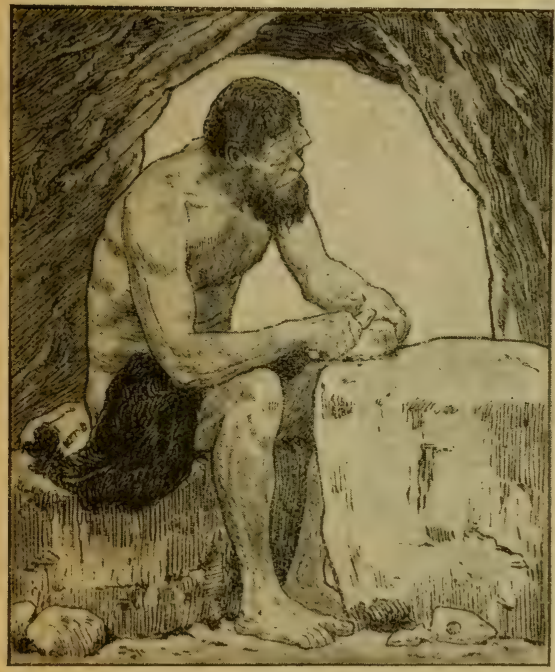

Vondemursprung des feuers ausgehend, als der einschneidendsten Entdeckung der Menschineit, schildert der Verfasser, wie der Urmensch, dessen Obdach noch die Höhle ist, seine Werkzeuge, Geräte und Waffen aus dem Steine herstellt, wie or dann Pfahlbauten als Wohn- und Zufluchtsstätte errichtet, sich mit Hilfe des feuers Kupfer, Bronze und Eisen für seine Zwecke dienstbar macht und so in jahrtausendlanger Entwicklung von einer Kulturstufe zur anderen schreitet.

,Hier ist Gelegenheit zu einer gründlichen finführung in das reizvolle Gebiet der ersten fntwicklung des Menschentums. Eine fülle wissenschaftlicher Kenntnisse erschliefjt sich dem Leser und die trefflichen Bilder vervollkommnen die gewonnenen Einblicke. Dem Buche ist weite Verbreitung zu wünschen."

Kleine Presse, frankfurt a. m.

\section{In 3 Jahren 35000 Exemplare verkauif!}

$\mathrm{Zu}$ beziehen durch jede Buchhandlung oder direkt vom Verlage von Strecker \& Sdröder in Stuttgart 


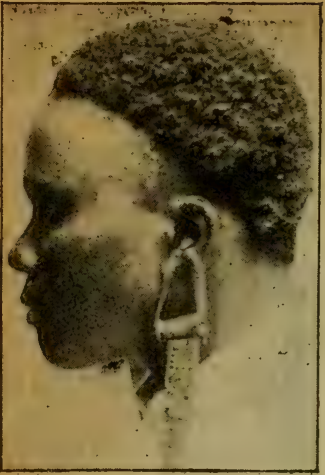

\section{Die Völker des Erdballs}

in Geschichte, Sprache, Rasseneigentümlichkeiten, Obdach, Kleidung, Cebensunterhalt, Sitten und Gebräuchen veranschaulicht das prächtige, hochinteressante Werk:

\section{Jllustrierte Völkerkunde}

Unter Mitwirkung von Dr. A. B yh an, W. Krickeberg, Dr. R. Lasch, Prof. felix oon Luschan, Prof. Dr. W. Volz herausgegegeben von Dr. G. Buschan. 480 Seiten mit 211 Tafeln und Abbildungen. Geheftet nur $\mathrm{m} 2.60$, gebunden $\mathrm{m} 3.50$.

\section{Wie wird über das Buch geurteilt?}

Se. Kgl. Hoheit Prinz Rupprecht von Bayern (i. H. Auftr. Graf Pappenheim): "Ein ausgezeichnetes, vortrefflich ausgestattetes Werk."

Dr. M. Haberlandt, Kustos am k. u. k. Maturhistorischen museum in Wien: ,fin prächtig gelungenes Werk. Ein solches Buch hat uns bisher gefehlt."

Wirkl. Geh. Rat Professor Dr. Ernst Häckel, Exz.: Darstellung und Illustration dieses reichhaltigen, populären Werkes sind vortrefflich; ich wünsche ihm weiteste Verbreitung."

Professor Dr. E. Seler, Direkfor am Kgl. Museum für Völkerkunde in Berlin: "Ich halte dies Buch für eine der dankenswertesten Bereicherungen unseres "Büchermarktes."

H. Singer, Herausgeber des, ,Globus": ,Ein höchst verdienstliches Werk, das weiteste Verbreitung verdient. Selten ist in Deutschland für einen so geringen Preis etwas inhaltlich und äufjerlich Gleichwertiges auf irgend einem Wissensgebiet geboten worden."

Ein einzig dastehendes Buch für das deutsche Haus! Vier Wochen nach Rusgabe erschien das 16.-19. Tausend.

Zu beziehen durch jede Buchhandlung oder direkt vom Verlage von Stredzer \& Schröder in Stuttgart 


\section{Die Abstammung des Menschen}

schildert Dr. Ludwig Wilser in seinem Buche: „Menschwerdung, Ein Blatt aus der Schöpfungsgeschichte". Mit 7 Tafeln und 21 Textabbildungen. 144 Seiten. Geheftet M 1.-, gebunden m 1.80 .

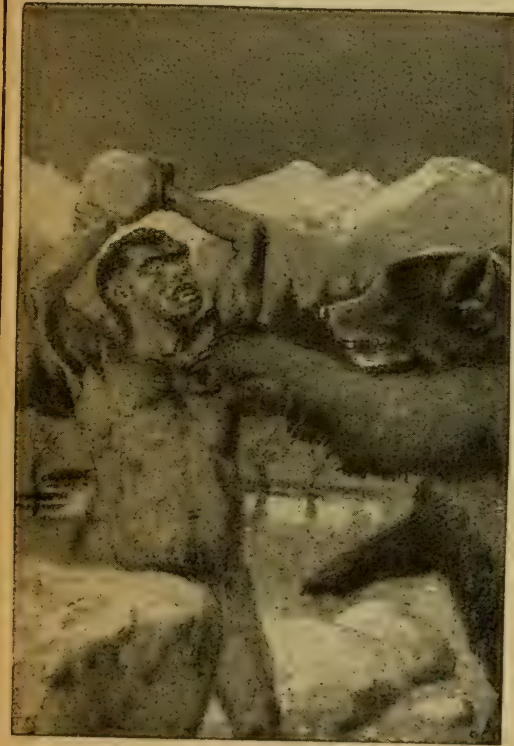

Eine zoologische Entwicklungsgeschichte des menschen. Alle bisher gefundenen Vorfahren oder Verwandte des Menschen werden uns geschildert. Sämtliche funde von Urmenschen erhalten, unterstützt durch ein ausgewähltes Bildermaterial, eine eingehende Darstellung.

คus dem Inhalt: I. Ab. stammung. II. Der Vormensch. III. Der Urmensch. IV. Ausblicke: Sprache und Schrift - Kampf ums Dasein-Naturzüchtung und Artenbildung -

Einzelauslese und Rassenkampf - Fortpflanzung - Vererbung - Zuchtwahl beim Menschen usw.

„Die Schrift ist geeignet, manchen nebel zu zerstreuen und der frforschung der Wahrheit, des höchsten Zieles des Menschen, den Weg zu weisen. Gute Abbildungen fördern die Lektüre." Globus, Braunschweig.

\section{In $23 / 4$ Jahren 24000 Exemplare verkauft!}

Zu beziehen durch jede Buchhandlung oder direkt vom Verlage von Strecker \& Schröder in Stuttgart 


\title{
Ein Buch über die 3werguölker \\ Die Stellung der Pygmäenoölker in der Entwicklungsgeschichte des Menschen
}

\author{
Von P. W. Schmidt, S. V.D. \\ Grob=0ktav. 315 Seiten. Geheftet $M \mathbf{9 . 6 0}$
}

Der Verfasser gibt zunächst einen Ueberblick über die Körpereigenschaften der Zwerguölker und bespricht dann ausführlich ihre materielle und geistige Kultur: Körperschmuck, Kleidung, Wohnung, Bereitung des feuers, Waffen und Werkzeuge - geistige Befähigung, Sprache, Kunst, Religion, Sitten und Gebräuche.

Schlieł $\}_{l}$ ich gibt er eine finteilung und Gliederung der Pygmäenuölker und zeigt, dafj diesez wergrassenkeine Verkúmmerungsformendarstellen, sondern unter die ältesten Völker der Erde gezählt werden müssen und überall dort, wo wir sie jetzt nochantreffen, als die ältesten, die urvölker, anzusehen sind.

\section{Die Balkanoölker in Vergangenheit und Gegenwart von Dr. Georg Buschan}

Oktav. 56 Seiten mit 18 Abbildungen. Geheftet M 1.-

Ausgehend von den Nachrichten der Alten über die vorgeschichtlichen Välker der Balkanhalbinsel schildert der Verfasser im ersten Tell seiner Arbeit die verschiedenen vorgeschichtlichen stämme auf Grund ihres uns durch die Ausgrabungen überkommenen Kulturbesitzes, der von ihnen erhaltenen skelettüberreste, der bildlichen Darstellungen auf dem Tropäum zu Adamklissi usw. Sodann gibt er einen kurzen Rükkblick über die Völkerbewegungen, die in der geschichtlichen Zeit bis zur Besitzergreifung durch die Osmanen stattgefunden haben, und beschäftigt sich im zweiten Teil ausführlich mit den heute auf dem Balkan ansässigen Völkern, ihrer Körperbeschaffenheit, ihrerTracht, Sprache, ihrensittenund Gebräuchen. Schlie ${ }_{3}$ lich streift er kurz die politischen Verhältnisse und versucht einen Ausblick in die zukünftige Verteilung der Balkanvälker zutun.

\section{Die morphologische Abstammung des}

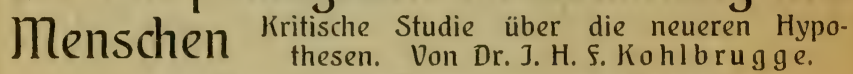
Grory-Oktav. 104 Seiten. Geheftet M 3.60

,Auf Grund reicher, durch langjährigen fufenthalt in den Tropen gesammelter Erfahrungen spricht der Verfasser die persönliche Ueberzeugung aus, dafy es keine minder- oder mehrwertigen Rassen gibt, sondern nur ein Anderssein, ein zeitweises Zurückgebliebensein bei nicht gleicher, aber doch gleichwertiger Anlage."

naturae novitates.

$\mathrm{Zu}$ beziehen durch jede Buchhandlung oder direkt vom Verlage von Strecker \& Schröder in Stuttgart 


\section{Freube, Snterhaltung und $\mathfrak{B e l e b r u n g}$}

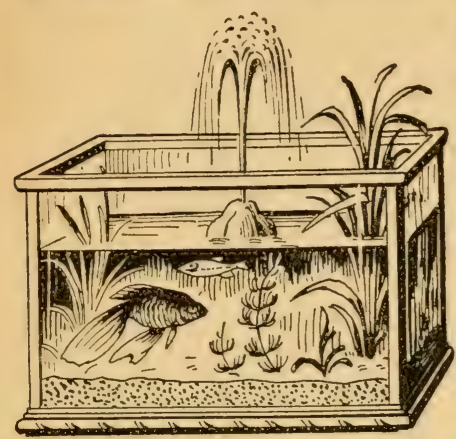

verid)afft jedem 9Ratur= freunde ein richtig ein. gerichtetes, wenig Dflege exforberndes, hubjches

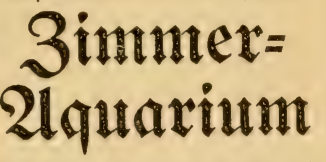

Berlangen Gie jof. Ratal. mit 230 2lbbiloungen über 2lquarien, Fif d)e, Dflan= zen uín. und auzfiilbrliche Unleitung gegen 25 Pf. in Narfen oder ifluitrierte

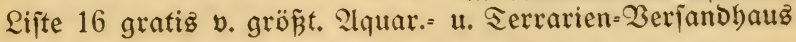

\section{A. (Glaid)fer, Leipzig 3 .}

\section{Aquarien=Inititut - Reptilientaus Gablze \& Pörzichte, Berlin}

Rontor und Laben: Arexanderitr. 28 a, Berjand und Lager:

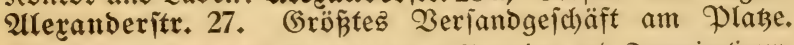
Gteter Eingang von शeubeiten in Squarien= und Serrarientieren,

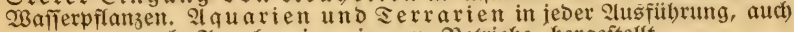
nach) Singabe, im eigenen 3 etriebe hergeitellt.

siffimitel zur Fif = und Reptifienpflege. - Eigene Eammier in allen Eroteilen -

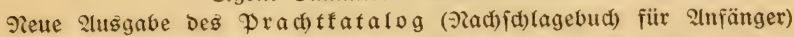

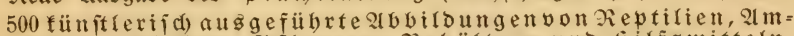
phibien, Tifden, Drianzen, 3 ebältern und silfsutteln,

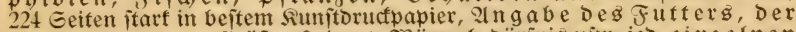

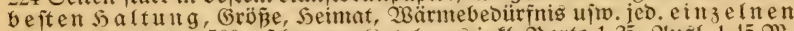

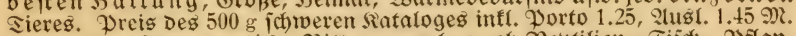
Zorratgliften gratis. 3itte ant3geben, ob Reptilien=, Fifd $=$, Pflan= zell $=$ Doer 3 ebälter $=$ uno siffimitteflifte gemünich)t morb.

Feich iffutr. Qif̂te über Qquarien, Serrarien und Silfsmittel geg. 20 DF. Reid) ifuitr. Qijte über 3 aller $=$ und Serrarienpflanzen geg. 20 Џf. Fact)=

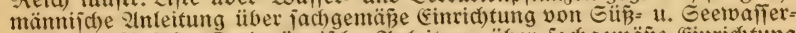

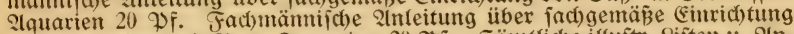

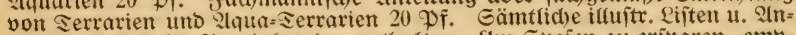
leitungen fitt im prad)tfatalog entbalten. SIm Epeien zu eriparen, emp= fieblt es fids, Der 3eitelung Den 3etrag in Narfen beizurugen. 


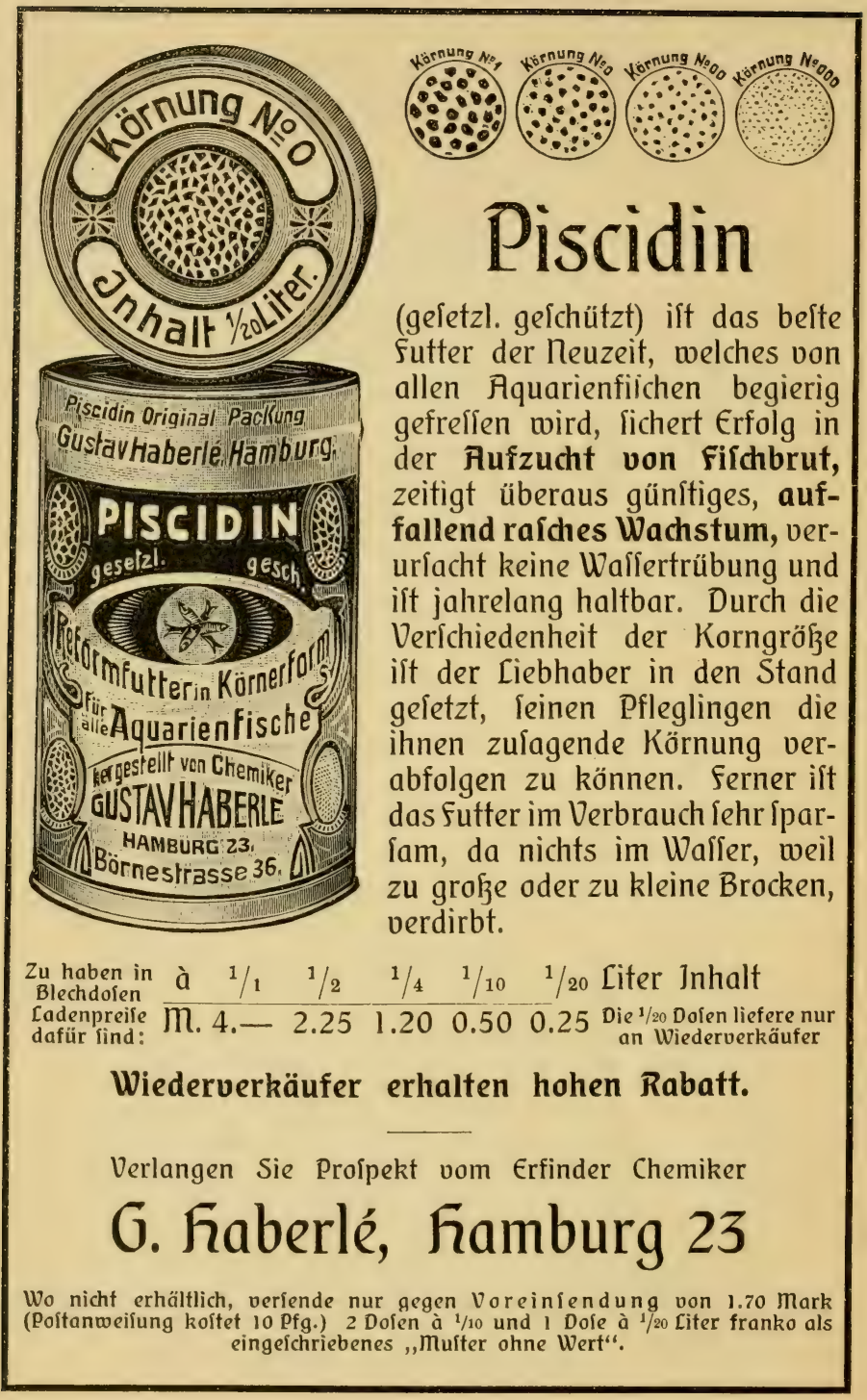




\section{Reichelts Cierexport \\ Berlin N 24, Eliajeritráze 12 .}

Fernsprecher Amt III, \$131

empfiehlt

Reptilien, Hmphibien in grösster Auswabl

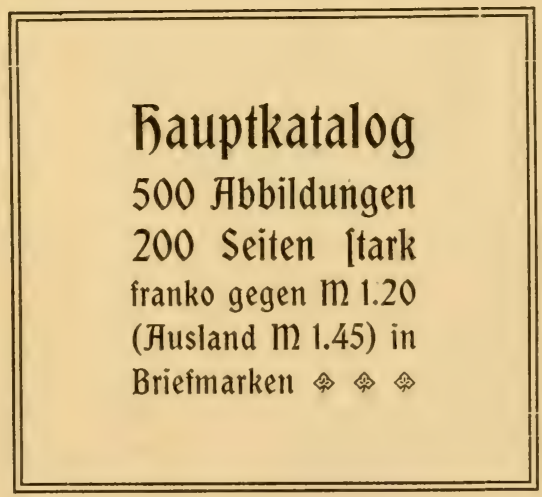




\section{Berlag von Etrecter \& Echröber in Stuttgart}

Sebem Raturfreund feibeftens empfoblen:

\section{Die Raturdenfmalpflege}

Die Beitrebungen zur Erbaltung Der Naturbenfmäler und igre $\mathscr{D} u r c h$ fïhrung

Bon Profefior $\mathfrak{B}$. Boct

(Beichäftz̧ fübrer bez Sannoverfchen Drovinzial= und Bezirfźtomitee für Taturbenfmalpflege

Nit 8 Safeln und 17 abbiloungen im Sert. Oftav. 117 Geiten. Gebeftet $\mathfrak{X} 1,-$, gebunden $\mathfrak{X} 1.40$

("Naturbifienichaftlidbe 2 Begweifer ${ }^{\mu}$, Gerie A, 3and 10)

Der Gdúf ber $\mathfrak{R a t u r}$ ift bie vornehmite 2 lufgabe jebes wahren Naturfreundes.: Nächtig bat in Den lerbten Jahren

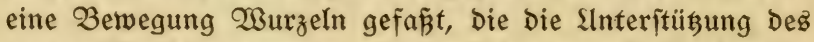
ganzen $\mathfrak{B o l f e z}$ verdient. Sie will die zum Seil f(t)on im Berid) rinden uno 2luşiterben begriffenen Gdjönbeiten ber heimatlidben Natur, "Die Naturde,nfmäler", erhalten

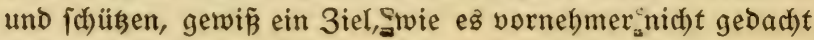
werben fann.

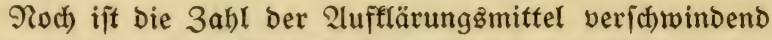
gering, und es werfen fich Deăhalb bei Der Teubeit Der Bewegung täglich) Die Fragen aufl:

$\mathfrak{B a z}$ jind Raturdenfmäler?:

Warum jollen fie gejhitist werben?

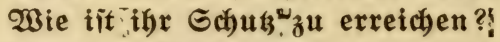

In fachfundiger Weife gibt bas vorliegende $3 a ̈ n d(h e n$

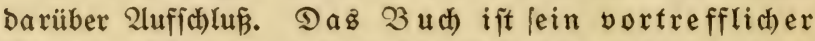
Berater für jeden, Dem bie Errbaltung Der $n$ atür.

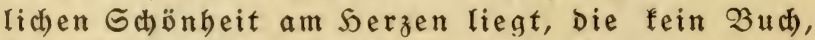
fein Bild und fein Modell erferen fann.

$3 \mathfrak{u}$ beziehen Durch jede 3 uchhandlung ober Direft vom Berlage Etrecfer \& Gdyröber in Etuttgart 


\section{Zerlag von Gtrecter \& Garböber in Gtuttgart}

\section{Samait, Ditmifronefien und Gamoa}

Neine zweite Gitbjeereife (1897-1899) zum Gtubium Der Qltolle und

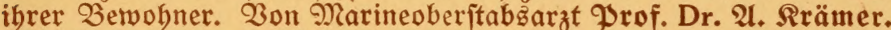
Nit 20 Safeln und 136 Sertabbildungen. Grof́-Oftav. 585 Geiten.

(3eh. 22 10, 一, geb. 2 12, 一

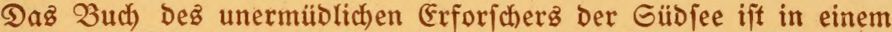
angenehmen Plauberton gefdrieben, Der fich mit itrengrwifienichaft. licher (Bründlichteit paart. In Diejer glüctlicten 2 ereinigung liegt Die (Garantie, Dẩ Daв Werf́ von Den zahlreichen (Bebildeten, Die fïc) für QänDer- und Bölferfunde interefifieren, gern gelejen wirb. Tas WBerf bringt aber audh für Den Belebrten, Den 3oologen, Beologen, Rolonial. gelebrten manche 2lnregung. Die ethnologijhe Literatur ijt Durch

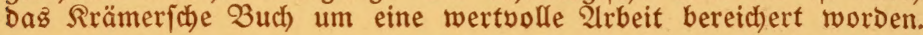

Rrämer zäblt zu ben berufenitensdilde. rern ber Gübiee.

gabrelang bat er auf ber Derle ber Gitofee, $G a m o a, z u=$ gebract, mit $\mathfrak{L} a n d$ und Qeuten vertraut wie roenige, undin. nigenanteilgenom= men an Dem unru= big wedflolollen Geídict Dieiesbert. lichen Pandes; aud in anderen Seilen 叉oly. nefiens und bejonders auct in Sitmifronefien ifit

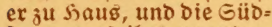
lee bat $\mathrm{eg}$ ibm angetan, fie loct ibn immer wieder binaus. Im vorltegenden 23uch roendet er fith an ein breiteres publtum uno gibt eine feflelnde Gchilderung ieiner zroei= ten Gübieereife. Eine Gülle von $R$ ulturs iditiderugenfindet Der Lefer bier, uno a u (b) ib exf $a \bar{B} t$ beis nabeeine Gebniud nad der Gübiee.

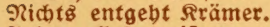
Uleber alles weí̉ er zu beridten, iber Eitten un๖ Bebräude, ஐertzeuge und

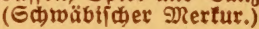




\section{Dreipig Sabre in Der Giidjee}

Land uno Qeute, Gitten und (Bebräuctse im Bismarcfarchipel und auf ben Deutict)en Galomoinfeln. Zon $\Re$. Yartinion. Serauggegeben von Dr. 23. Anfermann, Direftorial-2lifitent am Rönigl. शujeum für $\mathfrak{Z}$ ölferfunde zu Berlin. Nit 56 Safeln, 141 Sertabbildungen und 4 Sleberfichtg̈arten. (Broź-Oltav. XXII, 876 Geiten.

\section{Gebeftet $\mathfrak{M} 14,-$, gebunden $\mathfrak{M} 16 .-$}

\section{Der $\mathbf{B}$ ezug fant aud gegen Ratenzahlungen exfolgen.}

Wobl feiner Der Lebenden hat in unjeren Sübjeej(huggebieten mebr gejeben und erlebt alz Richard Parfinion. (Er madjte fich im Iabre 1875 als einer Der wenigen Roloniften, Die Der Deutichen Jlagge babnbrechend vorausimarjchierten, auf Gamoa anjäifig, um im Jahre 1882 auf die Gsazellebalbinjel überzujedeln. Bon bier aus bat er, all Die (Gefahren nid)t adtend, Die inn oft begleiteten, fämtliche Rüiten Des 21rchipelz auf zahlreichen Reifen bejucht und immer wieder bejucht. Parfinjon hat Dabei berfoledene $\mathfrak{I n j e l n ~ e n t b e c f t , ~ d i e ~ v o r ~ i f m ~ n o d ) ~ f e i n ~}$

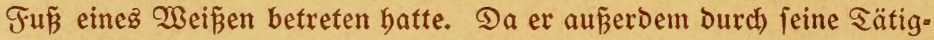
feit alz Pflanzer in Die Lage verjekt war, Arbeiter anzumerben, io war er in ftändigem Berfehr mit zahlreichen Fingeborenen Der verfdiebeniten Landezteile und ift im Laufe Der 3eit ber beite Renner ber Eingeborenen geworben.

Dartinjon befá ein angeborenes Salent, mit feindlichen und furcht. famen "Wilden" umzugeben. Die Fingeborenen lernten feine Silfe

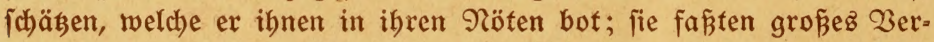

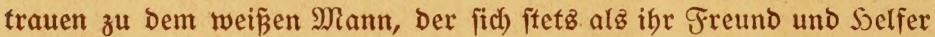

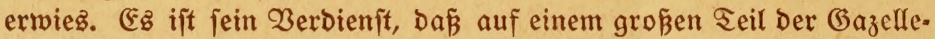
balbinjel friedlicbe und georonete 3 uftände einzogen.

Parfinfon hat Die Gitten und (bebräude Der Dortigen $\mathfrak{B}$ blfer bis in ihre intereffanteften und intimpten Einzel. heiten fennen gelernt und itudiert und weís den Lefer burch feine rebenswabre, pactende Darftellung fowie burd) die Beigabezahlreid)er vorzïglider anfang bib Ende zu feffeln.

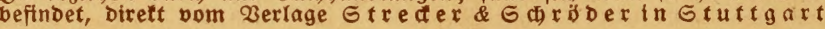




\section{Berlag von Gtrecfer \& Gibrïder in Gtuttgart|品}

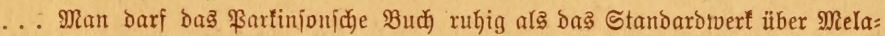

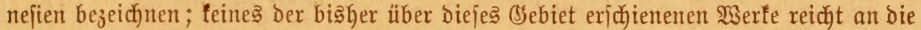

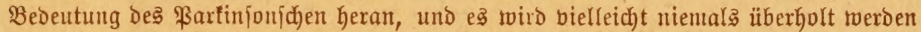

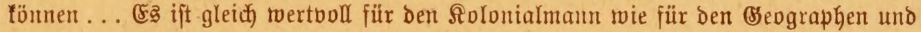
(Ethnologen. Durd) bie feffelnde Darftellung, das \&ebendige und Mnmittelbare ber

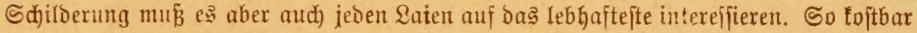

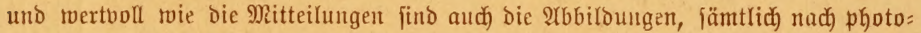

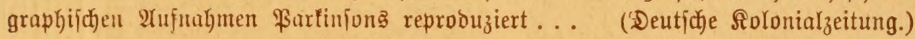

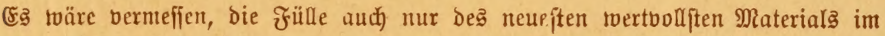
Ruhmen ciner Beiprectung herborkeben zu twollen; ber

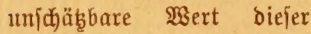
mifienjudaftlidjen \&ebensెer= fahrangen roiro in vollem Ulmfautg erjt ipäteren šene= rationen ertentbar werben, sern die Miöglichleit per= fïnlidier Arnjadaung ber jeşt jchon zum Teil twohl nux noch in Partinjons cigenen Sammlungen ber: tretenten Beid)en feiner Süb= jeezeit nod) mehr dem शatur= leben entzogen fino, uno das geht, wie gefagt, nux all=

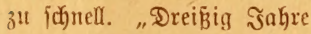
in Der Sildjee" bedeutet bie Inichrift einesె unber= gängriđuen sontmalsె zum Rubm eines genialen Rolo= niften, bem bie Miffenjuaft ber Mitrelt, nod) mehr aber ber Rachivelt grofien Dan? (id)uldoet.

(ßetermanns geographifhe Mitteilungen.)

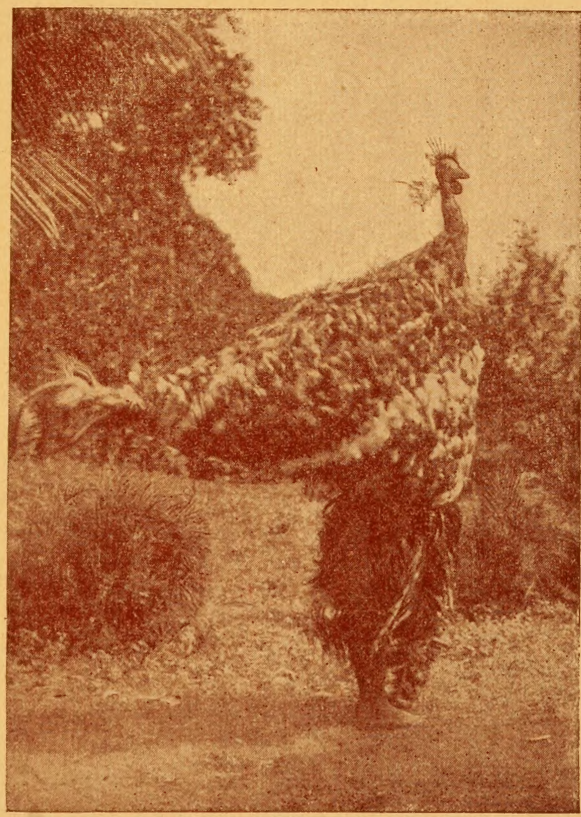

Sabnenmaste. Bazellebalbinjel 2bbiroung aus: " Partinjon, Dreibitg Sabre in ber Gibjee" 
